\title{
Corrosion of Candidate High Temperature Alloys in Supercritical Carbon Dioxide
}

by

Curtis J. Parks, B.Eng.

\author{
A Thesis submitted to \\ the Faculty of Graduate and Postdoctoral Affairs \\ in partial fulfilment of \\ the requirements for the degree of \\ Master of Applied Science
}

Ottawa-Carleton Institue for Mechanical and Aerospace Engineering

Carleton University

Ottawa, Ontario, Canada

April 2013

Copyright (C)

2013 - Curtis J. Parks, B.Eng. 


\section{Abstract}

The corrosion resistance of three candidate alloys is tested in supercritical carbon dioxide $\left(\mathrm{S}-\mathrm{CO}_{2}\right)$ at different levels of temperature and pressure for up to 3000 hours. The purpose of the testing is to evaluate the compatibility of different engineering alloys in $\mathrm{S}-\mathrm{CO}_{2}$ for use in a $\mathrm{S}-\mathrm{CO}_{2}$ Brayton cycle. The three alloys used are austenitic stainless steel 316, iron-nickel-base superalloy 718, and nickel-base superalloy 738 .

Each alloy is exposed to four combinations of temperature and pressure, consisting of either $550^{\circ} \mathrm{C}$ or $700^{\circ} \mathrm{C}$ at either 15 or $25 \mathrm{MPa}$ for up to 1500 hours. At each temperature, an additional sample set is tested for 3000 hours and experienced an increase in pressure from $15 \mathrm{MPa}$ to $25 \mathrm{MPa}$ after 1500 hours of testing.

All three alloys are successful in producing a protective oxide layer at the lower temperature of $550^{\circ} \mathrm{C}$ based on the logarithmic weight gain trends. At the higher temperature of $700^{\circ} \mathrm{C}, 316 \mathrm{SS}$ exhibits unfavourable linear weight gain trends at both pressures of 15 and $25 \mathrm{MPa}$. In comparison, IN-718 and IN-738 performs similarly in producing a protective oxide layer illustrated through a power weight gain relation. The effect of pressure is most pronounced at the operating temperature of $700^{\circ} \mathrm{C}$, where the higher pressure of $25 \mathrm{MPa}$ results in an increased rate of oxide formation.

SEM analysis exposes a thin film oxide for both IN-718 and IN-738 but severe intergranular corrosion is exhibited by IN-738. Based on the testing conducted, both alloys show favourable characteristics for use in $\mathrm{S}-\mathrm{CO}_{2}$ conditions up to $700^{\circ} \mathrm{C}$, but further testing is required to characterize the effect of the intergranular corrosion on 
the stability of oxide in IN-738. 316SS provided favourable results for use in temperatures of $550^{\circ} \mathrm{C}$, but the protective oxide deteriorated at an operating temperature of $700^{\circ} \mathrm{C}$. 


\section{Acknowledgments}

I would like to express my thanks and appreciation to my supervisor, Dr. Henry Saari, for his guidance and support throughout my studies at Carleton University. His expertise in materials science and engineering, in addition to effective coordination with Natural Resources Canada, provided me the opportunity and resources for this project.

Furthermore, I'd like to thank those in the Zero-Emission Technologies group at the Bell's Corners Complex of Natural Resources Canada who were involved in supporting the experiments conducted. The assistance of Dr. Kourosh Zanganeh and Carlos Salvador is especially noted in providing the opportunity and support for this project.

Finally, I would like to thank my friends and family for their continued support, especially Tara, who provided the added encouragement and motivation throughout the years. 


\section{Table of Contents}

Abstract

$\begin{array}{lll}\text { Acknowledgments } & \text { iv }\end{array}$

Table of Contents r v

List of Tables $\quad$ viii

List of Figures $\quad$ ix

1 Introduction $\quad 1$

1.1 Next Generation of Power Conversion Cycles . . . . . . . . . . . . . . 1

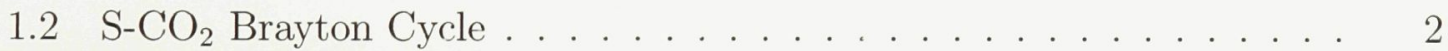

1.3 High Temperature $\mathrm{S}-\mathrm{CO}_{2}$ Corrosion . . . . . . . . . . . . . . 6

1.4 Objective and Organization of Thesis . . . . . . . . . . . . . . 6

2 Background $\quad 8$

2.1 High Temperature Materials . . . . . . . . . . . . . . . 8

2.1.1 Iron-Nickel- and Nickel-Base Superalloys . . . . . . . . . . . . 13

2.1.2 Austenitic Stainless Steel . . . . . . . . . . . . . . . 14

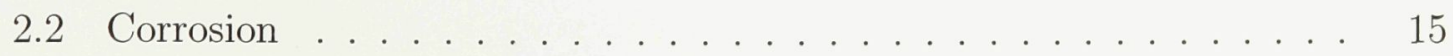

2.2.1 High Temperature Oxidation . . . . . . . . . . . 17

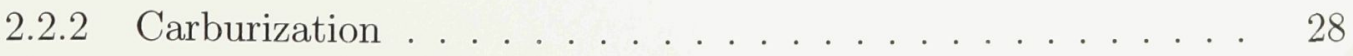


2.2 .3 Metal Dusting . . . . . . . . . . . . . . . . . . . . 30

2.3 High Temperature Corrosion Testing . . . . . . . . . . . . . 31

2.3.1 Methods of Corrosion Testing . . . . . . . . . . . . . 32

2.3.2 Supercritical $\mathrm{CO}_{2}$ Corrosion Testing . . . . . . . . . . 36

3 Experimental Approach $\quad 43$

3.1 Materials . . . . . . . . . . . . . . . . . . 43

3.1.1 Austenitic Stainless Steel . . . . . . . . . . . . . . . . . 44

3.1 .2 Nickel-Base Superalloys _. . . . . . . . . . . . . . . . . 45

3.2 Sample Preparation . . . . . . . . . . . . . . . . . . . . . . . 45

3.2 .1 Labelling of Coupons . . . . . . . . . . . . . . . . . 46

$3.2 .2 \quad \mathrm{Au}-\mathrm{Pd}$ Coating . . . . . . . . . . . . . . . . . 47

3.3 The Carleton-NRCan $\mathrm{S}^{-\mathrm{CO}_{2}}$ Corrosion Rig . . . . . . . . . . . . . 49

3.3 .1 Rig Design . . . . . . . . . . . . . . . . . 50

3.3 .2 Rig Operation . . . . . . . . . . . . . . . 55

3.4 Experimental Procedure . . . . . . . . . . . . . . . . 58

3.5 Coupon Characterization . . . . . . . . . . . . . . 63

4 Results and Discussion $\quad 66$

4.1 Oxide Surface Characterization . . . . . . . . . . . 67

4.2 Weight Gain Analysis . . . . . . . . . . . . . . . . . 71

4.2 .1 Comparison of Test Alloys . . . . . . . . . . . . . . 71

4.2 .2 Dependence on Temperature . . . . . . . . . . . 76

4.2 .3 Dependence on Pressure . . . . . . . . . . . . . . . 78

4.3 Oxide Cross Section Characterization . . . . . . . . . . . . . 82

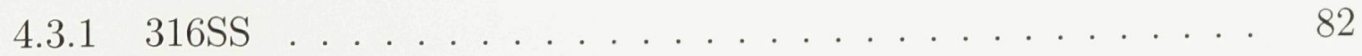

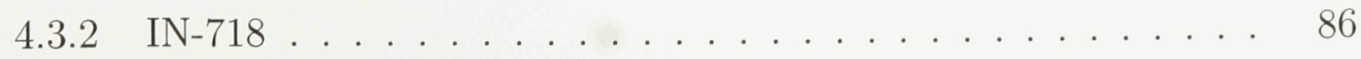

$4.3 .3 \quad \mathrm{IN}-738 \ldots \ldots \ldots \ldots \ldots \ldots$ 
4.3.4 Summary of Results . . . . . . . . . . . . . . . . 92

5 Conclusions $\quad 96$

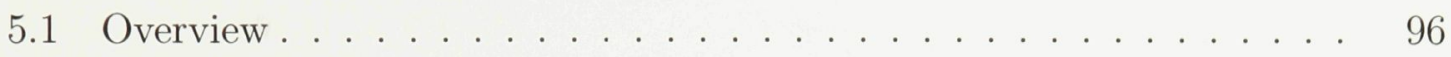

5.1.1 Weight Gain . . . . . . . . . . . . . . . . 97

5.1.2 Oxide Growth . . . . . . . . . . . . . . . 98

5.2 Future Work . . . . . . . . . . . . . . . . . . . . 98

$\begin{array}{ll}\text { List of References } & 101\end{array}$

$\begin{array}{ll}\text { Appendix A Weight Gain Plots } & 105\end{array}$ 


\section{List of Tables}

1 Composition of major elements in $\mathrm{Fe}-\mathrm{Ni}-, \mathrm{Ni}-$, and Co-base superalloys. 10

2 Purpose of elemental additions to superalloys. . . . . . . . . . . . 12

3 Common engineering alloys with respect to use temperature . . . . 18

4 Resulting weight gain of superalloys in $\mathrm{S}^{-\mathrm{CO}_{2}} \ldots \ldots \ldots \ldots$

5 A summary of studies for corrosion in $\mathrm{S}^{-} \mathrm{CO}_{2} \ldots \ldots \ldots \ldots 42$

6 Nominal compositions of test alloys. . . . . . . . . . . . 45

$7 \quad$ Coupon numbering scheme. . . . . . . . . . . . . . 47

$8 \quad$ Furnace controller set points for $15 \mathrm{MPa} \ldots \ldots \ldots \ldots . \ldots 57$

9 Test matrix. . . . . . . . . . . . . . . . . . . . 59

$10550^{\circ} \mathrm{C}$ experiment: removal of coupons. . . . . . . . . . . . . 62

$11700^{\circ} \mathrm{C}$ experiment: removal of coupons. . . . . . . . . . . 63

12 Variation of carbon and oxygen from sample cross-section, normalized to inner sampling point. . . . . . . . . . . . . . . . 92 


\section{List of Figures}

1 Typical direct Brayton cycle configuration. . . . . . . . . . . . 2

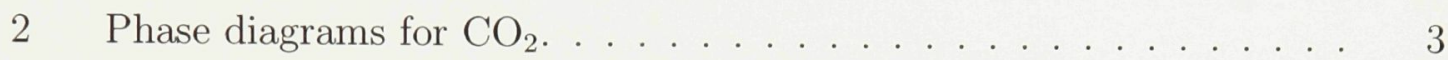

3 Enthalpy-entropy diagram for $\mathrm{S}-\mathrm{CO}_{2}$ Brayton cycle. . . . . . . . 4

4 Comparison of efficiency of Rankine, helium, and $\mathrm{S}_{-} \mathrm{CO}_{2}$ power conversion cycles. . . . . . . . . . . . . . . ...... 4

5 Comparison in size of Rankine, helium, and $\mathrm{S}-\mathrm{CO}_{2}$ power conversion

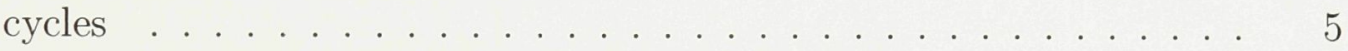

6 Rupture strength of common superalloys. . . . . . . . . . . . . 11

7 Rupture strength of 316 SS . . . . . . . . . . . . . 11

8 Alloying elements used in Ni-base superalloys . . . . . . . . . . . 12

$91000 \mathrm{hr}$ stress-rupture plot for some Ni-base superalloys. . . . . . . . 14

10 Multi-layer oxidation of Ni-Cr alloy . . . . . . . . . . . . . . . . . 19

11 Transport of ions for oxide formation according to Wagner's theory. . 20

12 Ellingham diagram: free energy of formation. . . . . . . . . . . . 22

13 Common kinetics of oxidation: rate laws. . . . . . . . . . . . 23

14 Rate of oxide growth leading to breakaway oxidation. . . . . . . . . 25

15 Ellingham Diagram for carburization with transition metals. . . . . . 29

16 Initial carburization of nickel-base alloy with subsequent carbon supersaturation and graphite nucleation in the production of coke. . . . . 30

17 Possible experimental variability induced by discontinuous testing. . . 33 
18 Conventional spring balance used for continuous corrosion testing .

19 Typical automatic recording balance used for continuous corrosion testing 35

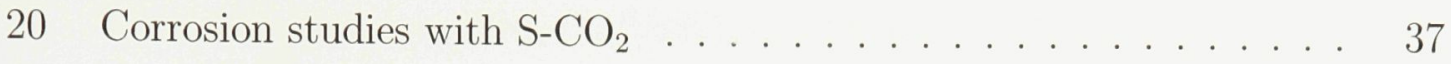

21 MIT S- $\mathrm{CO}_{2}$ corrosion test rig. . . . . . . . . . . . . . 38

22 Results of $\mathrm{S}-\mathrm{CO}_{2}$ corrosion testing from the University of WisconsinMadison. . . . . . . . . . . . . . . . . . . . . . . . . . 39

23 EDX scan of $\mathrm{F} 91$ after 310 hours at $550^{\circ} \mathrm{C}$ and $25 \mathrm{MPa}$ in $\mathrm{S}-\mathrm{CO}_{2}$. . 41

24 Sample 16 of IN-718. . . . . . . . . . . . . . . . . 47

25 Coupons before and after sputter coating with Au-Pd. . . . . . . . . 48

26 Au-Pd sputter coating using Argon plasma. . . . . . . . . . . . . . . 49

27 The Carleton-NRCan $\mathrm{S}_{-} \mathrm{CO}_{2}$ Corrosion Test Rig . . . . . . . . . . . 51

28 The Carleton-NRCan $\mathrm{S}_{-} \mathrm{CO}_{2}$ Corrosion Test Rig P\&ID. . . . . . . . . 52

29 Grayloc $\AA$ clamping mechanism . . . . . . . . . . . . . . . . 53

30 Internal thermal profile of pressure vessel at $700^{\circ} \mathrm{C} \ldots \ldots \ldots 4$

31 Molybdenum heat reflectors on thermocouple probe. . . . . . . . . 55

32 Coupon loading of specimen boat. . . . . . . . . . . . . . . . 59

33 Internal pressure and temperature of corrosion test rig during typical

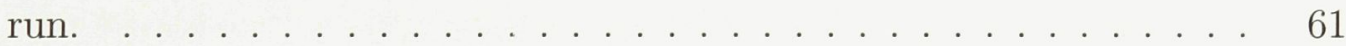

34 Placement of samples in SEM. . . . . . . . . . . . . . . . . . 64

35 Elemental analysis of sample cross-section using Oxford Inca Engergy 250 X EDS. . . . . . . . . . . . . . . . . . . . 65

36 Photos of coupons after 100 hours of exposure to $550^{\circ} \mathrm{C} / 25 \mathrm{MPa} \mathrm{S}_{-} \mathrm{CO}_{2}$. 68

37 Photos of coupons after 100 hours of exposure to $700^{\circ} \mathrm{C} / 25 \mathrm{MPa} \mathrm{S}_{-} \mathrm{CO}_{2}$. 70

38 Weight gain plots of individual coupons. . . . . . . . . . . . 73

39 Weight gain plots of individual coupons. . . . . . . . . . . . 74

40 Comparison of IN-718 and IN-738 to IN-625 coupons that were exposed to $15 \mathrm{MPa}$ and $25 \mathrm{MPa}$ at $550^{\circ} \mathrm{C}$ and $700^{\circ} \mathrm{C}$ for at total of 6000 hours. 
41 Weight change comparison of $316 \mathrm{SS}$, IN-718, and IN-738 based on temperature and pressure for 1500 hours.

42 Weight change comparison of 316SS, IN-718, and IN-738 based pressure at $550^{\circ} \mathrm{C}$ for 3000 hours

43 Weight change comparison of $316 \mathrm{SS}$, IN-718, and IN-738 based on pressure at $700^{\circ} \mathrm{C}$ for 3000 hours. . . . . . . . . . . . 81

$44316 \mathrm{SS}$ sample 121 cross section after 3000 hours at $700^{\circ} \mathrm{C}, 15 / 25 \mathrm{MPa} . \quad 83$

45 Elemental scan of 316 SS sample 121. . . . . . . . . . . . . 85

46 Composition based on varying position of 316SS sample 121. . . . . 86

47 IN-718 sample 221 at $3000 \mathrm{x}$ and $7000 \mathrm{x}$ after 3000 hours at $700^{\circ} \mathrm{C}$ at 15

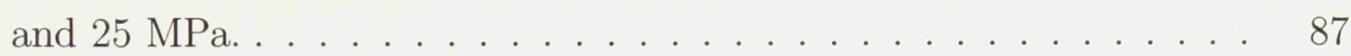

48 Elemental scan of IN-718 sample 221. . . . . . . . . . . . . . . 88

49 Composition based on varying position of IN-718 sample 221 . . . . 89

50 IN-738 sample 321 at $2000 \mathrm{x}$ and $7000 \mathrm{x}$ after 3000 hours at $700^{\circ} \mathrm{C}$ at 15 and $25 \mathrm{MPa} . \ldots . \ldots . \ldots . \ldots . \ldots . \ldots 90$

51 Elemental scan of IN-738 sample 321. . . . . . . . . . . . . . . . . . . 91

52 Composition based on varying position of IN-738 sample 321. . . . . 92

53 Comparison of corrosion studies for 316SS in $\mathrm{S}_{-} \mathrm{CO}_{2}$. . . . . . . . 94

54 Comparison of corrosion studies for $\mathrm{IN}-718$ in $\mathrm{S}_{-} \mathrm{CO}_{2}$. . . . . . . . 95

55 Weight gain for individual $316 \mathrm{SS}$ coupons at $550^{\circ} \mathrm{C} \ldots \ldots 5$

56 Weight gain for individual IN-718 coupons at $550^{\circ} \mathrm{C} \ldots \ldots$. . . . 106

57 Weight gain for individual IN-738 coupons at $550^{\circ} \mathrm{C} \ldots \ldots$. . . . . 107

58 Weight gain for $316 \mathrm{SS} . \ldots \ldots \ldots$. . . . . . . . . . . . . . 108

59 Weight gain for IN-718. . . . . . . . . . . . . . . 108

60 Weight gain for IN-738. . . . . . . . . . . . . . . 109 


\section{Chapter 1}

\section{Introduction}

\subsection{Next Generation of Power Conversion Cycles}

With the already high and increasing demand for electricity across the world, new and more efficient power conversion cycles are required. Significant electrical innovations have emerged throughout the last thirty years that are causing higher loads than when the original power plants were developed [1]. With an increasing world population and quality of life, current power plants can be overwhelmed with demand, and as Canadian nuclear stations are reaching their design life, the industry is in need of new technology that can be implemented within the time and budgets of suppliers. Furthermore, the majority of electricity today is produced through the combustion of fossil fuels, which are contributing significant amounts of hazardous emissions to the environment. The efficiency of these plants, or expansion of lower emission sources, such as nuclear, can be addressed through the advancement of power conversion cycles.

Conventional Rankine cycle steam turbines require high temperatures, large infrastructure, and incur high capital costs, only to operate at efficiencies reaching $40 \%$ [2]. Alternative power conversion cycles are being developed in conjunction with the Generation-IV nuclear reactors to offer sustainable and economic alternatives to 
conventional power conversion systems. Some of these include: supercritical Rankine steam cycle, helium Brayton cycle, and supercritical carbon dioxide $\left(\mathrm{S}-\mathrm{CO}_{2}\right)$ Brayton cycle. The popularity of the $\mathrm{S}-\mathrm{CO}_{2}$ Brayton cycle, derived mostly from manipulating the non-ideal gas above the critical point, has given rise to small and large scale development projects focussing on a variety of potential applications. Much of these characteristics and developments will be discussed in the following section.

\section{$1.2 \quad \mathrm{~S}-\mathrm{CO}_{2}$ Brayton Cycle}

The $\mathrm{S}-\mathrm{CO}_{2}$ Brayton cycle is a high efficiency closed-loop power conversion cycle that is being developed for direct or indirect use with a variety of heat sources. An illustration of a typical Brayton cycle directly heated from a nuclear reactor core is included in Figure 1.

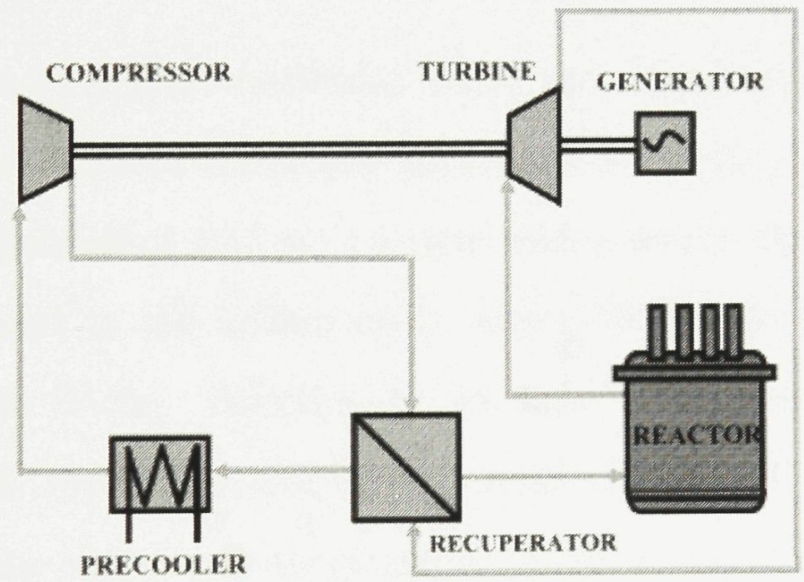

Figure 1: Typical direct Brayton cycle configuration [3]. An indirect design would use a heat exchanger instead of direct contact with the reactor core. Other heat sources could include: fossil fuels, waste heat from conventional plants, geothermal, or solar.

The high efficiency stems from the low compressibility of $\mathrm{CO}_{2}$ above the critical point $\left(31.1^{\circ} \mathrm{C}\right.$ and $\left.7.39 \mathrm{MPa}\right)$, causing a rapid change in density with minimal change 
in pressure. Figure 2 illustrates this relationship with phase diagrams for $\mathrm{CO}_{2}$ in the pressure and temperature plane, as well as the pressure and density plane, while a representation of a $\mathrm{S}-\mathrm{CO}_{2}$ Brayton cycle in shown in Figure 3.
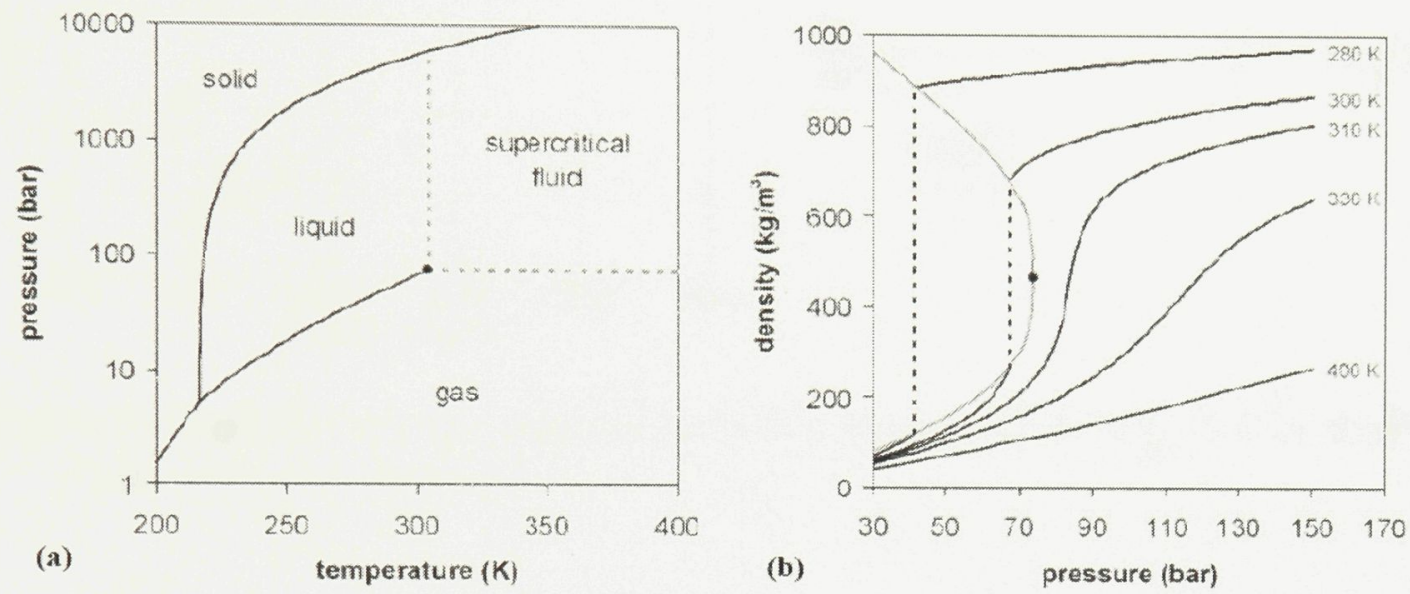

Figure 2: Phase diagrams for $\mathrm{CO}_{2}$ : (a) pressure and temperature, (b) pressure and density [4].

Under these non-ideal fluid conditions above the critical point, the overall efficiency of the cycle is increased due to less work required by the compressor. Research has shown that efficiencies of $45 \%$ are possible with a source temperature of $600^{\circ} \mathrm{C}$. This can be compared to the helium cycle, where $50 \%$ more work is required in compression than for $\mathrm{S}-\mathrm{CO}_{2}$. Additionally, in order for the helium cycle to reach an efficiency of $45 \%$, the source temperature must reach $900^{\circ} \mathrm{C}$ [3]. A comparison between the efficiency and source temperature of the $\mathrm{S}_{-} \mathrm{CO}_{2}$ Brayton cycle, helium cycle, and Rankine steam is provided in Figure 4. 


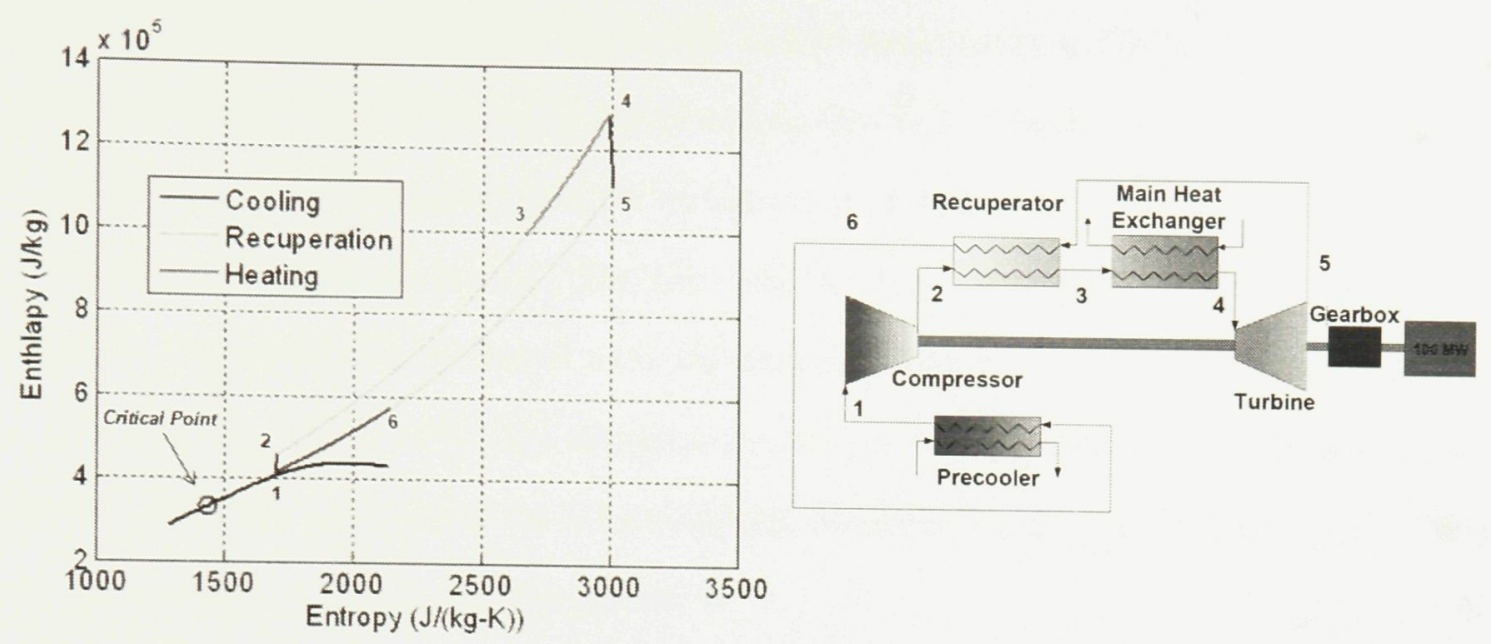

Figure 3: Enthalpy-entropy diagram for $\mathrm{S}-\mathrm{CO}_{2}$ Brayton cycle [left], $\mathrm{S}-\mathrm{CO}_{2}$ Brayton cycle schematic [right] [5].

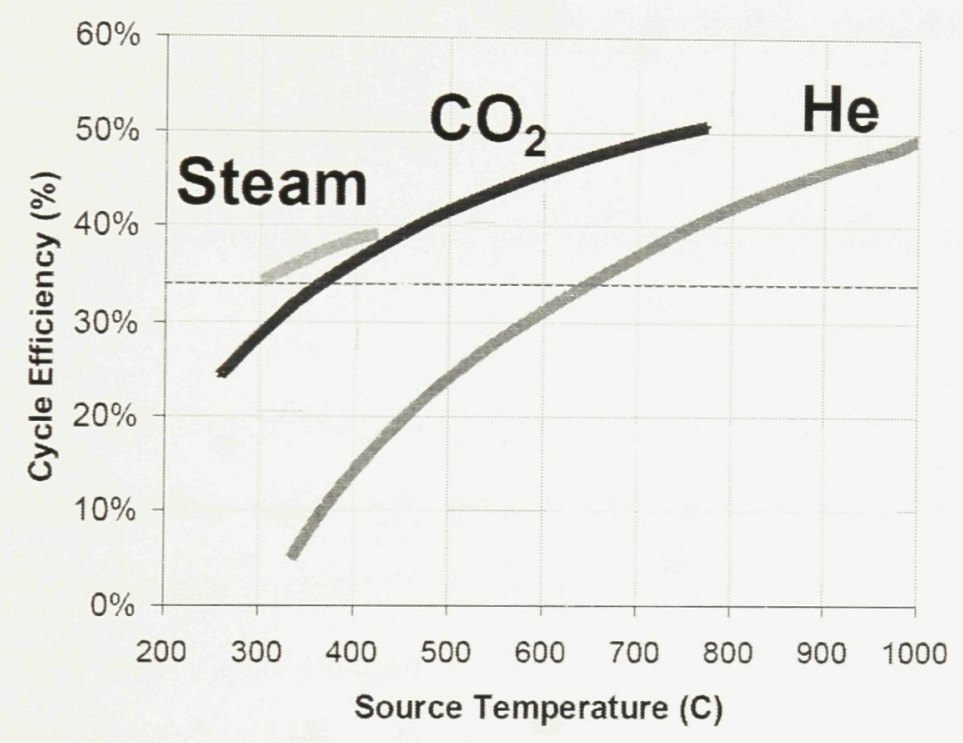

Figure 4: Comparison of efficiency of Rankine, helium, and $\mathrm{S}_{-} \mathrm{CO}_{2}$ power conversion cycles [2].

Although the Rankine cycles can operate at a slightly higher efficiency than the S- $\mathrm{CO}_{2}$ Brayton cycle at lower temperatures, the broad range of critical zone for $\mathrm{CO}_{2}$ allows for a wider acceptance of source temperatures.

The helium cycle is capable of operating at similar efficiencies but requires higher 
source temperatures. Although operating at less pressure than the $\mathrm{S}-\mathrm{CO}_{2}$ Brayton cycle, the helium cycle is limited in applications due to the high temperatures required. In considering materials selection for either cycle, material strength is impacted more by temperature than pressure. For this reason, the structural design of the $\mathrm{S}-\mathrm{CO}_{2}$ Brayton cycle is highly favoured over the helium cycle [6].

The overall design of $\mathrm{S}-\mathrm{CO}_{2}$ Brayton cycle systems also offers a significant reduction in size when compared to a traditional Rankine cycle and helium cycle. This size comparison is illustrated in Figure 5.

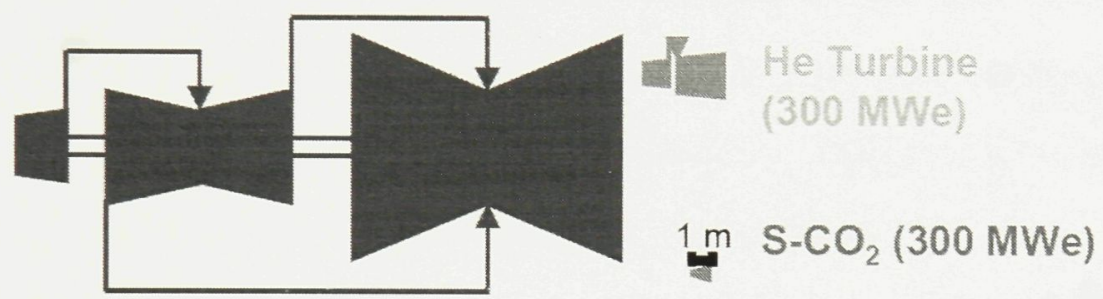

\section{Steam Turbine (250 MWe)}

Figure 5: Comparison of size of Rankine, helium, and $\mathrm{S}-\mathrm{CO}_{2}$ power conversion cycles [2].

The properties of $\mathrm{S}-\mathrm{CO}_{2}$ allow for a significant reduction in size of major components. This is especially true when considering thermal conductivity properties, which allow for a significant reduction in the size of heat exchangers for indirect cycles. This reduced size further expands the range of possible applications for the $\mathrm{S}-\mathrm{CO}_{2}$ Brayton cycle, but most importantly results in reduced capital costs.

Overall, the $\mathrm{S}-\mathrm{CO}_{2}$ Brayton cycle provides a high efficiency power conversion cycle that is desirable over other traditional and competing cycles. The wide range of operating temperatures, small size, and reduced capital costs, show potential for remote and portable applications, or secondary forms of power generation at existing power generation stations. Originally envisioned for power conversion systems of the lead-cooled fast reactor and sodium-cooled fast reactor, the $\mathrm{S}-\mathrm{CO}_{2}$ Brayton cycle has 
quickly shown potential for other applications involving solar towers, marine and ship power, as well as geothermal [3].

\subsection{High Temperature $\mathrm{S}-\mathrm{CO}_{2}$ Corrosion}

The $\mathrm{S}-\mathrm{CO}_{2}$ Brayton cycle operates at pressures and temperatures up to 20-25 $\mathrm{MPa}$ and $550-700^{\circ} \mathrm{C}$, respectively, which can impose high stresses and challenge material integrity in many areas of the system. Beyond these initial factors, it is equally important to understand corrosion resistance of candidate materials in order to prevent unexpected deterioration of components or decline in efficiency. Although generally considered to be thermally stable at temperatures below $1500^{\circ} \mathrm{C}$, little is known about material compatibility of $\mathrm{CO}_{2}$ under supercritical conditions.

Beyond the initial use of $\mathrm{CO}_{2}$ as a working fluid in the advanced gas-cooled reactors in the United Kingdom, little $\mathrm{CO}_{2}$ corrosion research has been conducted until recent studies by Dunlevy (2007) [6] and Gibbs (2010) [7]. Further corrosion testing is required to understand the kinetics and mechanisms of corrosion on a variety of candidate materials at a range of operating conditions. The testing conducted in this work exposes materials to temperatures of $550^{\circ} \mathrm{C}$ and $700^{\circ} \mathrm{C}$ at pressures of 15 $\mathrm{MPa}$ and $25 \mathrm{MPa}$, in an effort to understand the corrosion resistance of varying alloy compositions and its dependance on temperature and pressure.

\subsection{Objective and Organization of Thesis}

The motivation for the work conducted was to explore the compatibility of various high temperature alloys in $\mathrm{S}-\mathrm{CO}_{2}$ and to determine suitable alloys for further investigation. In the collaborative project between Carleton University and Natural 
Resources Canada (NRCan), corrosion testing was conducted at four different combinations of pressure and temperature, including the highest combination of pressure and temperature that has been reported at this time. The test conditions were chosen to closely replicate the temperature and pressure expected in the operation of $\mathrm{S}-\mathrm{CO}_{2}$ Brayton cycles.

In the following chapter, an introduction to high temperature materials and corrosion is provided. Chapter 3 outlines the design and procedure of the corrosion testing conducted, while Chapter 4 provides a summary of the results. Finally, Chapter 5 summarizes the work presented and highlights notable results, followed by recommendations for future work. 


\section{Chapter 2}

\section{Background}

This chapter provides a summary of high temperature material corrosion in $\mathrm{S}-\mathrm{CO}_{2}$. A brief introduction to high temperature materials is provided, specifically focussed on austenitic stainless steel, iron-nickel-, and nickel-base superalloys. The mechanics and kinetics of corrosion and high temperature oxidation are later discussed with an application to $\mathrm{S}-\mathrm{CO}_{2}$ conditions, while finally focussing on a summary of $\mathrm{S}-\mathrm{CO}_{2}$ corrosion studies that have been completed.

\subsection{High Temperature Materials}

Under low temperature conditions, alloys can usually be selected for applications based on conventional properties of yield strength, modulus of elasticity, or corrosion resistance. When the operating temperature begins to exceed $50 \%$ of the alloy's melting temperature, the stability of the alloy must be considered. Long-term effects, such as creep and phase instability, can reduce the alloy's strength and eventually lead to premature failure through rupture and/or dimensional changes [8]. For turbine blade applications, creep can cause bowing of vanes or lengthening that can eventually lead to contact with the outer casing. High strength is also required in the support infrastructure for gas turbines, which include: process piping, heat exchangers, and 
turbomachinery casing.

Typically used in applications where temperatures exceed $540^{\circ} \mathrm{C}$, superalloys employ a variety of strengthening mechanisms based on their composition, melting procedures, forming process, and subsequent heat treatment [8]. For use under such conditions, superalloys were formulated to provide stable, high strength properties at high temperatures from careful balancing of elements for strength and corrosion resistance.

Superalloys primarily derive their strength from the construction of multiple forms of phases and carbides, which are created by a combination of composition, forming (cast or wrought), and heat treatments. The main phases of superalloys consists of: $\gamma, \gamma^{\prime}, \gamma^{\prime \prime}, \eta$, and $\delta$. The main superalloy matrix consists of the austenitic fcc $\gamma$ phase, where the remaining phases are composed of $\gamma^{\prime}$ fcc $\mathrm{Ni}_{3}(\mathrm{Al}, \mathrm{Ti}), \gamma^{\prime \prime}$ bct $\mathrm{Ni}_{3} \mathrm{Nb}, \eta$ hexagonal $\mathrm{Ni}_{3} \mathrm{Ti}$, and $\delta$ orthorhombic $\mathrm{Ni}_{3} \mathrm{Nb}$, in addition to fcc carbides $\mathrm{MC}, \mathrm{M}_{2} 3 \mathrm{C}_{6}$, $\mathrm{M}_{6} \mathrm{C}$, and $\mathrm{M}_{7} \mathrm{C}_{3}$. These phases are manipulated through heat treatments to maximize strengthening mechanisms for specific applications. [8].

The $\gamma$ phase is typically the main matrix phase in superalloys and contains most of the solid solution elements, which can include: cobalt, iron, chromium, molybdenum, and tungsten. The $\gamma^{\prime}$ phase can exist as a precipitate in cuboidal or spherical form along grain boundaries or within the grain. These precipitates form the primary high-temperature strengthening mechanism and has proven useful for increasing creep-rupture properties. Highest strength at high temperature is found through use of cuboidal precipitates. These properties are based on the volume fraction, size, and morphology of the precipitates, which is controlled through the relative additions of titanium and aluminum in conjunction with subsequent heat treatments. The niobium and nickel $\gamma^{\prime \prime}$ phase provides a dramatic increase in strength at low temperatures but is unstable at temperatures above $650^{\circ} \mathrm{C}$. Much of the strength is due to mismatch strains induced by the $\gamma$ phase [8]. 
Superalloys are classified into three main categories based on their major compositional element: nickel-, iron-nickel-, and cobalt-base alloys. A comparison of compositions is provided in Table 1 .

\begin{tabular}{lcc} 
& \multicolumn{2}{c}{ Composition (\%) } \\
\cline { 2 - 3 } Element & Fe-Ni/Ni-Base & Co-Base \\
\hline $\mathrm{Cr}$ & $5-25$ & $19-30$ \\
$\mathrm{Mo}, \mathrm{W}$ & $0-12$ & $0-11$ \\
$\mathrm{Al}$ & $0-6$ & $0-0.45$ \\
$\mathrm{Ti}$ & $0-6$ & $0-4$ \\
$\mathrm{Co}$ & $0-20$ & $\mathrm{Bal}$ \\
$\mathrm{Ni}$ & $\mathrm{Bal}$ & $0-22$ \\
$\mathrm{Nb}$ & $0-5$ & $0-4$ \\
$\mathrm{Ta}$ & $0-12$ & $0-9$ \\
$\mathrm{Re}$ & $0-6$ & $0-2$ \\
\hline
\end{tabular}

Table 1: Composition of major elements in $\mathrm{Fe}-\mathrm{Ni}-$, Ni-, and Co-base superalloys. Reproduced from [8].

The three categories of superalloys can generally be subdivided based on cast or wrought processing techniques. Cast alloys typically have a coarser grain when compared to wrought alloys, making them less susceptible to creep rupture. Furthermore, cast alloys offer additional processing control through the use of directional solidification techniques to further enhance creep and high temperature strength properties. In contrast, wrought alloys usually exceed cast alloys in tensile strength and low-cycle fatigue strength due to a finer grain size [9]. A comparison of these superalloy classes with respect to rupture strength in provided in Figure 7. 


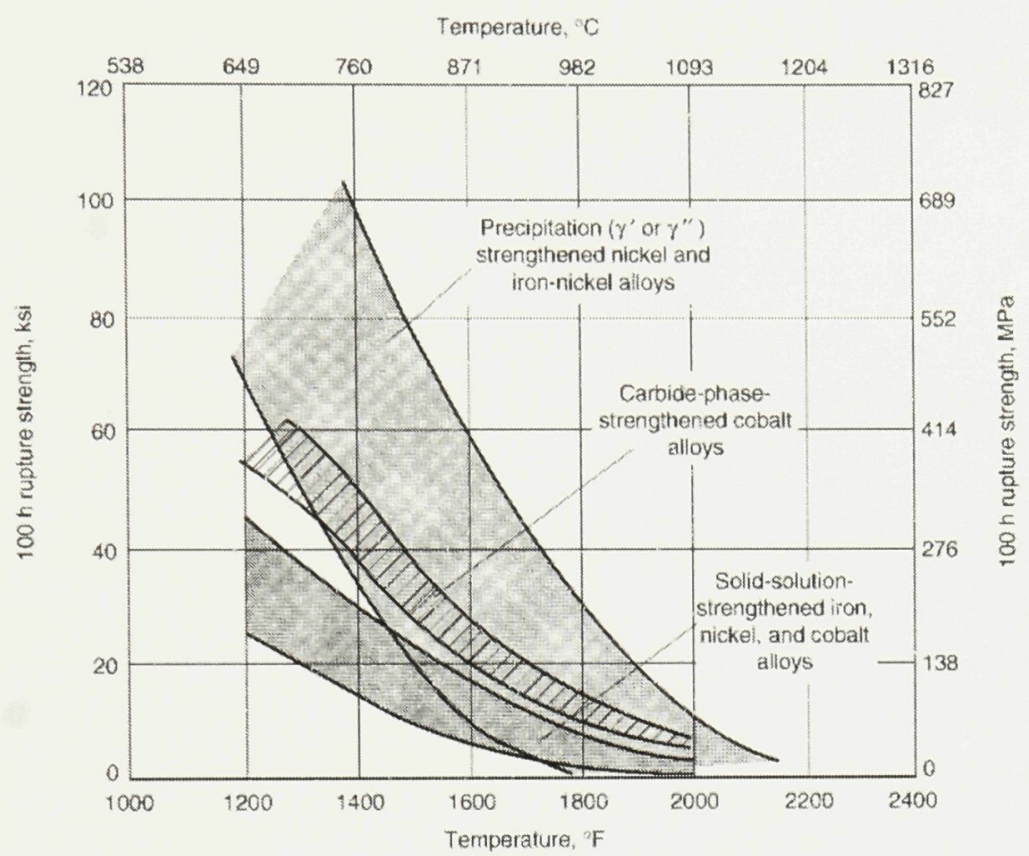

Figure 6: Rupture strength of common superalloys [8].

Temperature, ${ }^{\circ} \mathrm{C}$

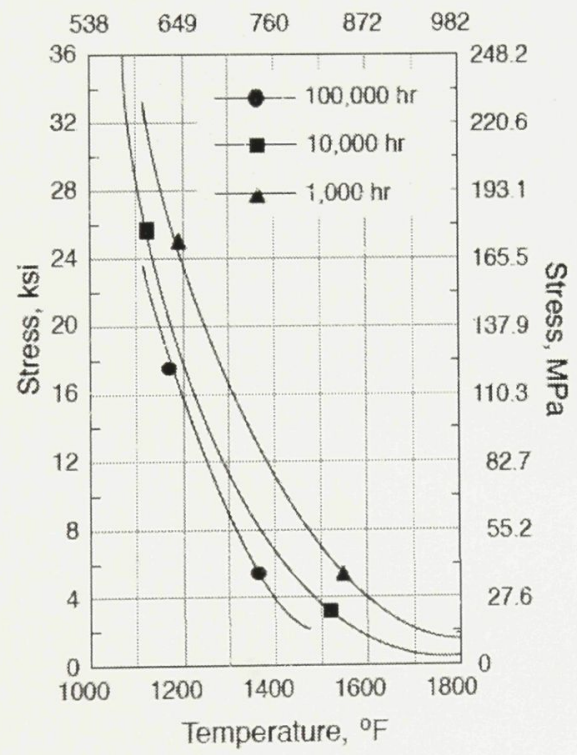

Figure 7: Rupture strength of 316SS [10].

In the formulation of superalloys, specific alloying elements are introduced to enhance specific qualities of the matrix. These properties are tabulated in Table 2. 


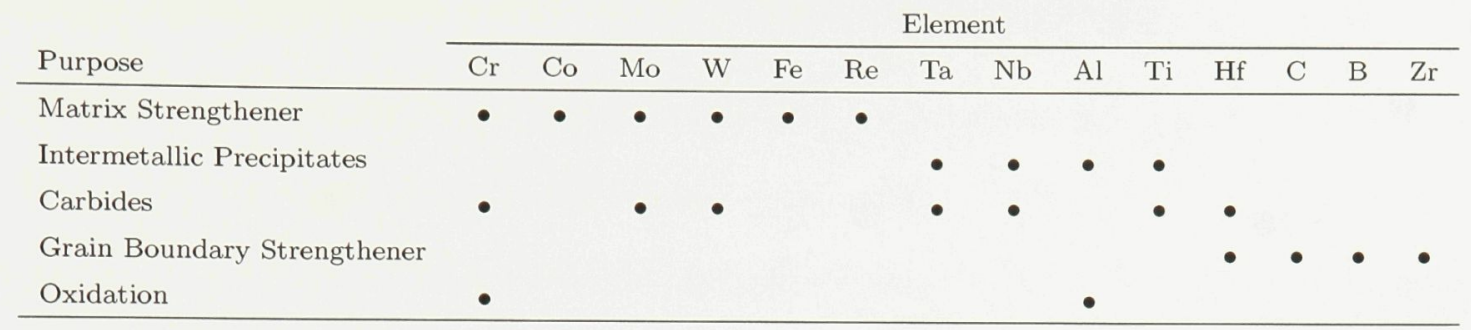

Table 2: Purpose of elemental additions to superalloys. Reproduced from [9].

Figure 8 depicts the benefits of specific elemental additions to iron-nickel/nickelbase superalloys.

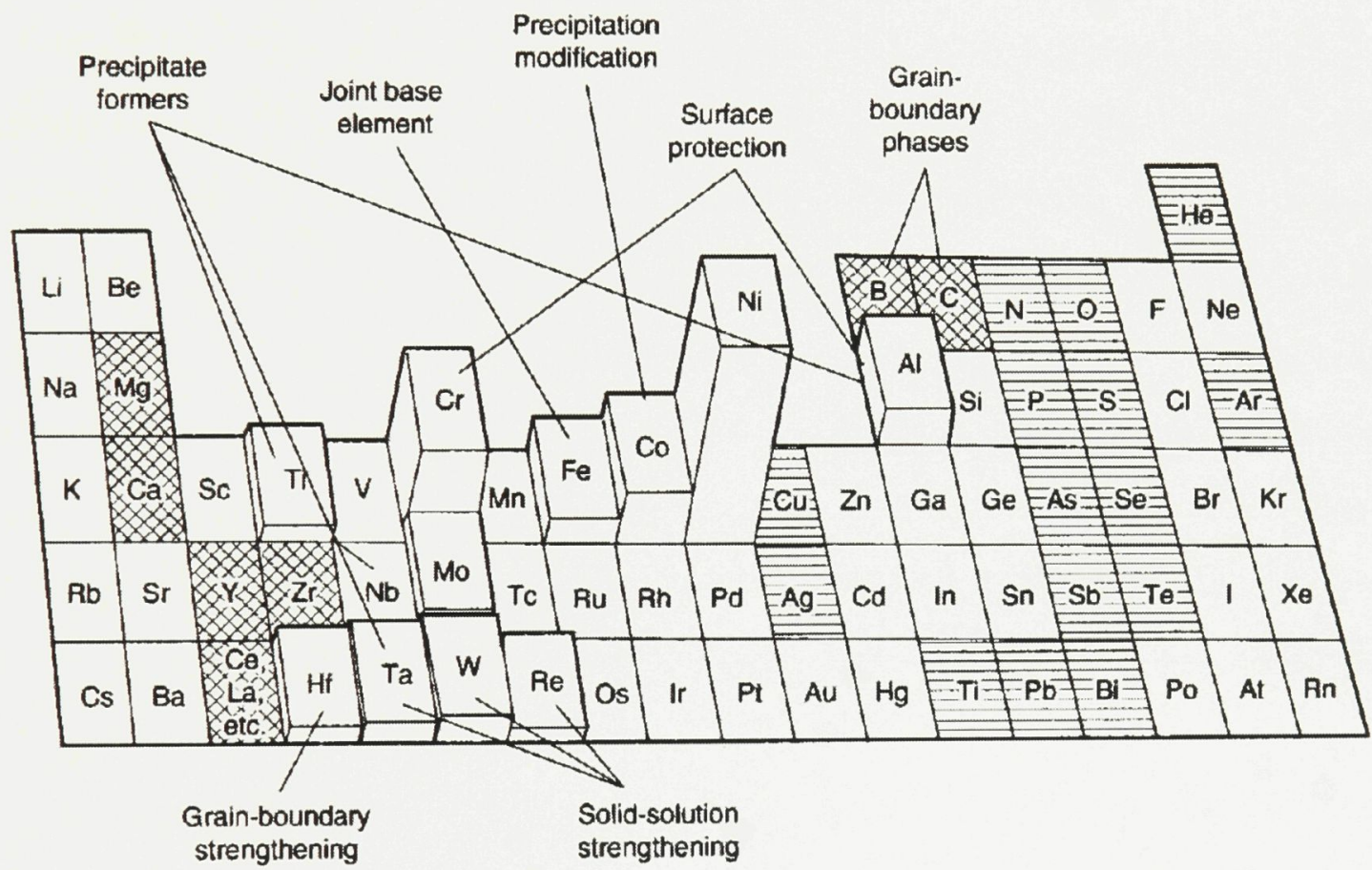

Figure 8: Alloying elements used in Ni-base superalloys [8]. Cross-hatched pattern represents beneficial minor elements; horizontal pattern represents detrimental elements. 


\subsubsection{Iron-Nickel- and Nickel-Base Superalloys}

In recent years, the division between iron-nickel- and nickel-base superalloys has narrowed with the addition and modification of new alloys. Both types rely on strengthening mechanisms of solid solution and precipitate hardening. The typical iron-nickelbase alloy's main strengthening mechanism is found in a fcc intermetallic compound precipitate, generally $\gamma^{\prime}$. Some of these alloys include A-286, V-57, and Incoloy 901. Other forms of iron-nickel-base alloys are found in modified stainless steels that are treated to produce $\gamma^{\prime}$ precipitates. Alloys such as, 19-9DL and Incoloy 800H, have an increased content of mainly nickel, but also titanium and aluminum [8].

Nickel-base alloys are predominantly strengthened by intermetallic compound precipitates in an austenitic fcc matrix. Nickel-base alloys are generally grouped into categories of solid-solution strengthened (Hastelloy X and IN-625), Ti-Al $\gamma^{\prime}$ precipitate strengthened (Waspaloy, U-700, and IN-713), and a combination of niobium $\gamma^{\prime \prime}$ and Ti-Al $\gamma^{\prime}$ strengthened (IN-718 and IN-706). In some cases, alloys such as IN-718 and IN-706 can be found listed as iron-nickel-base partially due to the increased composition of iron in the matrix. A further extension to the nickel-base alloy class is the oxide-dispersion strengthened alloys (IN-MA-754 and IN-MA-6000E). This type of alloy is strengthened in combination of inert particles (yttria) and $\gamma^{\prime}$ precipitation [8].

The two alloys used in this work were wrought IN-718 and cast IN-738, which consist of distinctly different compositions. This comparison can be found in Table 6 on page 45 , where the most notable difference is the $18.5 \mathrm{wt} \%$ of iron found in IN-718. This addition makes an iron-nickel matrix for IN-718 that governs the formation of secondary phases, and ultimately, maximum operating temperature. For this reason, IN-718 is generally limited in operating temperating to $816^{\circ} \mathrm{C}$. In comparison, IN738 provides a slightly lower strength alternative that is more stable at temperatures 
exceeding $816^{\circ} \mathrm{C}$ due to the cast nickel-base. Figure 9 offers a comparison of $1000 \mathrm{hr}$ rupture strength for some common nickel-base superalloys. Cast superalloys also offer greater control of microstructure for the optimization of equiaxed or directionally solidified grain structures [8].

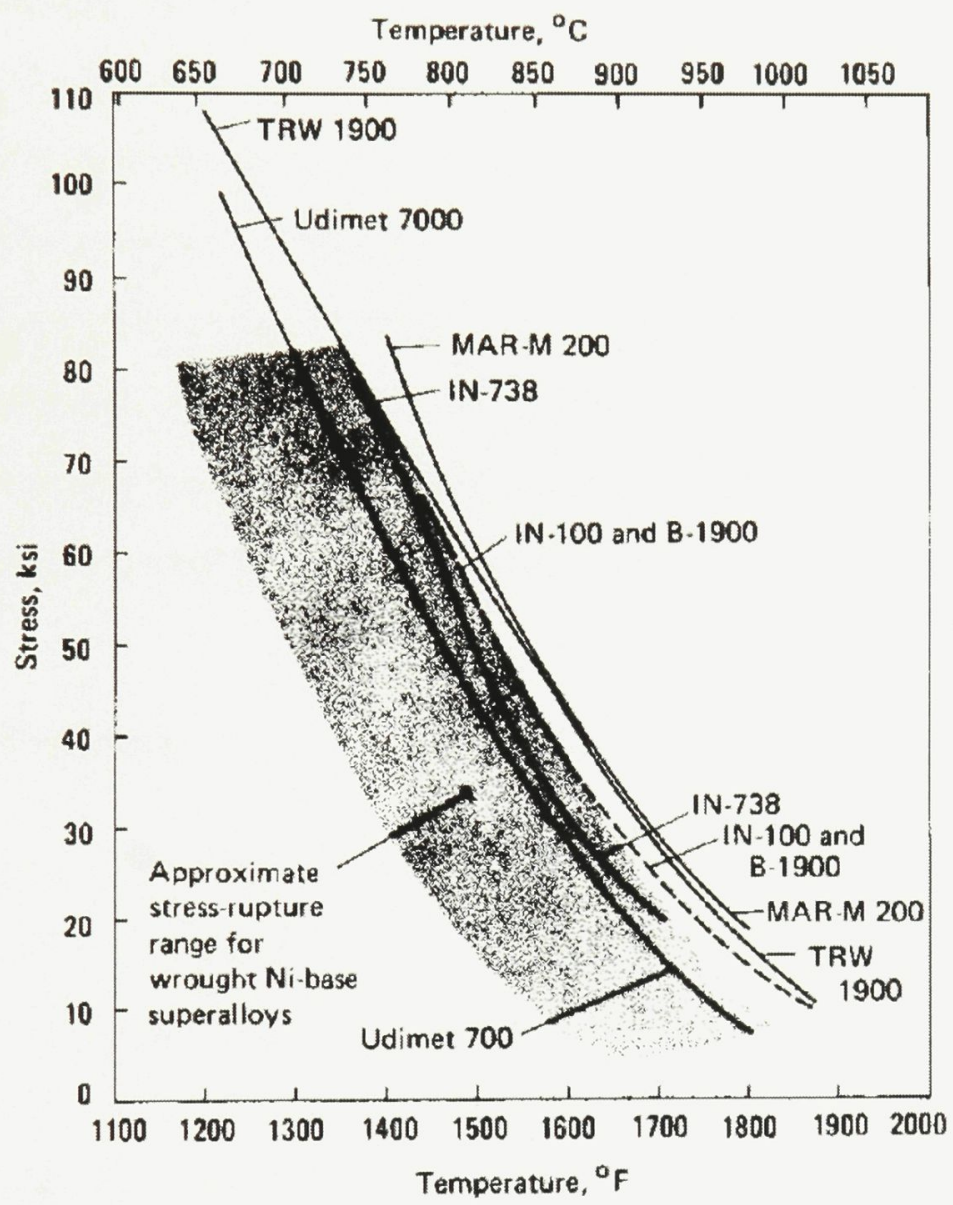

Figure 9: 1000 hr stress-rupture plot for some Ni-base superalloys [8].

\subsubsection{Austenitic Stainless Steel}

Austenitic stainless steels are a variation of chromium-iron steel where additions of nickel, and in some cases, molybdenum have been added. Additions of nickel help to stabilize the austenite phase and work with chromium to enhance corrosion resistance. Furthermore, the face-centered-cubic structure eliminates a ductile-to-brittle 
transition at low temperatures. The corrosion resistance of austenitic stainless steels can be highly dependant on temperature and environment, where high temperatures or acids can deteriorate the protective oxide layer. For this reason, molybdenum can be added to address some of these concerns by improving resistance to stress corrosion cracking and chloride pitting [7].

The austenitic stainless steel used in this work is 316SS. This alloy is one of the most popular stainless steels due to high rupture strength, creep strength, and excellent corrosion resistance. Originally developed for the paper mill industry, 316SS is used throughout industries including: food processing, heat exchangers, fasteners, and medical implants. Available in both standard and low carbon forms, it also offers better corrosion resistance and cold working properties than alloy 304, and is generally considered weldable for most applications $[7,11]$.

\subsection{Corrosion}

Corrosion consists of an electrochemical reaction between an anode and cathode. This reaction is based on the presence of an oxidizing agent that can be reduced by reaction with a metal ion [12]. In aqueous corrosion, or low-temperature corrosion, an electrolyte is required for the chemical reaction to occur and typically consists of a layer of moisture on the surface of the metal. The rate of corrosion increases proportionally with an increasing relative humidity [12]. The electrochemical reaction for aqueous corrosion can be outlined as [12]:

$$
\begin{gathered}
\mathrm{Me} \rightarrow \mathrm{Me}^{n+}+n e^{-} \\
\frac{1}{2} \mathrm{O}_{2}+\mathrm{H}_{2} \mathrm{O}+2 e^{-} \rightarrow 2 \mathrm{OH}^{-} \\
\mathrm{Me}^{n+}+\mathrm{nOH}^{-} \rightarrow \mathrm{Me}(\mathrm{OH})_{n}
\end{gathered}
$$


As temperatures exceed $100^{\circ} \mathrm{C}$, most metals begin to form thin, slow growing oxide layers on a scale that can only be observed using an electron microscope [13]. Any aqueous solution present in the gas will begin to take the form of a vapour rather than liquid. Although an electrochemical reaction, the driving force is thermodynamic, which causes the rate of reaction to increase with increasing temperature. The increasing temperature also begins to dry the atmosphere, which counteracts the atmospheric corrosion process and results in a maximum corrosion rate based on the varying degrees of moisture level and temperature at a certain point [12]. As temperatures approach $500^{\circ} \mathrm{C}$, corrosion mechanisms take the form of high temperature corrosion.

High temperature corrosion, or chemical corrosion, involves the exposure of metals to temperatures exceeding $500^{\circ} \mathrm{C}$ where the electrode reaction takes place in the presence of a dry gas [12]. The reaction involves the formation of a solid oxide on the surface of the metal that separates the atmosphere from the metal [13]. The rate of reaction is based on the ability of ions to transport through the oxide layer, which can depend on the temperature, microstructure, and composition of the oxide layer.

Below $500^{\circ} \mathrm{C}$, dry $\mathrm{CO}_{2}$ is generally inert, but as temperatures exceed $600^{\circ} \mathrm{C}$, significant corrosion can occur based on thermodynamic driving forces involved. Compositional additives can be used to combat corrosion and produce a stable and protective oxide layer but are usually not compatible with the required strengthening mechanisms within the alloy [13].

For applications involving $\mathrm{CO}_{2}$, there is little documented data on the compatibility of alloys beyond the initial use of $\mathrm{CO}_{2}$ in the advanced gas reactors (AGR) in the United Kingdom. Although operated at a relatively low pressure of $4 \mathrm{MPa}$, below the critical point of $\mathrm{CO}_{2}$, the reactors used low alloy steels in areas that were exposed to temperatures of $650^{\circ} \mathrm{C}[3]$. There are only a few recent studies that have started to look at high chromium and nickel alloys exposed to $\mathrm{S}-\mathrm{CO}_{2}$, but more studies are 
needed to look at the pressure and temperature limits that are expected in a Brayton cycle gas turbine.

There exists several forms of corrosion that can lead to catastrophic damages in a Brayton cycle gas turbine throughout areas of the turbine, piping, heat exchanger, and compressor. Some of these include: oxidation, nitration, carburization, metal dusting, holgenation, sulfidation, erosion-corrosion, and molten salt deposition, amongst others. For $\mathrm{CO}_{2}$, oxidation and carburization are considered the most important factors for material selection and will be discussed in subsequent sections.

\subsubsection{High Temperature Oxidation}

Oxidation is based on the electrochemical reaction between metal and oxygen ions, where a solid oxide product is formed on the surface of the metal. These oxides can be either protective or non-protective based on their ability to limit further oxide growth or metal loss. An oxide that forms a solid barrier to oxide ions will prevent metal loss by limiting diffusion of ions through the oxide. In contrast, an unstable oxide that cracks or deteriorates from factors such as: thermal stresses, porosity, or thermal expansion, are detrimental to the underlying metal.

A variety of oxide layers provide different elements of protection under specific atmospheric conditions, and are manipulated through the compositional design of the alloy. High temperature materials are alloyed with a selection of elements such as: $\mathrm{Al}, \mathrm{Ni}, \mathrm{Cr}, \mathrm{Co}$, and $\mathrm{Si}$, which have shown to form a variety of effective oxide layers at high temperatures. Table 3 provides an overview of high temperature materials and their maximum use temperature based on oxide stability. 


\begin{tabular}{lcc} 
Alloy Type & Oxide Formation & Maximum \\
\hline Low-alloy steel & $\mathrm{Fe}_{3} \mathrm{O}_{4}$ & 500 \\
Titanium-base & $\mathrm{TiO}_{2}$ & 600 \\
Ferritic stainless steel & $\mathrm{Cr}_{2} \mathrm{O}_{3}$ & $650^{*}$ \\
Austenitic Fe-Ni-Cr & $\mathrm{Cr}_{2} \mathrm{O}_{3}$ & $850^{*}$ \\
Austenitic Ni-Cr & $\mathrm{Cr}_{2} \mathrm{O}_{3}$ & 950 \\
Austenitic Ni-Cr-Al & $\mathrm{Al}_{2} \mathrm{O}_{3}$ & 1100 \\
\hline
\end{tabular}

*more based on creep properties

Table 3: Common engineering alloys with respect to use temperature [13].

The following section outlines the principles behind the formation of these oxides in high temperature conditions, in addition to factors that pertain to the stability and effectiveness of a protective oxide.

\section{Formation of Oxides}

High temperature oxidation consists of the electrochemical reaction between a metal and oxygen ions. The diffusion-controlled transport of oxygen anions and metal cations through an oxide, allow for the formation of new oxide products at either the oxide/oxygen, or oxide/metal interface [13]. This transport of ions determines the rate of oxide growth, consisting of metal depletion, and is the determining factor for the effectiveness of the oxide to protect the substrate metal. As illustrated in Figure 10, there can exist multiple oxide layers of different compositions, but an overall metal/oxide interface and oxide/oxygen interface exists on either side. 


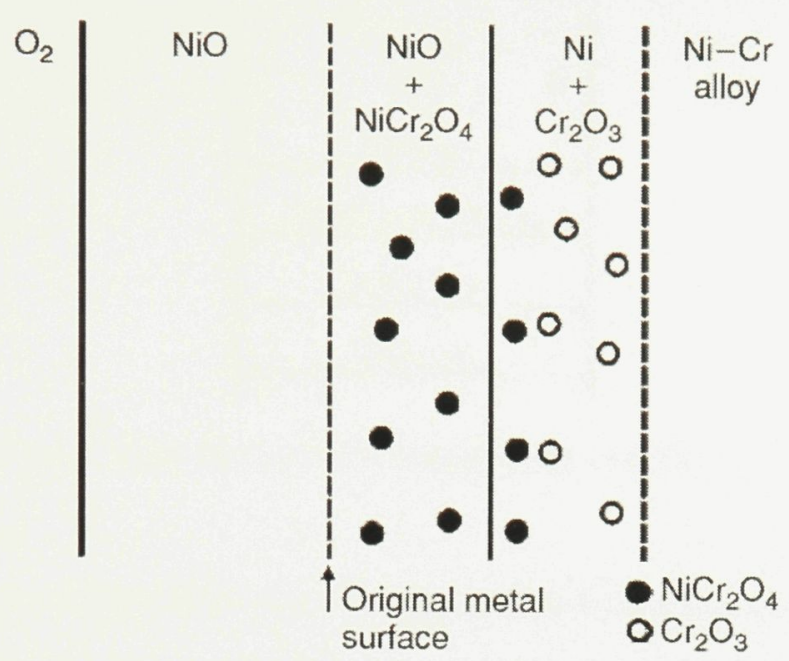

Figure 10: Multi-layer oxidation of Ni-Cr alloy [13].

The reaction for high temperature oxidation in producing the metal oxide product consists of the equation adapted from [9]:

$$
\frac{2 x}{y} M+O_{2} \leftrightarrow \frac{2}{y} M_{x} O_{y}
$$

A popular theory for explaining scale formation is Wagner's theory of oxidation. The theory explains the oxide growth rate based on the assumptions that solid oxide growth is from cation transport across the oxide layer, and that thermodynamic equilibrium exists on both oxide/oxygen and oxide/metal interfaces [13]. Metal cations and oxide ions will travel in opposite directions across the oxide layer, subsequently causing an electric field to be produced due to their ionic nature. Furthermore, the electric field will draw electrons from the metal, which will act to balance the net charge transferred between the two interfaces [13]. 


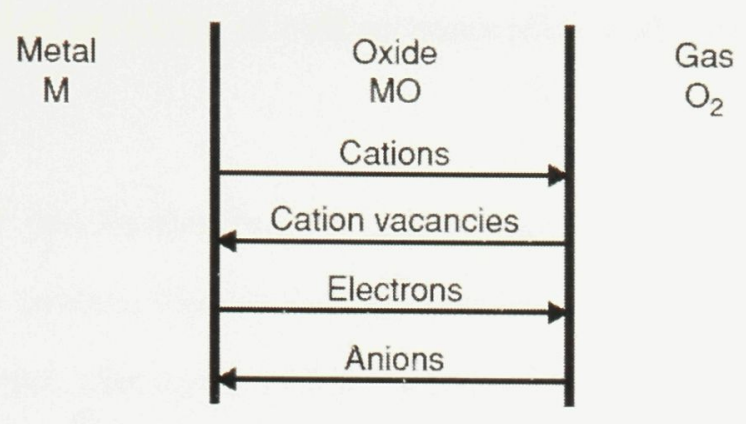

Figure 11: Transport of ions for oxide formation according to Wagner's theory [13].

Thermodynamics and kinetics are the two major factors in the formation of oxides and both conditions must be satisfied for the mechanism to take place. When considering thermodynamics, an oxide will be formed based on a favourable change in free energy from the formation of the oxide from the reactants [14]. This free energy can be taken as Gibbs free energy $(\Delta G)$, which represents the chemical potential for a reaction to occur based on the change in enthalpy $(\Delta \mathrm{H})$, entropy $(\Delta \mathrm{S})$, and absolute temperature:

$$
\Delta G=\Delta H-T \Delta S
$$

A negative $\Delta \mathrm{G}$ represents potential for a spontaneous reaction to occur, should the kinetics be favourable [15]. An Ellingham Diagram, provided in Figure 12, can be used to predict corrosion processes based on the thermodynamically feasible reactions derived from $\Delta \mathrm{G}$ and temperature, in addition to the partial pressure of oxygen, carbon monoxide, and carbon dioxide [7]. The plot consists of a series of lines for each reaction, where $\Delta \mathrm{S}$ is the slope and $\Delta \mathrm{H}$ is the $\mathrm{y}$-intercept, and remains a straight line unless a phase change occurs [15].

The Ellingham Diagram is used for three main reasons [15]:

- determine the spontaneity of a metal reduction reaction to form its oxide,

- determine the the equilibrium partial pressure of oxygen with a metal oxide, 
- determine relative amounts of carbon monoxide and carbon dioxide to form an oxide.

From the diagram, it can be determined that a metal will be oxidized if the oxygen, carbon monoxide, or carbon dioxide concentrations are above the equilibrium value. Conversely, if it is lower, the oxide will be reduced [15]. The relative vertical position of the line represents the stability of the oxide, where the most unstable reactions are near the top, and become more stable further down the diagram. It should be noted that the Ellingham Diagram only represents the thermodynamic feasibility of a reaction occurring, where kinetics, involving ion transport for oxide growth, must be achievable for the reaction to take place. 


\begin{tabular}{l}
$\mathrm{H}_{2} / \mathrm{H}_{2} \mathrm{O}$ ratio \\
$\mathrm{CO} / \mathrm{CO}_{2}$ ratio \\
\hline $10^{-8}$
\end{tabular}

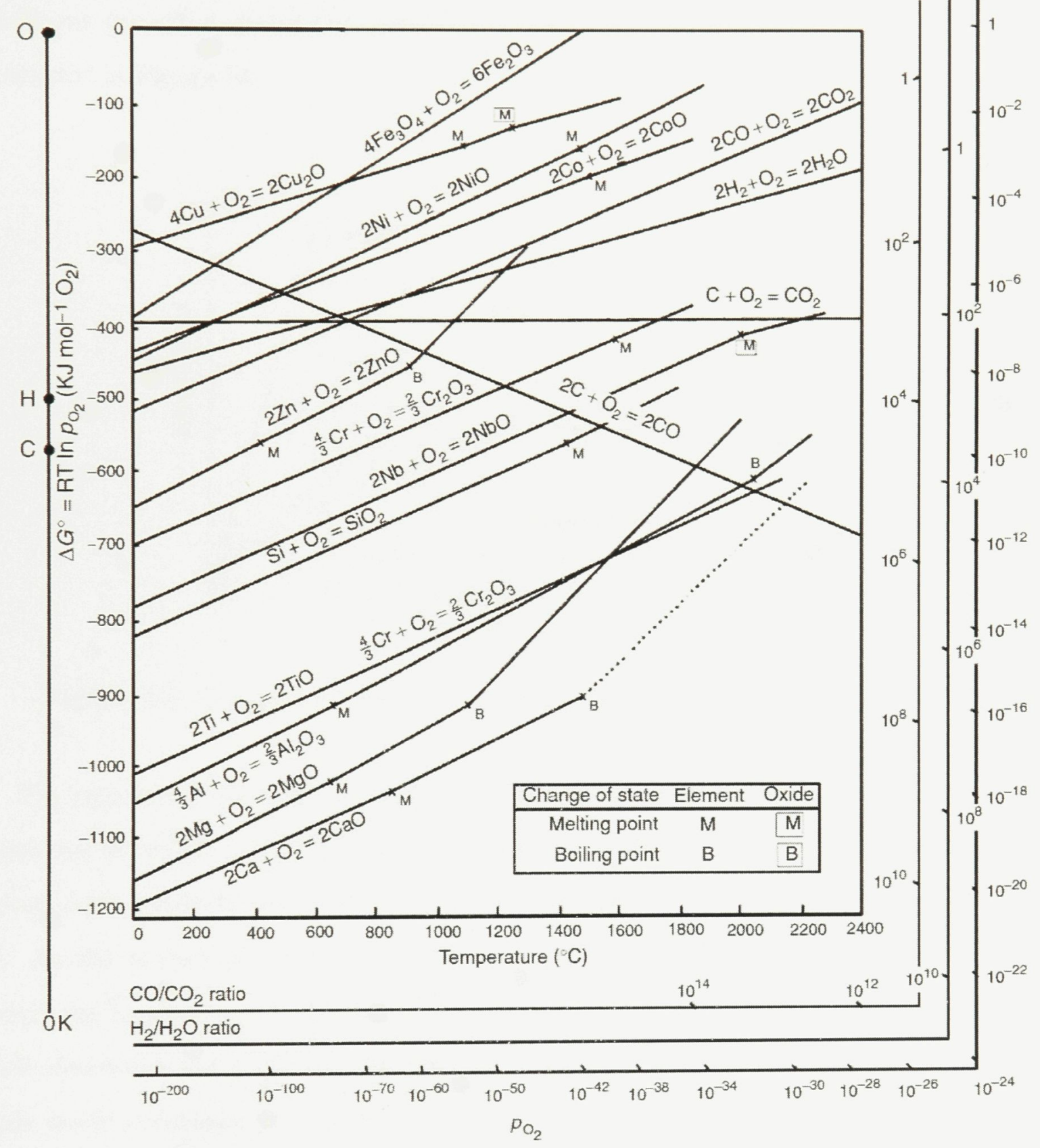

Figure 12: Ellingham diagram: free energy of formation [13].

As the thermodynamic conditions for oxide formation are met, the kinetics must be understood to determine the effectiveness of the oxide to protect the underlying metal. 
Oxide growth measurements are conventionally measured as weight gain per unit area as a function of time, and can follow four main relationships: linear $(y=m t+b)$, paralinear $\left(\mathrm{y}=\mathrm{at} \mathrm{t}^{\mathrm{x}}+\mathrm{y}=\mathrm{mt}+\mathrm{b}\right)$, parabolic $\left(\mathrm{y}=\mathrm{at} \mathrm{t}^{x}\right)$, and logarithmic $(\mathrm{y}=\mathrm{a} \ln (\mathrm{t}))$, as illustrated in Figure 13.

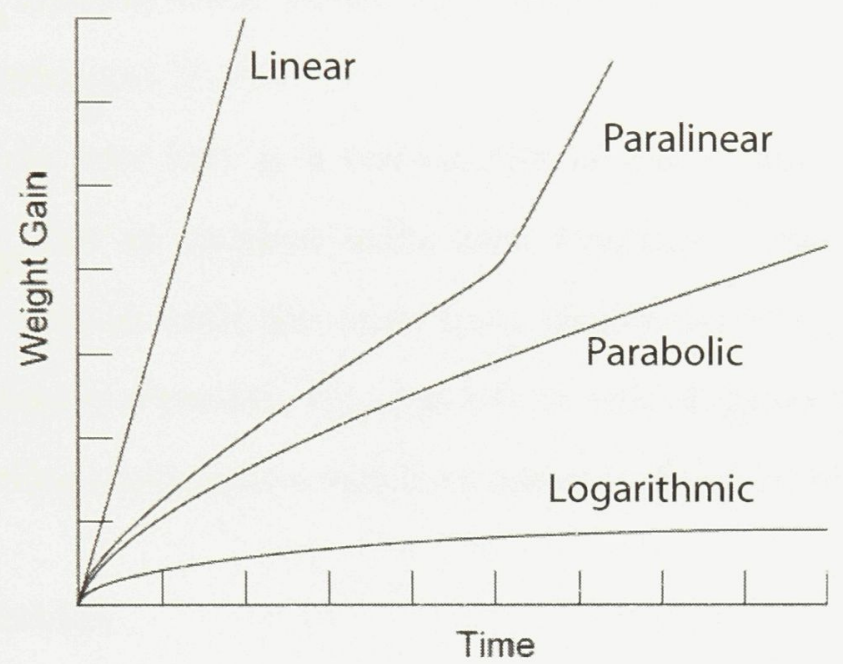

Figure 13: Common kinetics of oxidation: rate laws. Adapted from [9].

The rate laws illustrate the oxide growth over time and can be categorized as protective or non-protective. When there is initial contact between oxygen and the metal, oxide products are rapidly formed on the surface as per Equation 4 on page 19. As the surface of the metal is quickly covered, diffusion of ions becomes the underlying mechanism for oxide growth. The rate-determining characteristics of the oxide determine the ability of new oxidizing reactions to occur, where a protective oxide would eventually prevent further oxidization [9].

The linear rate law describes an oxidizing reaction that is constant with time. The produced oxide is non-protective in slowing diffusion or metal contact with oxygen. A linear rate law is not ideal for most engineering applications due to deterioration of the host metal and particulates that could cause clogging of a closed system such 
as a Brayton cycle gas turbine.

Parabolic and logarithmic rate laws are both considered protective due to the reducing rate of oxide formation. An alloy exhibiting this relationship is able to form a stable oxide that isn't prone to cracking, porosity, and is well adhered to the surface to prevent further metal exposure. Due to a higher rate of oxide growth, alloys with parabolic rates typically have oxides with higher diffusion coefficients and/or more defects for ion transport $[7,9]$.

The paralinear rate laws is a combination of linear and parabolic rates and is typically found after an incident oxide layer breakage. This can be attributed to parabolic oxide growth until the oxide layer was breached by means of mechanical contact, or breakaway corrosion, that has left an area of exposed metal. Alternatively, change in operating conditions could have adverse effects on the oxide growth rate.

\section{Stability of Oxides}

Several factors are considered when determining the ability of an oxide layer to protect the alloy, where a protective oxide layer would ideally have the following qualities:

- resistance to oxygen and metal ion transport,

- low microstructural imperfections,

- low thermal stress at operating temperature,

- good adhesion to resist spallation,

- high melting point,

- low vapour point to resist sublimation,

- similar coefficient of thermal expansion as the substrate alloy. 
An oxide layer must be able to adhere to the substrate metal under varying stress and temperature conditions in order to prevent exposing metal for further oxidation. For this reason, an ideal oxide would exhibit similar modulus of elasticity and coefficient of thermal expansion to prevent excessive stresses at the oxide/metal interface that could lead to cracking. Furthermore, melting and sublimation of the oxide can be of concern under high operating temperatures.

A non-protective oxide layer can have deteriorating effects on the alloy. As the oxide breaks down and metal ions are being consumed for the production of new oxide products, there is continuous metal loss from the surface. This could potentially reduce aerodynamics in a Brayton cycle gas turbine, and/or have detrimental affects on the structural integrity of the alloy in the form of creep resistance and stress rupture strength. With continual oxidation, the alloy will eventually become depleted of the required elements and will no longer be able to form a protective oxide. This phenomenon could lead to breakaway oxidation. Figure 14 illustrates the growth of an oxide layer that is eventually subject to breakaway oxidation.

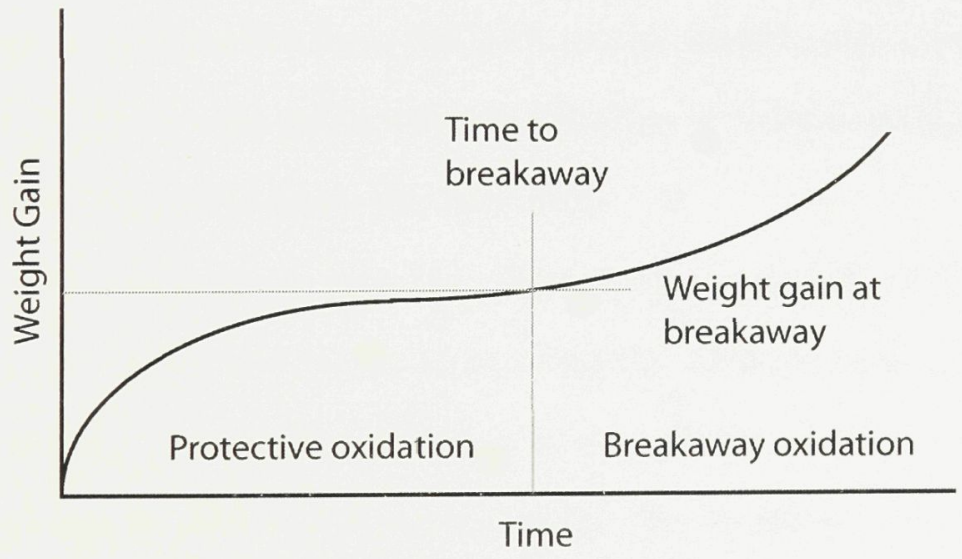

Figure 14: Rate of oxide growth leading to breakaway oxidation. Reproduced from [7]. 


\section{Common Types of Oxides}

In stainless steels, whose compositions are dominated by iron and chromium, three main oxides are typically produced: iron scales, chomia scales, and iron-chromia spinels. The iron oxide, magnetite $\left(\mathrm{Fe}_{3} \mathrm{O}_{4}\right)$ is typically found at temperatures above $500^{\circ} \mathrm{C}$ and is the least stable of the oxides to be discussed with a $\Delta \mathrm{G}=-210$ $\mathrm{kJ} /$ mole $\mathrm{O}_{2}$ [6]. Additional exposure to carbon, such as a $\mathrm{CO}_{2}$ environment, has been found to reduce adherence to the substrate and induce spallation.

In contrast, chromia oxide $\left(\mathrm{Cr}_{2} \mathrm{O}_{3}\right)$, is an effective protective oxide due to its dense microstructure and high resistance to anion/cation transport. It is generally stable up to temperatures of $900^{\circ} \mathrm{C}$, where it then readily reacts with oxygen in the formation of $\mathrm{CrO}_{3}$. The $\Delta \mathrm{G}$ of chromia oxide is approximately $-580 \mathrm{~kJ} / \mathrm{mole} \mathrm{O}_{2}$, making it a much more stable oxide. A chromium composition of at least 12 wt $\%$ has been found to be required in order to produce a continuous oxide layer, but excessive amounts of chromium can lead to the formation of chromia carbides that can deplete the chromium from the matrix and cause embrittlement $[6,16]$.

In nickel-chromium alloys, $\mathrm{NiO}$ and $\mathrm{Cr}_{2} \mathrm{O}_{3}$ form duplex scales, where high concentrations of oxygen will react to form $\mathrm{NiCr}_{2} \mathrm{O}_{4}$ at the oxide/metal interface. Chromium will eventually diffuse to the oxide/oxygen interface to form a continuous chromia oxide scale until it is depleted from the base alloy.

The addition of aluminum into the alloy matrix can add an additional form of protective oxide. About 3-4 wt $\% \mathrm{Al}$ is required with at least 15 wt\% chromium in order to produce a complete alumina scale. Since alumina oxide forms at an order of magnitude slower than chromia oxide, the chromia scale is usually formed quickly, leaving the aluminum to react with the slowly diffusing oxygen. The alumina oxide forms at the $\mathrm{Cr}_{2} \mathrm{O}_{3}$ /alloy interface, adding a further barrier to anion/cation movement. With an increased chromium composition, less aluminum is required due 
to a greater barrier for oxygen anions to penetrate the chromia scale $[6,16]$.

A more thermodynamically stable oxide is found in silica oxide, which is found to form at the chromia/alloy interface. Although silica oxide has a slow formation rate relative to chromia and alumina oxides, the addition of up to $4 \mathrm{wt} \% \mathrm{Si}$ can be beneficial to the formation of $\mathrm{Cr}_{2} \mathrm{O}_{3}$. This can be attributed to the suppression of iron oxide formation in favour of chromia oxide, which serves as a better protective oxide. On the contrary, silica oxide can easily form imperfections that aid ion transport and are also speculated to contribute to spallation in $\mathrm{Cr}$-Fe-Ni stainless steels with more than 0.95 wt $\%$ Si $[17]$.

\section{Pilling-Bedworth Ratio (PB)}

An oxide can also cause internal tensile stresses on itself through the formation of oxide products at the oxide/metal interface [7]. Pilling and Bedworth developed a ratio to determine the protectiveness of a specific oxide based on the volume of oxide produced $(W d)$ and to the volume of metal consumed $(n D w)$ :

$$
P B=\frac{W d}{n D w}
$$

Where $W$ and $d$ represent the molecular weight and density of the oxide, respectively, and $n, D$, and $w$ represent the number of metal atoms in the oxide molecule, the density of the pure metal, and the molecular weight of the pure metal, respectively.

A PB ratio slightly more than one is considered an adherent and protective oxide that is capable of creating moderate compressive stresses to resist spallation. A PB ratio far greater than one could lead to excessive compressive stresses and cause the oxide to buckle, where too much less than one would be tensile and cause spallation [6].

The Pilling-Bedworth ratio is very limited in its application due to its use of pure metals and their oxide. When considering a common oxide such as, $\mathrm{Cr}_{2} \mathrm{O}_{3}$, the 
resulting $\mathrm{PB}$ ratio is equal to 2.02 [7]. Although much higher than to be considered a protective oxide, chromia oxide is still widely considered an effective protective oxide.

\subsubsection{Carburization}

Carburization in $\mathrm{CO}_{2}$ atmospheres can be accelerated through the diffusion of carbon controlled by the operating temperature, diffusing medium, and carbon gradient across the the two interfaces. Many forms of carbides can form throughout the matrix based on carbon activity, some of which include: $\mathrm{Cr}_{3} \mathrm{C}_{2}, \mathrm{Cr}_{7} \mathrm{C}_{3}$, and $\mathrm{Cr}_{2} 3 \mathrm{C}_{6}$ [14]. Carburization typically reduces the corrosion resistance of the alloy due to the depletion of chromium available for chromia oxide formation. Furthermore, carbides reduce the toughness through embrittlement, which can lead to brittle fracture and creep failure.

Mitigating carburization relies on the formation of a protective oxide layer that can limit the diffusion of carbon atoms to the underlying alloy. It has been found that carbon migration is inevitable at temperatures between $400-800^{\circ} \mathrm{C}$, and that the rate is more strongly based on the carbon concentration in the atmosphere than the temperature and original carbon content of the alloy [18].

Nickel alloys offer an alternative to stainless steels in carburizing environments due to their resistance to carburization. This resistance is found from the low solubility of carbon in nickel.

Similar to oxide formation, an Ellingham diagram can be formulated for the formation of carbides with respect to temperature, included in Figure 15. 


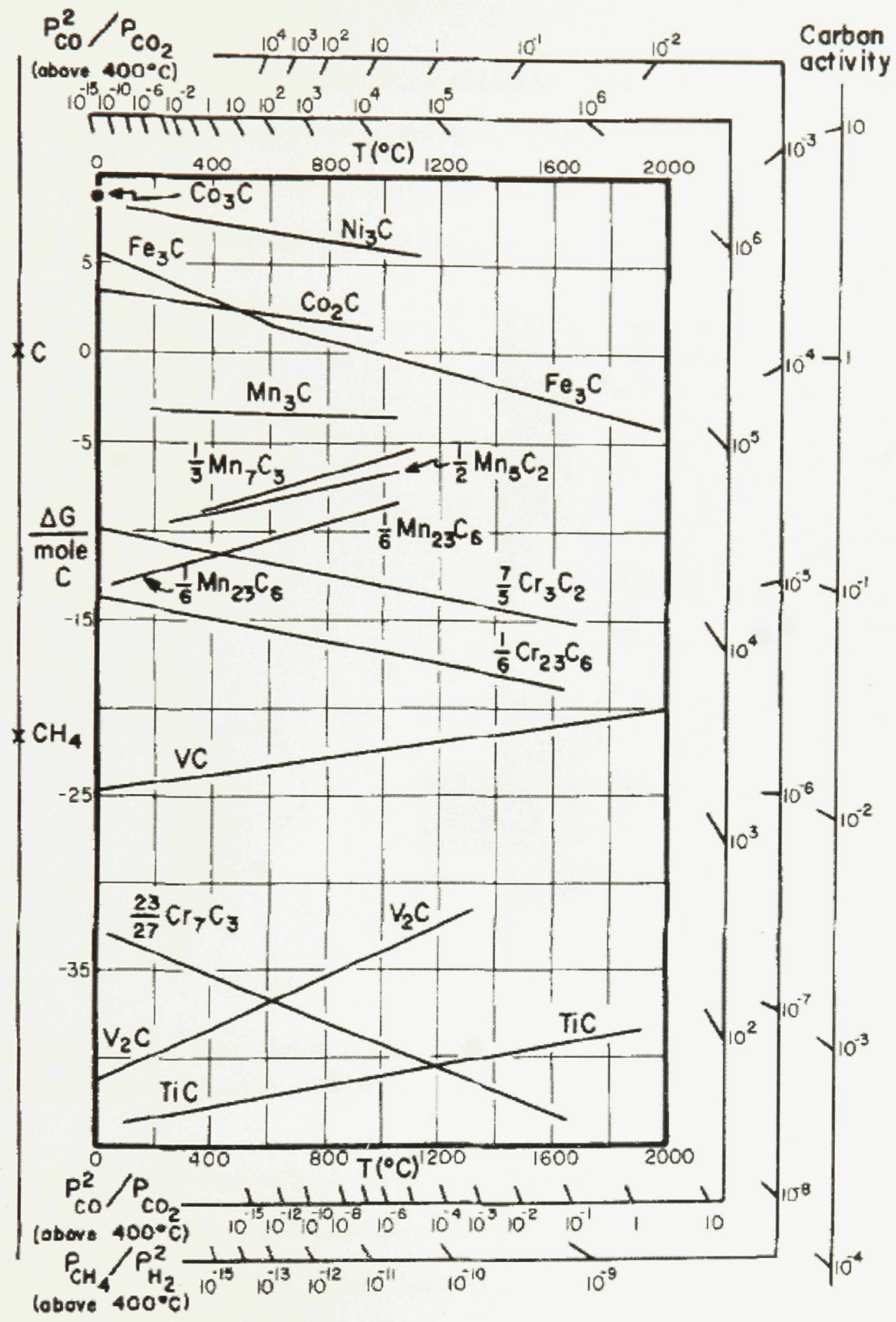

Figure 15: Ellingham Diagram for carburization with transition metals. Gibbs free energy is shown in units of calories [19]. 


\subsubsection{Metal Dusting}

Metal dusting is an extended form of carburization where susceptible materials are exposed to a carbon-rich gaseous environment. Carbon takes advantage of imperfections in the protective oxide layer to reach the underlying alloy and depletes the substrate of chromium through the synthesis of chromia carbides.

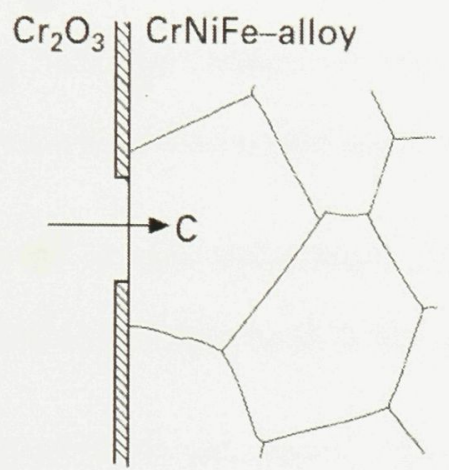

(a)

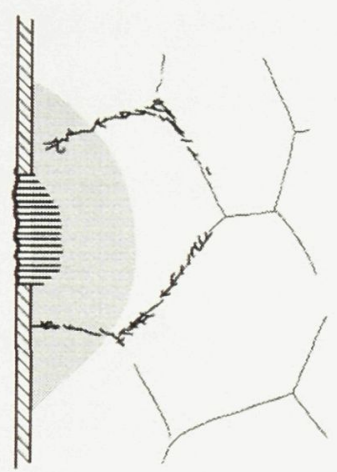

(c)

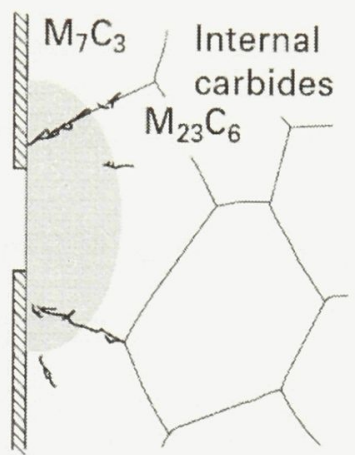

(b)

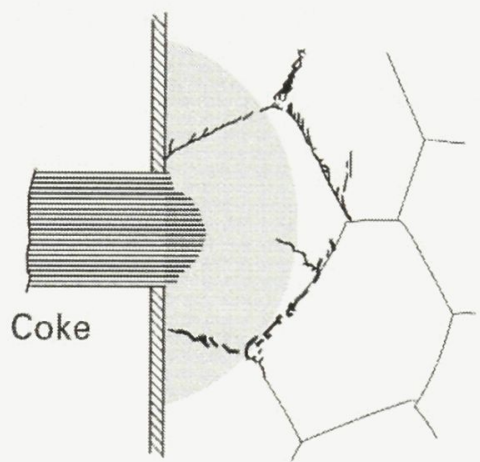

(d)

Figure 16: Initial carburization of nickel-base alloy with subsequent carbon supersaturation and graphite nucleation in the production of coke [20].

The carbide zone eventually becomes supersaturated with carbon and graphite nucleation begins to extend into the alloy. The "coke" corrosion product, formed from the amalgamation of carbides, oxides, and alloy components, destroys the existing oxide and grows outward from the substrate. Within time, the coke product is able to separate from the base alloy along the lines of carbides extending into the substrate. 


\subsection{High Temperature Corrosion Testing}

Common methods of high temperature corrosion testing are based on the assessment of reaction kinetics based on the metal oxidizing reaction of Equation 4 on page 19 . This reaction allows for quantitative measurements based on the following corrosion characteristics as outlined in [13]:

- quantity of metal consumed: Measured weight loss per unit area of the specimen after removal of the oxide and/or remaining metal thickness,

- quantity of oxygen consumed: Measured weight gain per unit area of the specimen and/or oxygen used from the atmosphere,

- quantity of oxide produced: Measured weight or thickness of oxide.

Specimens are typically placed in a carefully controlled atmosphere and allowed to corrode for a predefined period of time. The most accurate form of testing would ideally reproduce the environmental conditions that the material would be exposed to for its intended application. Careful planning should be conducted in the design of tests based on the temperature and pressure of the gas, in addition to test times, sample stress state, and gas flow rates, which should all reflect ideal operating conditions for the desired application in order to produce the most accurate results. Based on the design of the specific test apparatus, gas buoyancy should be considered with higher flow rates. With gases such as $\mathrm{S}_{-} \mathrm{CO}_{2}$, buoyancy could have significant effects on the oxide reactions. In most situations, the environment cannot be exactly replicated but there are a number of methods used to assess the kinetics and mechanisms of the corrosion reaction. 


\subsubsection{Methods of Corrosion Testing}

Corrosion testing can either be considered continuous or discontinuous based on the method of assessment. Oxygen consumption and weight gain are the only characteristics that can be measured on a continuous basis, where other characteristics, such as measuring metal or oxide thickness require destruction of the sample.

For the purpose of an initial assessment of material compatibility, discontinuous testing offers a simple and cost-effective method for corrosion testing.

\section{Discontinuous Corrosion Testing}

Discontinuous corrosion testing involves the interruption of testing for the purpose of measuring changes in weight and/or thickness of the oxide or metal. A number of samples are placed in an autoclave that is heated and pressurized to the required environmental condition. After a predetermined amount of time, the samples are removed and measured, typically for change in weight, and then placed back in the test chamber for the continuation of testing. A select sub-set of samples can be removed at each interval for further analysis by sectioning to quantify oxide and/or metal thickness, changes in composition, or integrity of the oxide.

The interval times for testing need to be carefully planned to capture the kinetics of oxide growth based on the alloy and oxidizing environment. If test points are too spread out, there will not be enough data points to characterize the oxide growth. On the contrary, excessive amounts of samples require more test intervals and introduce more experimental variability in the testing.

A disadvantage of discontinuous testing is the number of samples required to obtain data, including microstructural information, to properly characterize kinetics. Each sample induces experimental variability from the initial preparation, to the reaction to stresses causes from thermal cycling. Furthermore, the handling of samples 
has potential to damage the oxide layer or add undesirable particulates to the surface, such as: oil, dust, and moisture. The effect of these factors can be hypothetically illustrated in Figure 17, where the oxide scale is breached and breakaway oxidation occurs.

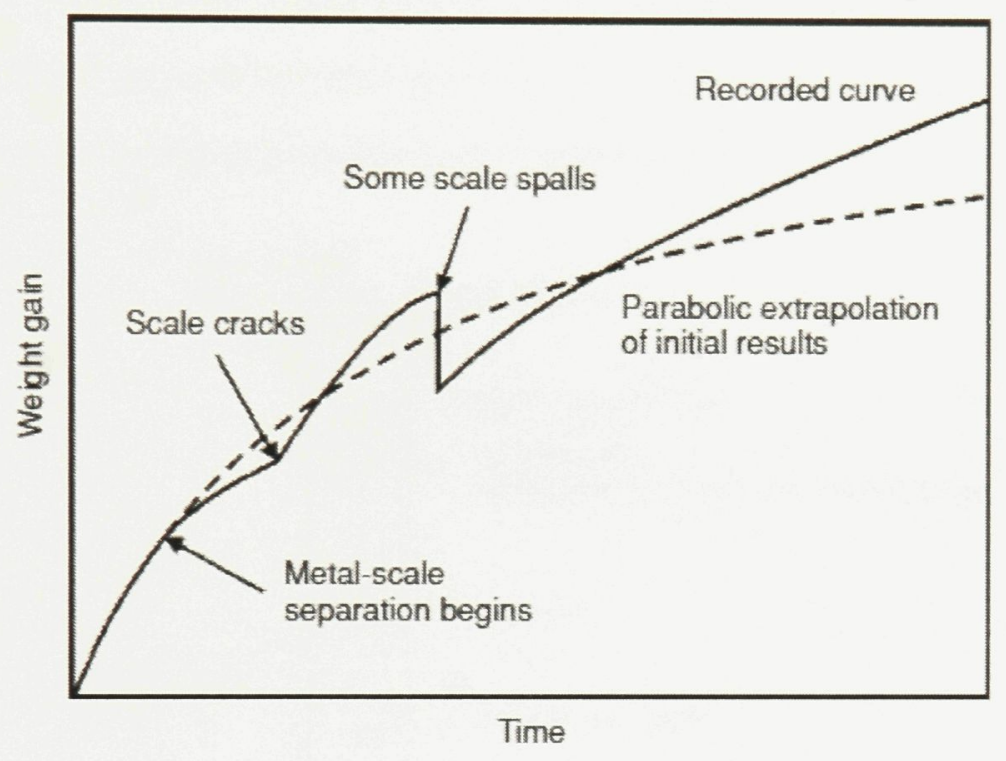

Figure 17: Possible experimental variability induced by discontinuous testing [13].

This illustrated result would not be captured with discontinuous testing because discrete weight gain measurements are recorded at specific times. In order to obtain an uninterrupted collection of weigh gain measurements, continuous corrosion testing is required.

\section{Continuous Corrosion Testing}

Continuous corrosion testing offers the ability to capture change in weight of corroding samples throughout the entire test. Although a much more complex and costly apparatus, the results accurately capture the kinetics of oxide growth, including points of oxide cracking and spallation. When weight change is to be monitored, use of a spring balance apparatus is the simplest form of testing. The apparatus, illustrated 
in Figure 18, typically consists of a glass tube with a sample suspended from a spring. Gas flows from one end to the other, through a heating region, and around the sample and support mechanism. Weight change is measured by the proportional extension of the spring, which is collected using a cathetometer [13]. Although the spring balance does not record data points automatically, sample weight measurements can be manually recorded at any desired time or interval. For this reason, the spring balance is considered a semi-continuous method of testing [13].

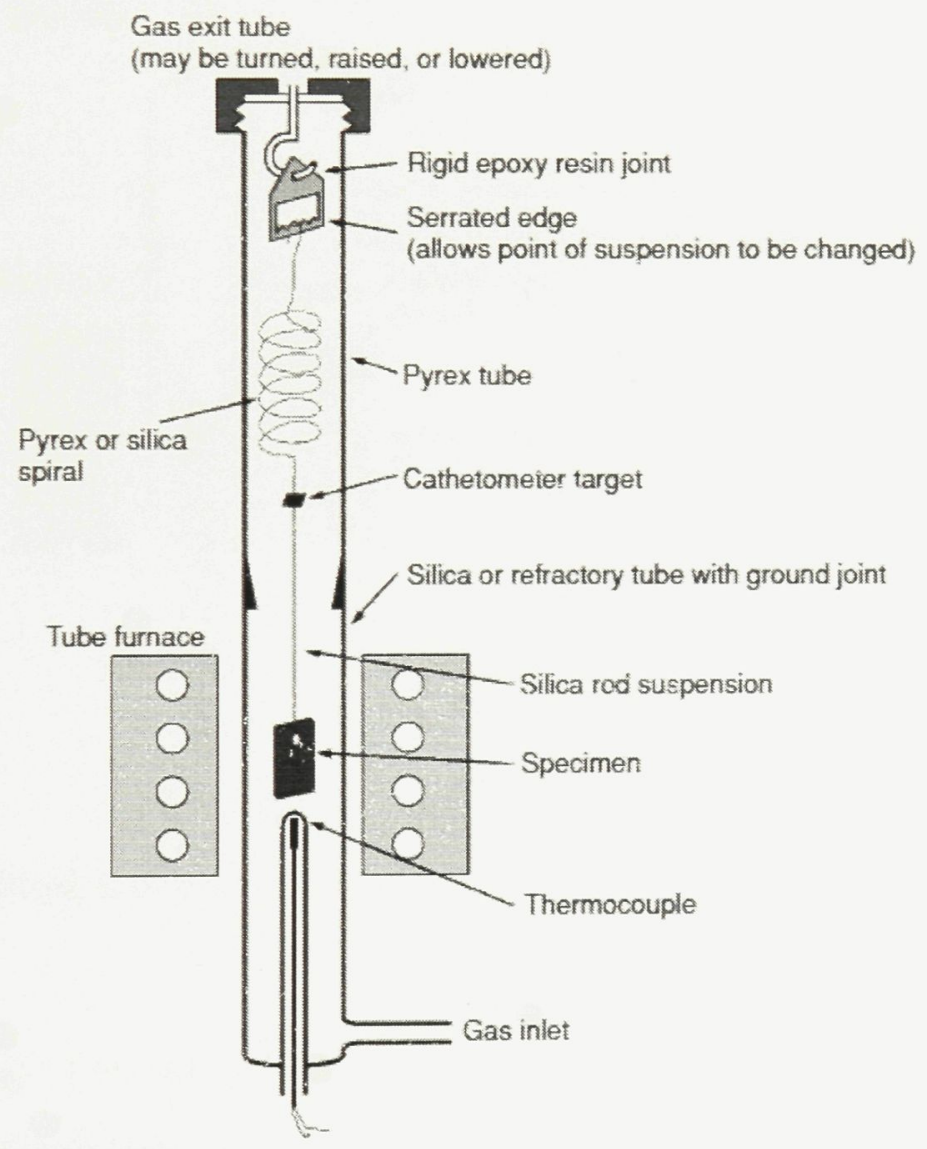

Figure 18: Conventional spring balance used for continuous corrosion testing [13].

A method for full continuous weight change data capture is with an automatic recording balance, as represented in Figure 19. This apparatus using a balance that is continuously recording the weight of the suspended sample while being exposed to 
the corrosive environment. The balance is protected from the corrosive environment through use of a shield gas, typically at a slightly higher pressure than the test gas.

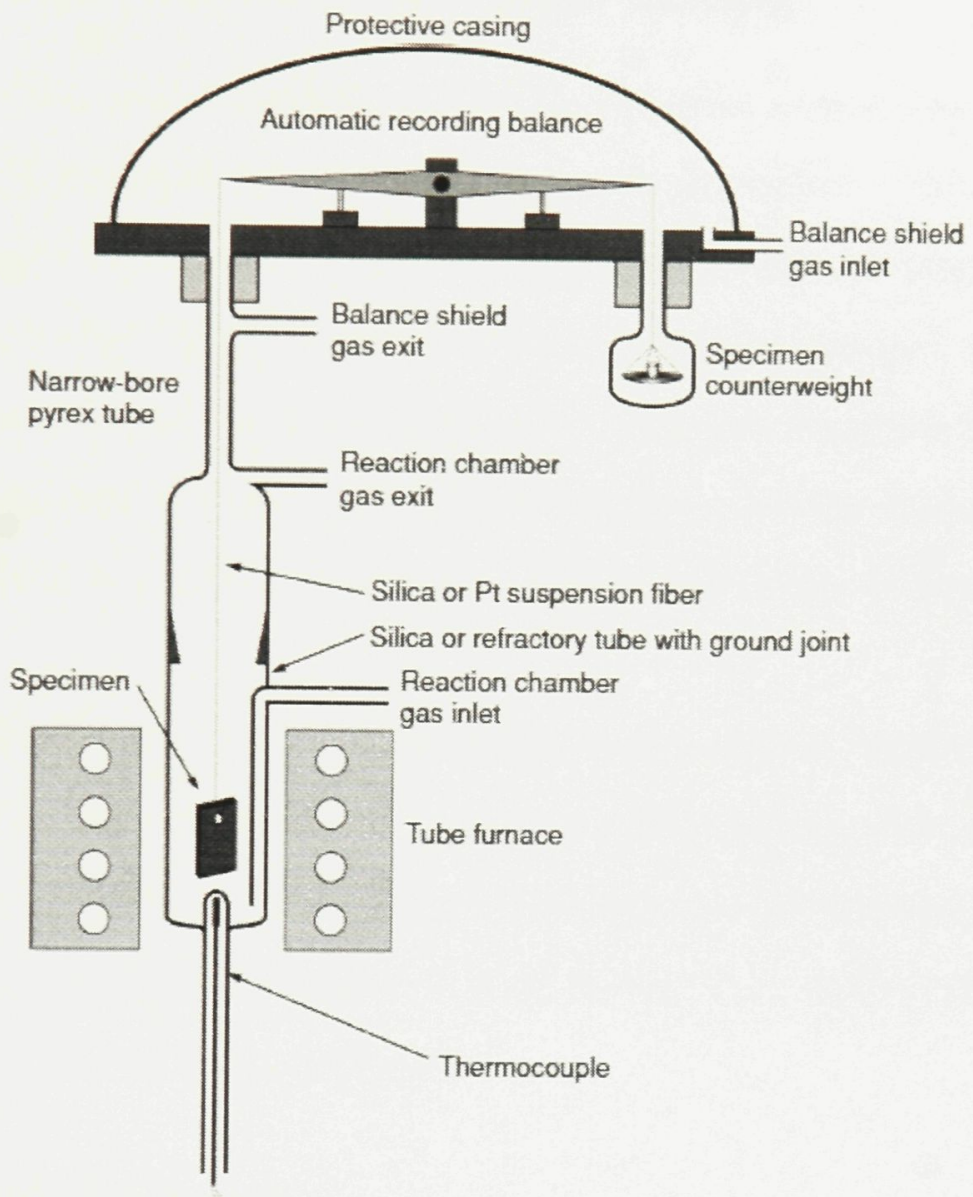

Figure 19: Typical automatic recording balance used for continuous corrosion testing [13].

Both methods of continuous corrosion are subject to drawbacks, which comes in the form of balancing of sensitivity and accuracy of the experiment. High accuracy in corrosion experiments utilize large samples that have a high surface area to volume ratio. This maximizes exposed surface for oxidation, making the newly formed mass more dominant in the overall weight of the specimen. Although, highly sensitive balances and springs cannot handle large loads. For this reason, continuous corrosion testing need to be designed appropriately to properly balance the required sensitivity 
and accuracy [13].

\subsubsection{Supercritical $\mathrm{CO}_{2}$ Corrosion Testing}

In recent years, the main motivation for $\mathrm{S}_{-} \mathrm{CO}_{2}$ corrosion testing comes from the research and dev'elopment of the $\mathrm{S}-\mathrm{CO}_{2}$ Brayton cycle gas turbine. Although relatively inert at low temperatures, $\mathrm{CO}_{2}$ can cause detrimental corrosion at temperatures above $500-600^{\circ} \mathrm{C}$. In a S- $\mathrm{CO}_{2}$ Brayton cycle gas turbine, corrosion can lead to deteriorating strength in essential components, in addition to clogging throughout piping, pumps, and microchannel heat exchangers. For these reasons, corrosion testing of candidate materials in $\mathrm{S}-\mathrm{CO}_{2}$ is an important step in preliminary design of Brayton cycle gas turbines.

The majority of testing has been conducted in an autoclave apparatus using sample coupons for periods up to 3000 or more hours. This testing offers an opportunity to begin an understanding of the kinetics and mechanics of corrosion in $\mathrm{S}_{-} \mathrm{CO}_{2}$ and learn the operational temperature limits of select materials, while highlighting materials that should be further investigated.

\section{Recent Laboratory Research}

A thorough review of previous $\mathrm{S}-\mathrm{CO}_{2}$ corrosion testing was conducted to assess the range of materials and extent of testing that has been completed. Table 5 summarizes these results, while adding to the literature review contained in Moore (2012) [18]. A graphical representation of recent test conditions in comparison to the presented Carleton-NRCan testing is illustrated in Figure 20: 


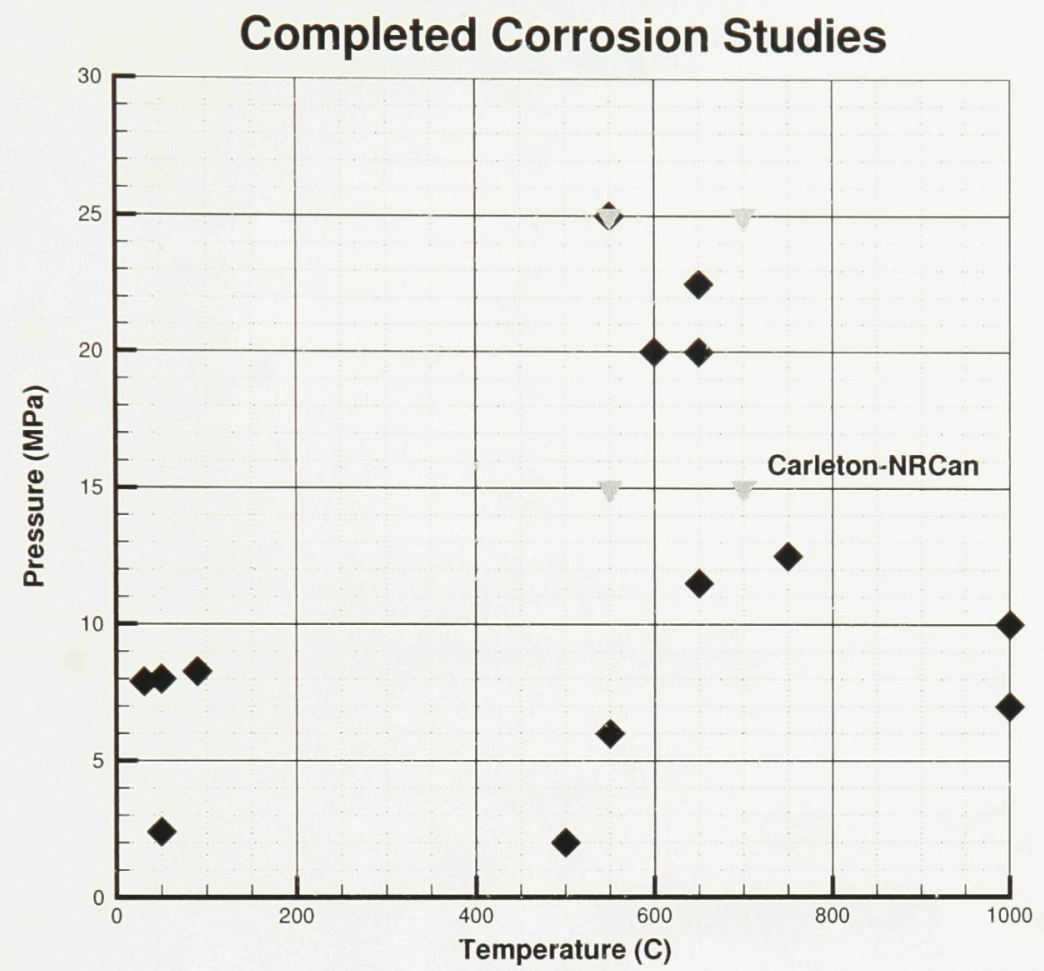

Figure 20: Corrosion studies with $\mathrm{S}_{-} \mathrm{CO}_{2}[18]$.

The most relevant $\mathrm{S}-\mathrm{CO}_{2}$ testing to this work, was performed by Gibbs (2010) [7] and Dunlevy (2007) [6] from Massachusetts Institute of Technology, in addition to Cao and Sridharan (2011) [21] from the University of Wisconsin-Madison. Their testing included nickel-based superalloys and stainless steels, in addition to a variety of carbon steels with chromium additions. Analysis was conducted by recording change in weight, visual inspection, and later use of a scanning electron microscope and $\mathrm{x}$-ray spectroscopy. Under testing conditions that ranged from $610-750^{\circ} \mathrm{C}$ and 12.5-20.7 $\mathrm{MPa}$ in $99.9999 \% \mathrm{CO}_{2}$, superalloys were found to have outperformed all other alloys. High chromium autstenitic stainless steels, such as alloy 316, performed much better than low chromium alloys, which were found to be unsuitable for $\mathrm{S}_{-} \mathrm{CO}_{2}$ operations. Some of the most notable results from Dunlevy (2007) [6] are included in Table 4 using the corrosion rig design found in Figure 21. 
Average Starting Average Weight Gain Average Weight Gain Total Weight

\begin{tabular}{|c|c|c|c|c|}
\hline Alloy & Weight (mg) & (mg) 0-250 hours & (mg) 250-500 hrs & Gain (mg) \\
\hline IN-690 & 26.04 & 0.07 & 0.01 & 0.08 \\
\hline IN-693 & 30.59 & 0.03 & 0 & 0.03 \\
\hline IN-718 (EG) & 35.60 & 0.04 & 0 & 0.04 \\
\hline IN-718 & 19.84 & 0.03 & 0 & 0.03 \\
\hline IN-725 (EG) & 33.34 & 0.05 & 0.01 & 0.06 \\
\hline IN-725 & 15.92 & 0.05 & 0 & 0.05 \\
\hline IN-740 & 26.53 & 0.04 & 0 & 0.04 \\
\hline IN-740+ & 34.54 & 0.02 & 0.01 & 0.03 \\
\hline AUSS 316L & 17.28 & 0.69 & 0.42 & 1.11 \\
\hline
\end{tabular}

Table 4: Resulting weight gain of superalloys in $\mathrm{S}_{-} \mathrm{CO}_{2}$ from [6].

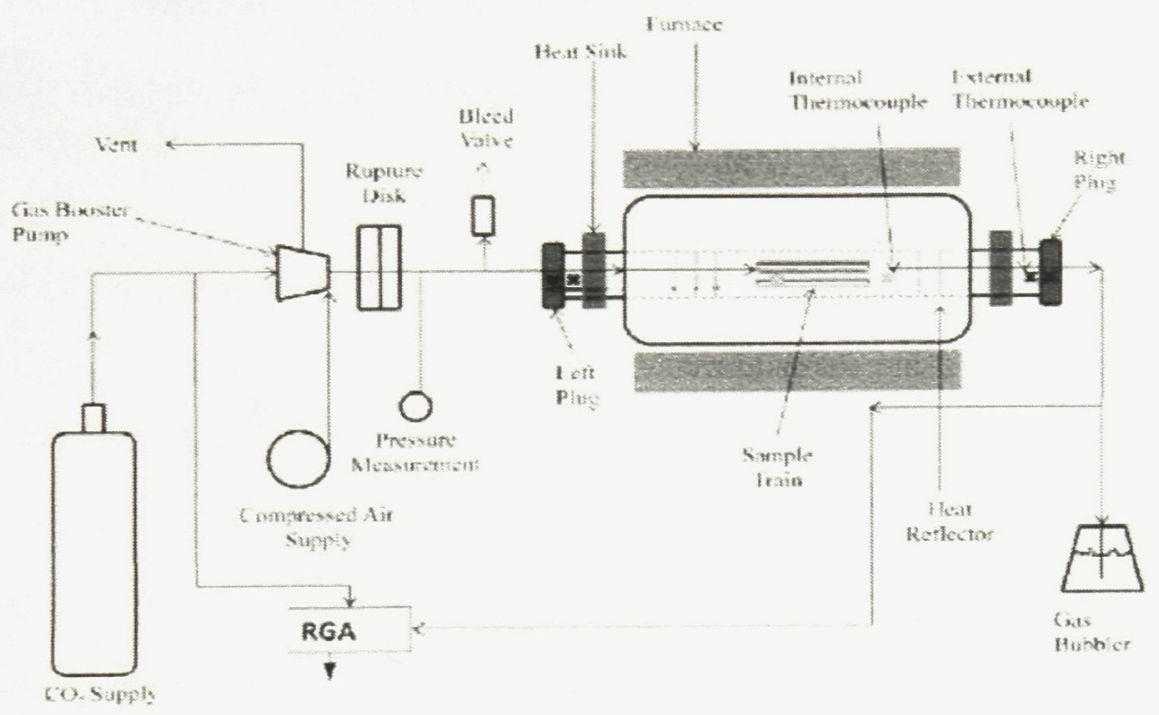

Figure 21: MIT $\mathrm{S}_{-} \mathrm{CO}_{2}$ corrosion test rig [7].

Weight gain results from testing completed at the University of WisconsinMadison is included in Figure 22, where testing was conducted for up to 3000 hours at $650^{\circ} \mathrm{C}$ and 20.7 MPa. These results show favourable corrosion resistance for nickelbase superalloys such as IN-625 in comparison to 316SS and 310SS. 


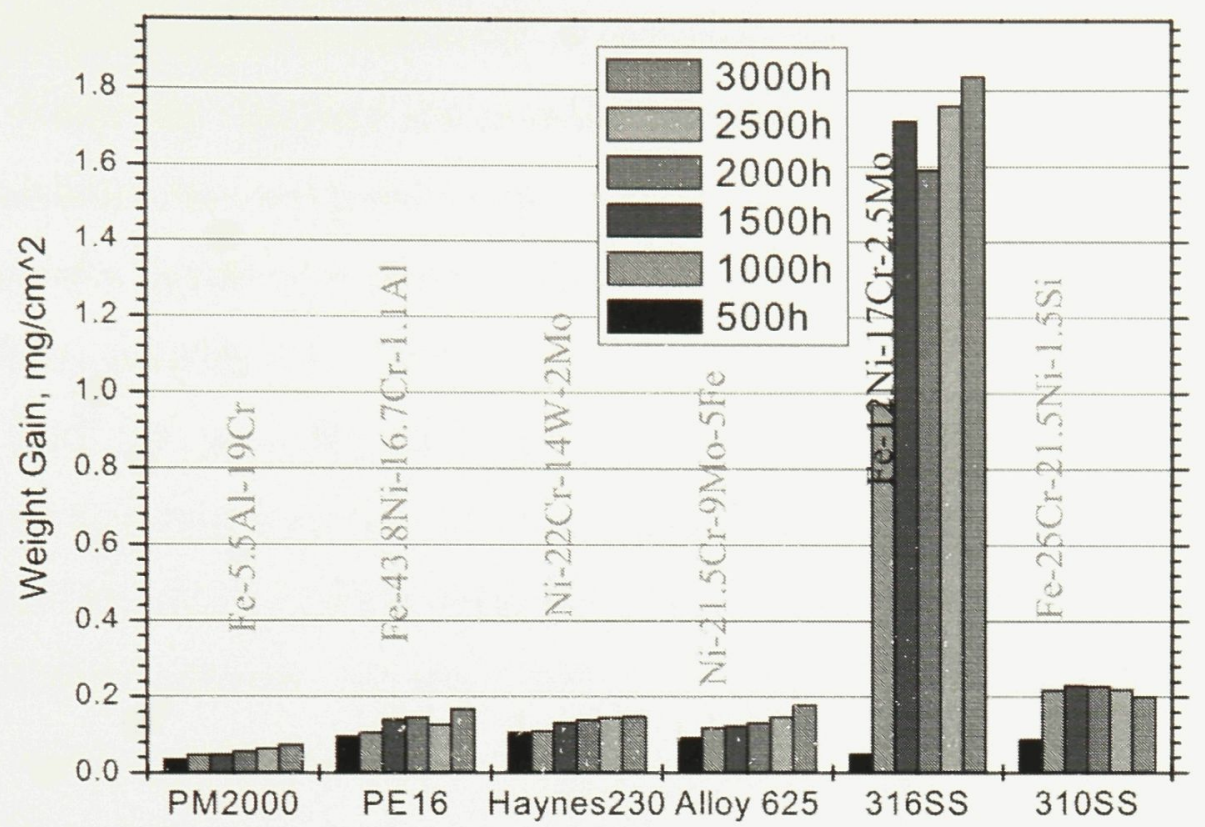

Figure 22: Results of $\mathrm{S}-\mathrm{CO}_{2}$ corrosion testing from the University of WisconsinMadison [21].

A number of studies have experimented with corrosion of alloys in $\mathrm{S}^{-\mathrm{CO}_{2}}$ with impurities such as: water, oxygen, sulphur dioxide, and methanol. All known testing from [22-25] used either low alloyed steels, stainless steels, or aluminium in conditions ranging from $50-500^{\circ} \mathrm{C}$ and $2.4-8 \mathrm{MPa}$ for short periods of time. The exception to this was Antill et al. (1968) [24] who reported experiments ranging from 400010,000 hours. The addition of water to the environment had a severe impact on the corrosion rate of carbon steels. The addition of $10 \%$ methanol also attacked samples of aluminum 2024, and copper CDA101 under low temperature and pressure conditions. Under test conditions of $500^{\circ} \mathrm{C}$, the addition of water had a significant impact on samples of low alloy steel A [24]. Furthermore, studies with $\mathrm{O}_{2}$ additions saw a rapid increase in corrosion [23].

Testing was conducted by Loriers et al. (1968) [26] on 10 alloys consisting of different concentrations of less than $2.5 \% \mathrm{Cr}, 1.0 \% \mathrm{Mo}$, and $0.6 \% \mathrm{Ni}$. The tests were conducted up to $550^{\circ} \mathrm{C}$ and from 2.5-6 $\mathrm{MPa}$ for 6000 hours. It was found that 
alloys with the highest concentrations of chromium and nickel performed the best in $\mathrm{S}-\mathrm{CO}_{2}$. Under the relatively low pressure conditions, there was not found to be a large correlation between pressure and corrosion rates. Further alloying with 0-1\% $\mathrm{Si}$ in showed a significant decrease in corrosion rates when exposed to $\mathrm{CO}_{2}$ at $500^{\circ} \mathrm{C}$ and ambient pressure [27]. These results were later confirmed with testing from Li et al. (2012) [28] in testing alloys with varying amounts of chromium, aluminum, and silicon in iron-base metals. At low pressures and a temperature of $800^{\circ} \mathrm{C}$, it was found that low additions of chromium resulted in an unproductive oxide scale in wet and dry $\mathrm{CO}_{2}$ conditions. The alloys with at least $6 \% \mathrm{Al}$ or a combination of $\mathrm{Al}$ and $\mathrm{Si}$ were able to produce a protective oxide layer in dry $\mathrm{CO}_{2}$.

Stainless steels 316 and 316L are typically outperformed by nickel-base alloys but have still been considered acceptable under most circumstances [29]. These austenitic steels that also include $800 \mathrm{H}$ and S30815, have shown to be more corrosion resistant than ferritic-martensitic T91 steels when tested at $550^{\circ} \mathrm{C}$ and $25 \mathrm{MPa}$ [30].

Testing at $650^{\circ} \mathrm{C}$ and 11.5-22.5 MPa was conducted for MA956, MA 957, PM2000, HY9, 316L, T91, and EP823 by Lim et al. (2008) [29]. The highly alloyed samples that contained aluminum and chromium were effective in producing a duplex alumina/chromia protective oxide film.

Carburization was found in T91 testing from Rouillard (2010) [30] at a temperature of $550^{\circ} \mathrm{C}$ and pressure of $25 \mathrm{MPa}$. Although short tests of only 310 hours, the alloy quickly formed a corrosion layer of $\mathrm{Fe}_{3} \mathrm{O}_{4}$. The resulting cross-section is illustrated in the EDX map of Figure 23. 


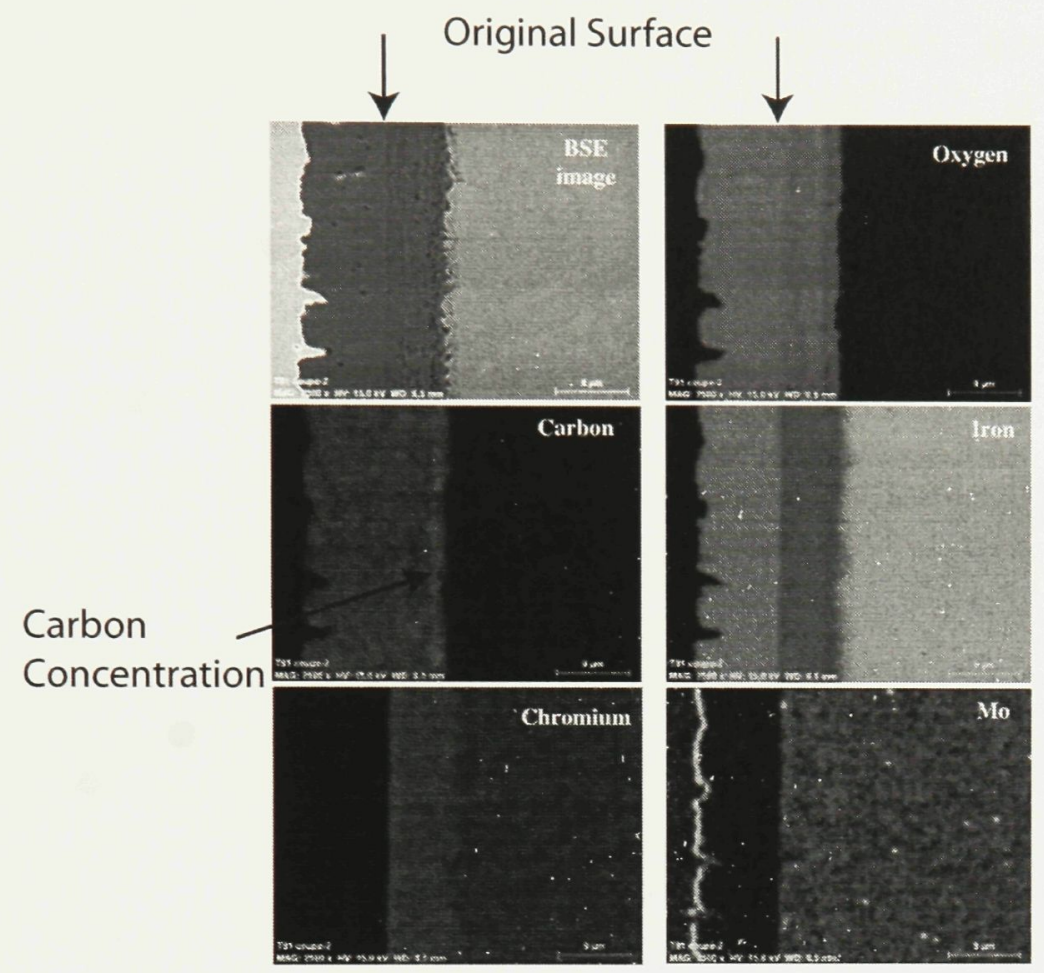

Figure 23: EDX scan of $\mathrm{F} 91$ after 310 hours at $550^{\circ} \mathrm{C}$ and $25 \mathrm{MPa}$ in $\mathrm{S}_{-} \mathrm{CO}_{2}$ [31].

From Rouillard (2010) [30], carburization was suggested to have occurred through the Boudouard reaction. This reaction begins with the reaction of carbon monoxide with metal to produce a metal oxide (magnetite) and carbon monoxide:

$$
3 \mathrm{Fe}+4 \mathrm{CO}_{2} \rightarrow \mathrm{Fe}_{3} \mathrm{O}_{4}+4 \mathrm{CO}
$$

The resulting carbon monoxide then contributes in the deposition of carbon within the metal through the Boudouard equation:

$$
2 \mathrm{CO} \rightarrow \mathrm{CO}_{2}+\mathrm{C}
$$

A brief summary of documented $\mathrm{CO}_{2}$ corrosion testing is provided in Table 5, organized by alloy type. 


\begin{tabular}{|c|c|c|c|c|c|}
\hline Alloy & Temp $\left({ }^{\circ} \mathrm{C}\right)$ & Pressure $(\mathrm{MPa})$ & Duration (Hours) & Impurities Used & Reference \\
\hline \multicolumn{6}{|c|}{ Chromium and Carbon Steels } \\
\hline \multirow[t]{4}{*}{$316 \mathrm{SS}$} & 50 & 2.4 & 24 & $\mathrm{H}_{2} \mathrm{O}, \mathrm{CH}_{4} \mathrm{O}$ & Russick et al. [22] \\
\hline & 610 & 20 & 3000 & & Gibbs [7] \\
\hline & 650 & 20.7 & 3000 & & Sridharan et al. [21] \\
\hline & $400-600$ & 20 & 2000 & & Furukawa et al. [32] \\
\hline \multirow[t]{3}{*}{$316 \mathrm{~L}$ SS } & 550 & 25 & 310 & & Rouillard et al. [30] \\
\hline & 650 & $11.5-22.5$ & 3000 & & Lim et al. [29] \\
\hline & $650 / 714 / 750$ & $20 / 12.5$ & $500-1000$ & & Dunlevy $[6]$ \\
\hline \multirow[t]{2}{*}{$310 \mathrm{SS}$} & 610 & 20 & 3000 & & Gibbs [7] \\
\hline & 650 & 20.7 & 3000 & & Sridharan et al. [21] \\
\hline \multirow[t]{2}{*}{ F91 } & 610 & 20 & 3000 & & Gibbs [7] \\
\hline & 650 & 20.7 & 3000 & & Sridhavran et al. [21] \\
\hline 304 SS & 50 & 2.4 & 24 & $\mathrm{H}_{2} \mathrm{O}, \mathrm{CH}_{4} \mathrm{O}$ & Russick et al. [22] \\
\hline 1018 & 50 & 2.4 & 24 & $\mathrm{H}_{2} \mathrm{O}, \mathrm{CH}_{4} \mathrm{O}$ & Russick et al. [22] \\
\hline$¡ 2.5 \%$ Cr Steels & 550 & 6 & 6000 & & Loriers et al. [26] \\
\hline 12-Cr Steel & $400-600$ & 20 & 2000 & & Furukawa et al. [32] \\
\hline $2.5 \% \mathrm{Cr}$ Steels & 550 & 6 & 6000 & & Loriers et al. [26] \\
\hline API 5 L X65 & 50 & 8 & 120 & $\mathrm{O}_{2}, \mathrm{H}_{2} \mathrm{O}, \mathrm{SO}_{2}$ & Choi et al. [23] \\
\hline Carbon Steels & 90 & 8.274 & $24,96,144$ & $\mathrm{H}_{2} \mathrm{O}$ & Wu et al. [25] \\
\hline $\mathrm{Fe}-(1,2,3 \%) \mathrm{Si}$ & 800 & Low & Minimal & & Li et al. [28] \\
\hline $\mathrm{Fe}-(2,3 \%) \mathrm{Si}-(6 \%) \mathrm{Al}$ & 800 & Low & Minimal & & Li et al. [28] \\
\hline $\mathrm{Fe}-(2,4,6 \%) \mathrm{Al}$ & 800 & Low & Minimial & & Li et al. [28] \\
\hline $\mathrm{HCM} 12 \mathrm{~A}$ & 650 & 20.7 & 3000 & & Sridharan et al. [21] \\
\hline Low alloy Steels & 500 & 2 & $4000-10000$ & $\mathrm{H}_{2} \mathrm{O}$ & Antill et al. [24] \\
\hline Mild steel & 600 & 4 & & & Shropshire et al. [33] \\
\hline Rimming Steel & 500 & 2 & $4000-10000$ & $\mathrm{H}_{2} \mathrm{O}$ & Antill et al. [24] \\
\hline T91 & 550 & 25 & 310 & & Rouillard et al. [30] \\
\hline \multicolumn{6}{|l|}{ Aluminum } \\
\hline 2024 & 50 & 2.4 & 24 & $\mathrm{H}_{2} \mathrm{O}, \mathrm{CH}_{4} \mathrm{O}$ & Russick et al. [22] \\
\hline 6061 & 50 & 2.4 & 24 & $\mathrm{H}_{2} \mathrm{O}, \mathrm{CH}_{4} \mathrm{O}$ & Russick et al. [22] \\
\hline 7075 & 50 & 2.4 & 24 & $\mathrm{H}_{2} \mathrm{O}, \mathrm{CH}_{4} \mathrm{O}$ & Russick et al. [22] \\
\hline \multicolumn{6}{|l|}{ Highly Alloyed } \\
\hline \multirow[t]{2}{*}{625} & 610 & 20 & 3000 & & Gibbs $[7]$ \\
\hline & 650 & 20.7 & 3000 & & Sridharan et al. [21] \\
\hline \multirow[t]{3}{*}{$800 \mathrm{H}$} & 550 & 25 & 310 & & Rouillard et al. [30] \\
\hline & 610 & 20 & 3000 & & Gibbs [7] \\
\hline & 650 & 20.7 & 3000 & & Sridharan et al. [21] \\
\hline \multirow[t]{2}{*}{ Haynes 230} & 610 & 20 & 3000 & & Gibbs [7] \\
\hline & 650 & 20.7 & 3000 & & Sridharan et al. [21] \\
\hline \multirow[t]{2}{*}{ AL- $6 \mathrm{XN}$} & 610 & 20 & 3000 & & Gibbs [7] \\
\hline & 650 & 20.7 & 3000 & & Sridharan et al. [21] \\
\hline \multirow[t]{3}{*}{ PM 2000} & 650 & $11.5-22.5$ & 3000 & & Lim et al. [29] \\
\hline & 610 & 20 & 3000 & & Gibbs $[7]$ \\
\hline & 650 & 20.7 & 3000 & & Sridharan et al. [21] \\
\hline 690 & $650 / 714 / 750$ & $20 / 12.5$ & $500-1000$ & & Dunlevy [6] \\
\hline 693 & $650 / 714 / 750$ & $20 / 12.5$ & $500-1000$ & & Dunlevy [6] \\
\hline 718 & $650 / 714 / 750$ & $20 / 12.5$ & $500-1000$ & & Dunlevy [6] \\
\hline 725 & $650 / 714 / 750$ & $20 / 12.5$ & $500-1000$ & & Dunlevy [6] \\
\hline 740 & $650 / 714 / 750$ & $20 / 12.5$ & $500-1000$ & & Dunlevy [6] \\
\hline $740+$ & $650 / 714 / 750$ & $20 / 12.5$ & $500-1000$ & & Dunlevy [6] \\
\hline EP823 & 650 & $11.5-22.5$ & 3000 & & Lim et al. [29] \\
\hline $\mathrm{HCM} 12 \mathrm{~A}$ & 610 & 20 & 3000 & & Gibbs [7] \\
\hline HT9 & 650 & $11.5-22.5$ & 3000 & & Lim et al. [29] \\
\hline $\mathrm{I}-617$ & 1000 & 7 & 175 & & Totemeier et al. [34] \\
\hline MA 754 & 1000 & 10 & 500 & & Totemeier et al. [34] \\
\hline MA 956 & 650 & $11.5-22.5$ & 3000 & & Lim et al. [29] \\
\hline MA 957 & 650 & $11.5-22.5$ & 3000 & & Lim et al. [29] \\
\hline PE16 & 610 & 20 & 3000 & & Gibbs [7] \\
\hline PE16 In-CM-639P & 650 & 20.7 & 3000 & & Sridharan et al. [21] \\
\hline S30815 & 550 & 25 & 310 & & Rouillard et al. [30] \\
\hline TP1 & 650 & $11.5-22.5$ & 3000 & & Lim et al. [29] \\
\hline
\end{tabular}

Table 5: A summary of studies for corrosion in $\mathrm{S}_{-} \mathrm{CO}_{2}$. Extended from [18]. 


\section{Chapter 3}

\section{Experimental Approach}

\subsection{Materials}

The experimental materials were chosen in support of the Carleton-NRCan S-CO Brayton cycle design, where candidate materials were being investigated for various components of compressor, turbine, heat exchanger, and process piping. Based on the design and simulation results, materials in the turbine and heat exchanger were to be exposed to a temperature of up to $700^{\circ} \mathrm{C}$ and a pressure of $25 \mathrm{MPa}$. These simulation results also indicated a requirement for materials compatible with operating conditions of $550^{\circ} \mathrm{C}$ and down to $15 \mathrm{MPa}$. For this reason, four test points of $15 \mathrm{MPa} / 550^{\circ} \mathrm{C}, 25 \mathrm{MPa} / 550^{\circ} \mathrm{C}, 15 \mathrm{MPa} / 700^{\circ} \mathrm{C}$, and $25 \mathrm{MPa} / 700^{\circ} \mathrm{C}$ were chosen for an investigation of material compatibility with $\mathrm{S}_{-} \mathrm{CO}_{2}$. A sample set of each material was to be exposed to each combination of pressure and temperature for 1500 hours. For the purpose of investigating pressure effects on oxidation, two additional sample sets were used where one was exposed to 1500 hours of $15 \mathrm{MPa} / 550^{\circ} \mathrm{C}$ and then an additional 1500 hours of $25 \mathrm{MPa} / 550^{\circ} \mathrm{C}$. The second additional sample set was exposed to the same conditions except at $700^{\circ} \mathrm{C}$. 


\subsubsection{Austenitic Stainless Steel}

The materials chosen for experimental analysis were based on an investigation into candidate materials for the operating conditions of the Carleton-NRCan Brayton cycle design. In an effort to minimize manufacturing costs of the Brayton cycle, stainless steel would provide a cost effective alternative to conventional superalloys where appropriate. The austenitic stainless steel alloy, 316, was chosen as a baseline test alloy for a number of reasons. 316SS has been tested under several $\mathrm{S}_{-} \mathrm{CO}_{2}$ conditions, such as $[6,7,22]$, which serves as a point of comparison to ensure repeatable results. Furthermore, previous $\mathrm{S}-\mathrm{CO}_{2}$ testing did not reach the limits of $700^{\circ} \mathrm{C}$ and $25 \mathrm{MPa}$, or characterize the effect of pressure by exposing a sample set to different pressure conditions.

316SS was chosen for potential applications in the manufacturing of compressor components in the Carleton Brayton cycle gas turbine. Due to the low operating temperature in the compressor region of just above the $\mathrm{CO}_{2}$ critical point of $31.1^{\circ} \mathrm{C}$, 316SS could offer a cost-effective alternative to superalloys due to its strength, stability, and corrosion resistance. Further investigation was required to understand the limits of the alloy's corrosion resistance to $\mathrm{S}_{-} \mathrm{CO}_{2}$ in terms of temperature and pressure to better understand other areas of the Brayton cycle gas turbine where it could be used.

316SS is a chromium-nickel steel with molybdenum additives, which increases corrosion resistance and strength at high temperatures [35]. It is available in a low carbon form that is particularly useful in weldment applications due to low susceptibility to the formation of carbides. 316SS offers better corrosion resistance than alloy 304SS and is extensively used in a variety of industries that include: pharmaceuticals, photography, HVAC, and marine equipment [35]. 


\subsubsection{Nickel-Base Superalloys}

Candidate materials for high temperature portions of the Brayton cycle gas turbine are the iron-nickel-base IN-718 and nickel-base IN-738 alloys. Both materials have highly alloyed compositions as outlined in Table 6, which are specifically designed for high corrosion resistance, stability, and strength at temperatures exceeding $540^{\circ} \mathrm{C}$. From a preliminary investigation of candidate materials, IN-718 and IN-738 have potential for use in the manufacturing of the Carleton-NRCan gas turbine based on factors of strength, creep resistance, and availability. IN-718 has had limited corrosion testing in $\mathrm{S}_{-} \mathrm{CO}_{2}$ based on results from Dunlevy 2007 [6]. There were no results found for corrosion testing of IN-738 in $\mathrm{S}-\mathrm{CO}_{2}$.

Two samples of IN-625 were also added to the sample set to monitor oxidation of the IN-625 pressure vessel throughout testing. These two samples were exposed to a total of 6000 hours at each combination of pressure and temperature: $15 \mathrm{MPa}$, $25 \mathrm{MPa}, 550^{\circ} \mathrm{C}$, and $700^{\circ} \mathrm{C}$.

\begin{tabular}{ccccccccccc} 
& \multicolumn{10}{c}{ Composition $(\%)$} \\
\cline { 2 - 11 } & $\mathrm{Cr}$ & $\mathrm{Ni}$ & $\mathrm{Co}$ & $\mathrm{Mo}$ & $\mathrm{Nb}$ & $\mathrm{Ti}$ & $\mathrm{Al}$ & $\mathrm{Fe}$ & $\mathrm{C}$ & Other \\
\hline 625 & 21.5 & 61 & $\ldots$ & 9.0 & 3.6 & 0.2 & 0.2 & 2.5 & 0.05 & $\ldots$ \\
718 & 19.0 & 52.5 & $\ldots$ & 3.0 & 5.1 & 0.9 & 0.5 & 18.5 & 0.08 & $0.15 \mathrm{Cu}$ \\
738 & 16 & 61.5 & 8.5 & 1.75 & 2 & 3.4 & 3.4 & $\ldots$ & 0.17 & $0.1 \mathrm{Zr}, 0.01 \mathrm{~B}, 2.6 \mathrm{~W}$ \\
316 & $16-18$ & $10-14$ & $\ldots$ & $2-3$ & $\ldots$ & $\ldots$ & $\ldots$ & $\mathrm{Bal}$ & 0.08 & $2 \mathrm{Mn}, 1 \mathrm{Si}, 0.045 \mathrm{P}, 0.03 \mathrm{~S}$ \\
\hline
\end{tabular}

Table 6: Nominal compositions of test alloys. $[8,36]$

\subsection{Sample Preparation}

All 90 samples were prepared using the same method for sectioning, surface polishing, and cleaning, in order to reduce variability between the samples. The three alloys of $316 \mathrm{SS}$, IN-718, IN-738 were sectioned from $12.7 \mathrm{~mm}$ diameter round bar to a 
thickness of approximately $1.2 \mathrm{~mm}$ using a Buehler Isomet 1000 saw. This thickness was chosen to maintain a high surface area to volume ratio that would provide better weight gain measurements. An investigation was conducted and found that the as received surface condition of the test alloys could range from 400-800 grit [6,7]. For this reason, the samples were prepared to a 600 grit finish to better characterize the use of alloys under industrial conditions.

After sectioning, a $3.97 \mathrm{~mm}$ (5/32") hole was drilled approximately $3.18 \mathrm{~mm}\left(1 / 8^{\prime \prime}\right)$ above the centre of each coupon. A drill rig was manufactured and used to ensure identical hole placement for all samples. The purpose of the hole is to allow the coupons to hang from the alumina rod in the specimen boat. The samples were then wet-polished with four stages of $\mathrm{SiC}$ abrasive paper in increments of $120,240,400$, and 600 grit finishes. The samples were rinsed with water between stages and finally cleaned in a bath of ethyl alcohol in an ultrasonic cleaner for 45 minutes.

\subsubsection{Labelling of Coupons}

The labelling of the samples consisted of a three number tag, $[\mathrm{x}][\mathrm{xx}]$, where the first number represents the material type, and the second two numbers represents the sample number of that alloy. Table 7 illustrates the numbering of the samples. The number was engraved into each coupon using a hand engraver, as shown in Figure 24. 


\begin{tabular}{cccc}
$316 S S$ & IN-718 & IN-738 & IN-625 \\
\hline 101 & 201 & 301 & 401 \\
102 & 202 & 302 & 402 \\
103 & 203 & 303 & \\
104 & 204 & 304 & \\
105 & 205 & 305 & \\
$\ldots$ & $\ldots$ & $\ldots$ & \\
130 & 230 & 330 & \\
\hline
\end{tabular}

Table 7: Coupon numbering scheme.

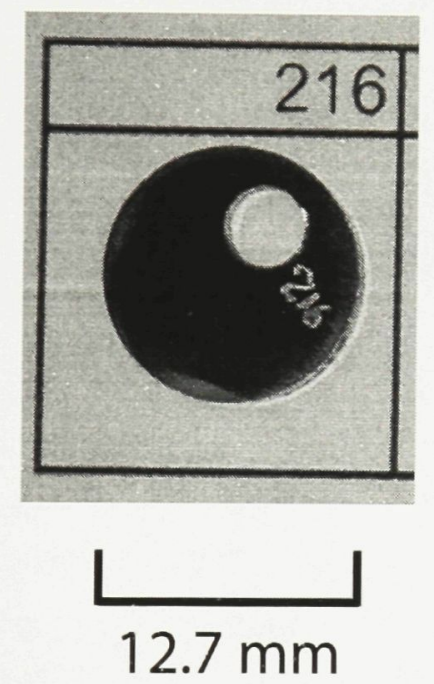

Figure 24: Sample 16 of IN-718.

\subsubsection{Au-Pd Coating}

In an effort to identify the original alloy surface prior to corrosion, a portion of the sample's surface was sputter coated with Au-Pd. All of the samples were masked using copper tape except for an area approximately $3.18 \mathrm{~mm}\left(1 / 8^{\prime \prime}\right)$ from the edge of the coupon. The small strip of exposed surface was to be used as a marker for post-analysis when the coupon was later sectioned. This marker would identify the 
location of the original surface prior to oxidation and could be used to quantify the direction and magnitude of oxide layer growth. Figure 25 shows a number of coupons that have been masked prior to, and after, sputter coating.

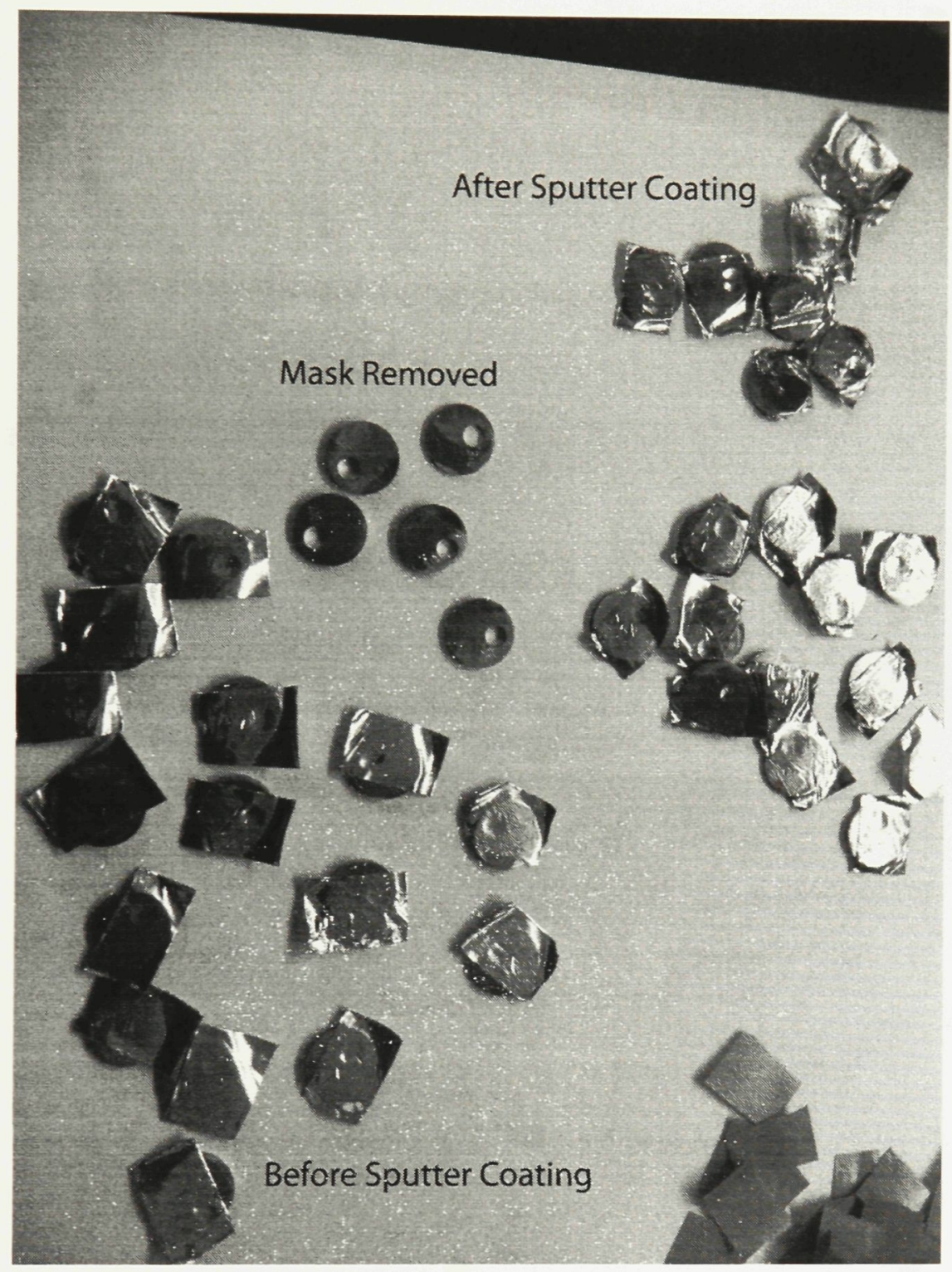

Figure 25: Coupons before and after sputter coating with $\mathrm{Au}-\mathrm{Pd}$.

An Anatech Ltd. Hummer VII sputter coating machine was used to deposit AuPd onto the unmasked surface of the coupons. Figure 26 shows the coupons under vacuum with Argon plasma used as the medium for transferring Au-Pd from the 
source ring to the coupons below.

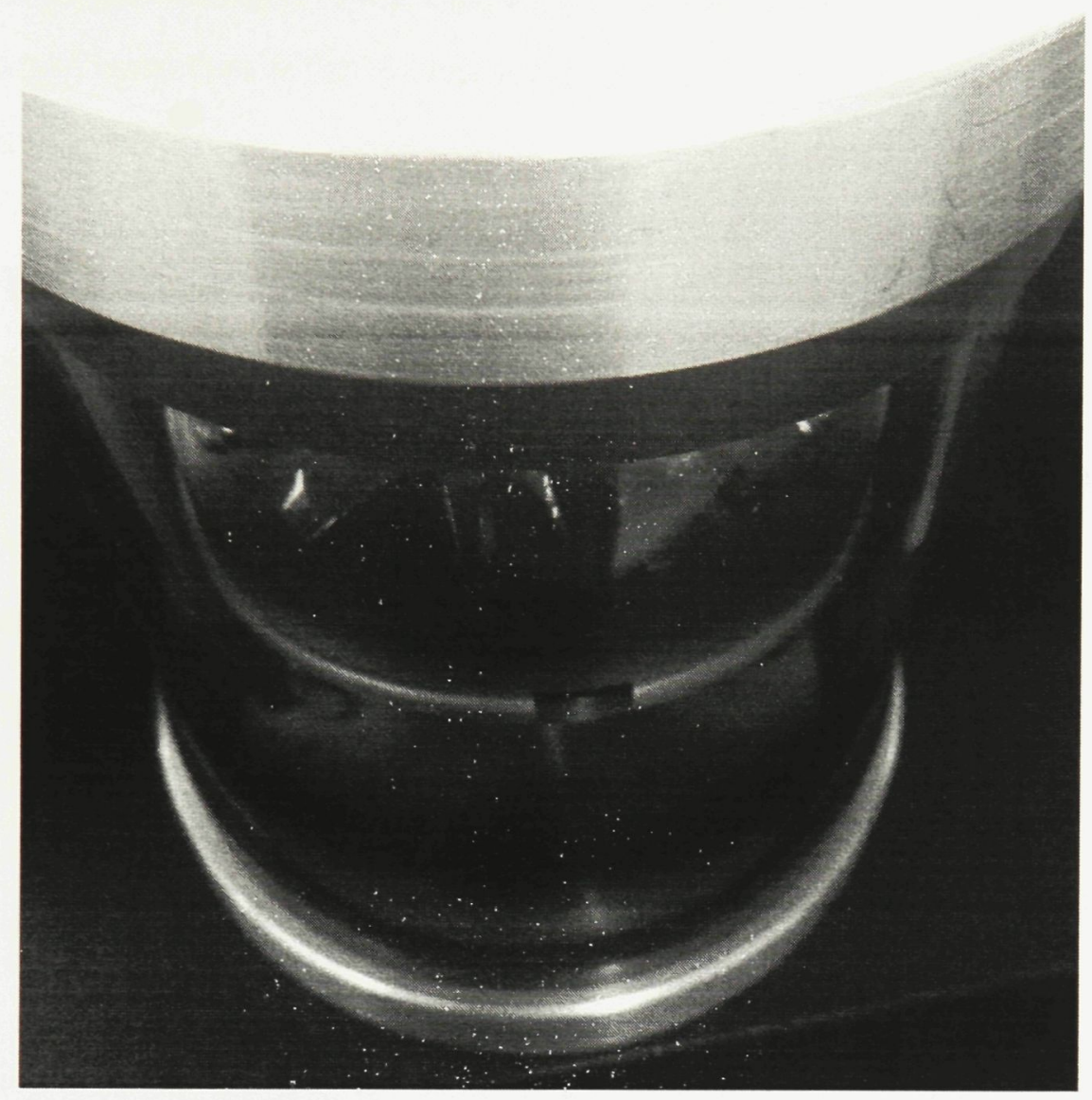

Figure 26: Au-Pd sputter coating using Argon plasma.

After the Au-Pd coating was complete, the sample mask was removed and the samples were once again cleaned in an ethyl-alcohol bath in an ultrasonic cleaner for 45 minutes. The coupons were then dried and stored in individual resealable bags and placed in a desiccator until used in the corrosion test rig.

\subsection{The Carleton-NRCan S- $\mathrm{CO}_{2}$ Corrosion Rig}

The corrosion test rig was developed in partnership with Carleton University and the Zero-Emission Technologies group of CanmetEnergy - Natural Resources Canada. 
Located at the CanmetEnergy site in Bells Corners, Ontario, the rig was commissioned and began corrosion studies in September 2011. The following sections detail the design and operation of the corrosion test rig as it applies to the corrosion research conducted.

\subsubsection{Rig Design}

The Carleton-NRCan S-CO $\mathrm{CO}_{2}$ corrosion test rig is an autoclave design for testing a series of metal coupons at a variety of temperature and pressure combinations. The rig offers the ability to monitor the kinetics and overall compatibility with small samples of candidate materials in $\mathrm{S}-\mathrm{CO}_{2}$. The rig was designed to accommodate metal coupons with a diameter up to $12.7 \mathrm{~mm}\left(0.5^{\prime \prime}\right)$ at a maximum operating temperature of $750^{\circ} \mathrm{C}$ at $15 \mathrm{MPa}$ or $700^{\circ} \mathrm{C}$ at $25 \mathrm{MPa}$, at a flow rate of approximately $1 \mathrm{~L} / \mathrm{hr}$ [9]. Designed in support of the Carleton University $\mathrm{S}-\mathrm{CO}_{2}$ Brayton Cycle Test Loop, the rig's test envelope reflects operational conditions for materials in a $\mathrm{S}_{-} \mathrm{CO}_{2}$ Brayton cycle.

The test rig is an open system with a continuous supply of $\mathrm{CO}_{2}$ of at least $99.9 \%$ purity, which can be controlled using a two-stage needle valve assembly for flow rates ranging from $0.5-15 \mathrm{~L} / \mathrm{hr}$. The system can be isolated at either end using shut-off ball valves for static experiments. The $\mathrm{CO}_{2}$ is supplied at a pressure of $1.52 \mathrm{MPa}$ and flows through a $15.0 \mu \mathrm{m}$ particulate filter to a two-stage GBT-15/30 gas booster. The $\mathrm{CO}_{2}$ is then routed through a $7 \mu \mathrm{m}$ particulate filter to a $300 \mathrm{~mL}$ buffer tank in an effort to minimize pressure pulsations during booster operation. Prior to entering the pressure vessel, the $\mathrm{CO}_{2}$ passes the Flowsafe F84-M safety relief valve, a SFAZ rupture disk, and an Endress+Hauser Cerabar S PMP71 pressure transducer. A series of OMEGA(R) KQIN thermocouple probes are positioned at various locations inside and around the pressure vessel, as illustrated in Figure 28. A thermocouple probe is inserted from both ends of the pressure vessel and are positioned approximately 


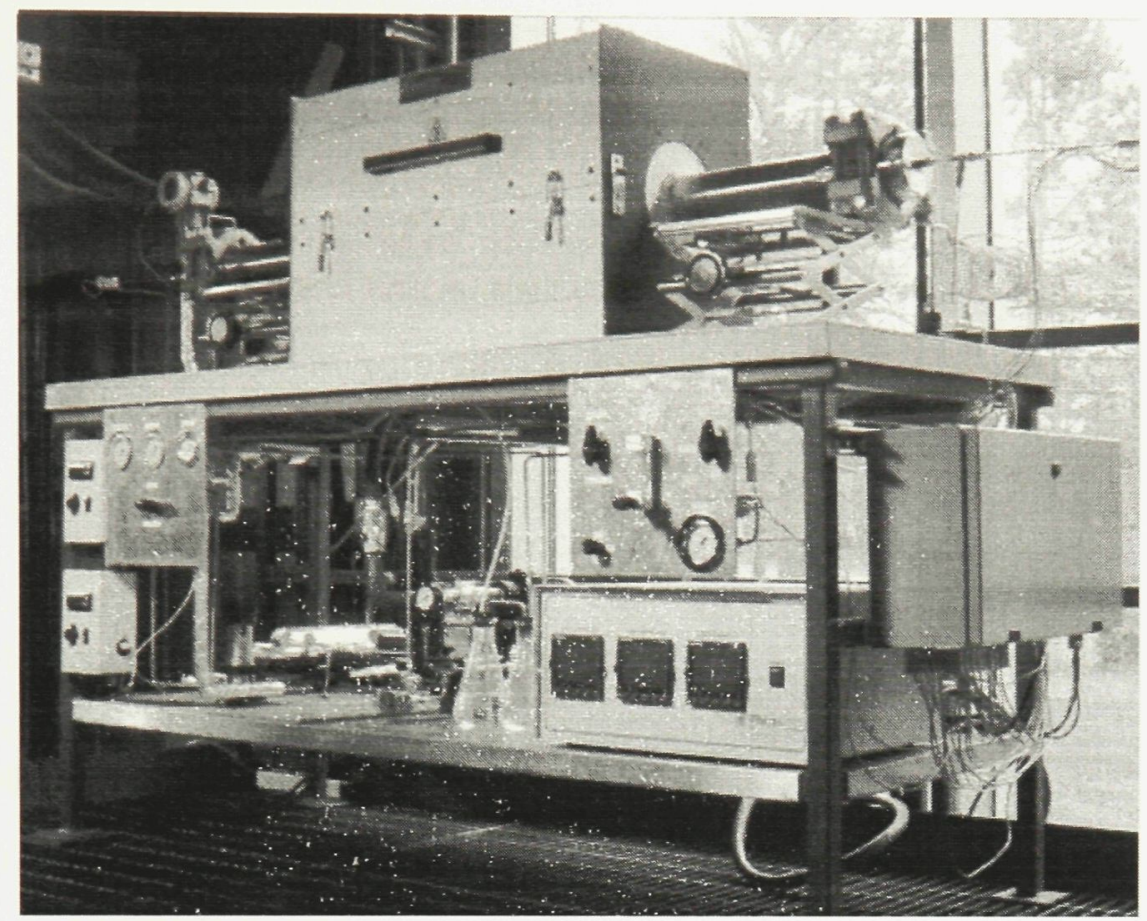

Figure 27: The Carleton-NRCan $\mathrm{S}-\mathrm{CO}_{2}$ Corrosion Test Rig [9].

$50 \mathrm{~mm}$ from either end of the specimen boat. All pressure and temperature devices are sampled and recorded using a Graphtec GL820 data logger.

Beyond the passive safety features of the relief valve and burst disk, active safety features are enabled by the Graphtec data logger's alarm channels. The alarm channels are set to maximum levels of pressure and temperature and connected to a normally-open relay that supplies power to two normally-closed solenoid valves. When an alarm is triggered, the relay interrupts power to the solenoid valve, which shuts off the supply of $\mathrm{CO}_{2}$ and compressed air to the gas booster.

The centre section of the pressure vessel is heated by a 3-zone Thermocraft XST6-0-24-3V furnace, which is controlled using a Thermcraft 3-1-40-230-E15SP furnace controller. The furnace controller can be programmed to a number of automatic heating patterns at specific rates and times. For all operation of this rig, the furnace controller was programmed to increase temperature at a rate of $200^{\circ} \mathrm{C} / \mathrm{hr}$ to a target temperature (set prior to the test). 


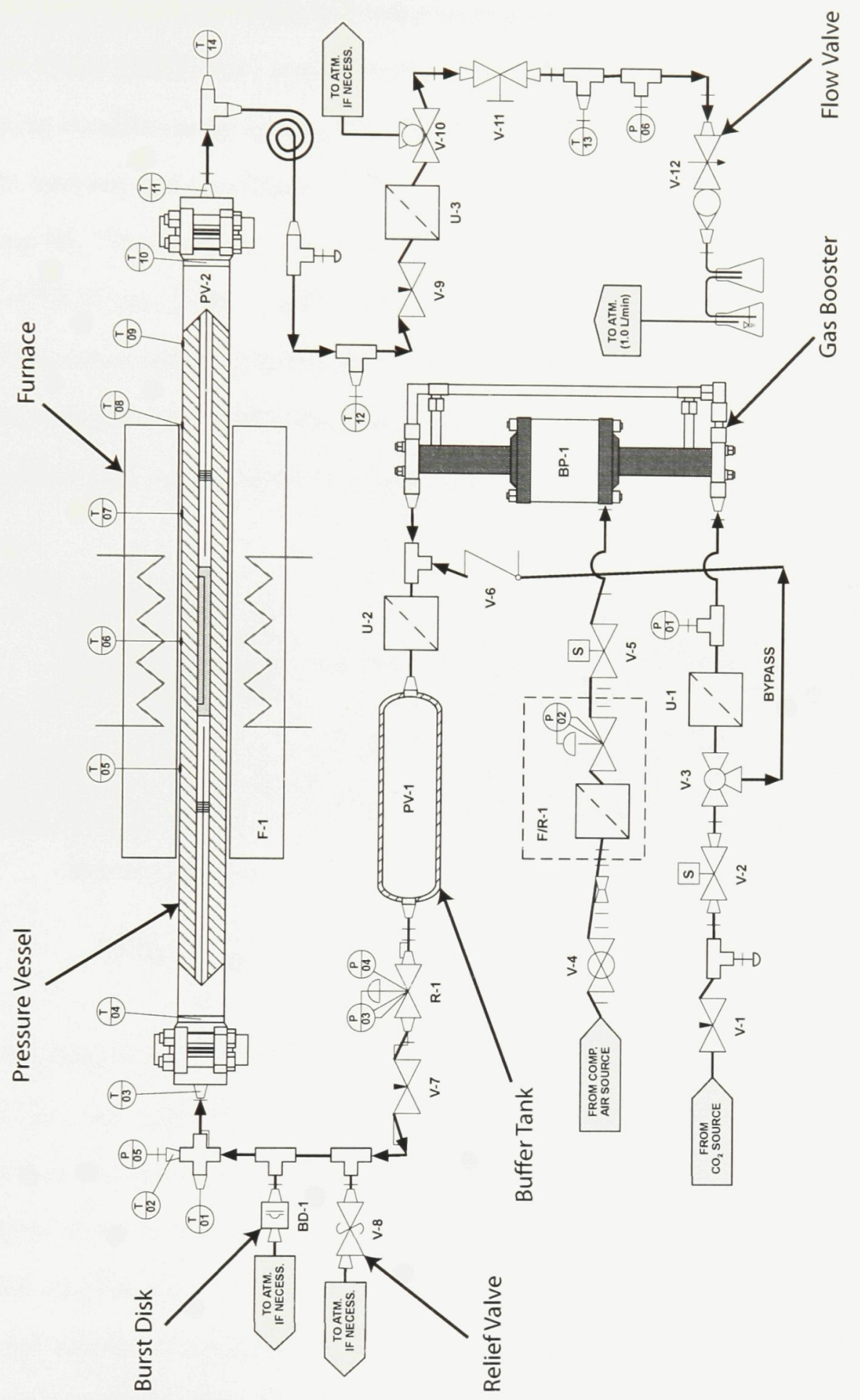

Figure 28: The Carleton-NRCan $\mathrm{S}-\mathrm{CO}_{2}$ Corrosion Test Rig P\&ID. 
The pressure vessel was designed in accordance to ASME VIII-1 Boiler and Pressure Vessel Code (2007) and approved for a Canadian Registration Number (CRN) for operating conditions up to $750^{\circ} \mathrm{C}$ at $29.41 \mathrm{MPa}$ and $800^{\circ} \mathrm{C}$ at $17.65 \mathrm{MPa}$, in order to provide internal gas conditions of $750^{\circ} \mathrm{C}$ at $15 \mathrm{MPa}$ or $700^{\circ} \mathrm{C}$ at $25 \mathrm{MPa}$ for corrosion testing [9]. The pressure vessel was manufactured from IN-625 with an internal diameter of $19.05 \mathrm{~mm}(0.75 ")$, and length of $1460.5 \mathrm{~mm}(57.5 ")$ in order to allow space for heat dissipation before reaching the end caps. The end caps are 316-SS Grayloc R connectors composed of blind hubs, clamping assembly, and a polytetraflouroethylene coasted sealing ring, as depicted in Figure 29.

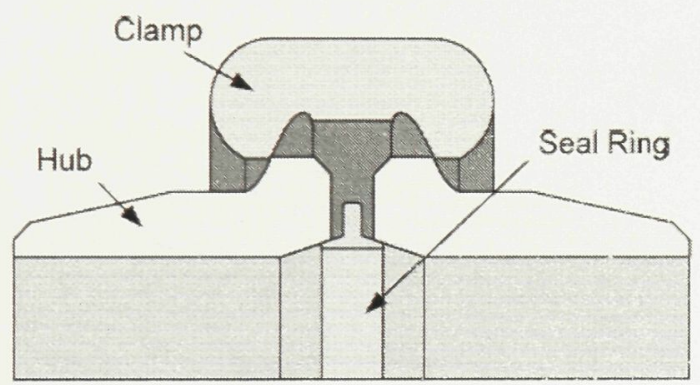

Before Tightening

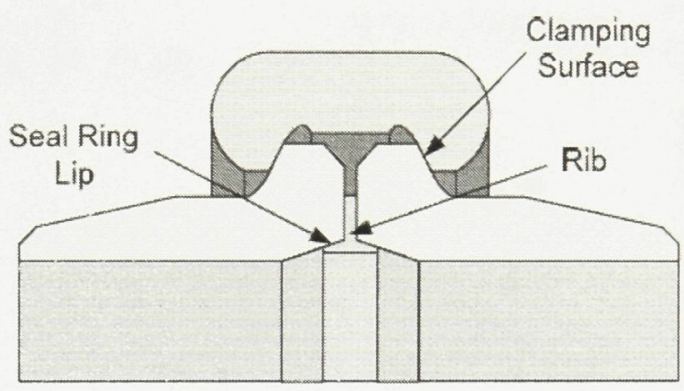

After Tightening

Figure 29: Gravloc尺) clamping mechanism [9].

Material coupons are designed to hang in an alumina specimen boat, shown in Figure 32 , and are separated with $3.18 \mathrm{~mm}\left(1 / 8^{\prime \prime}\right)$ alumina spacers. The specimen boat positions the coupons in the centre of the pressure chamber and electrically isolates them from the pressure vessel and each other.

The flow of $\mathrm{CO}_{2}$ is controlled through a two-stage needle valve downstream from the pressure vessel. Variable from 0-15 L/hr, all testing that has been conducted with the rig has used a flow rate of approximately $1 \mathrm{~L} / \mathrm{hr}$. With an internal volume of approximately $0.416 \mathrm{~L}$, a rate of $1 \mathrm{~L} / \mathrm{hr}$ "feed-and-bleed" flow would expect a complete replenishment of $\mathrm{CO}_{2}$ in slightly over two hours of operation. 
In order to minimize heat loss from the test section of the pressure vessel, heat reflectors were added to either side of the thermocouple probe during commissioning. Spaced $25.4 \mathrm{~mm}$ apart and starting at the outermost edge and working towards the centre of the furnace, three $19.05 \mathrm{~mm}$ diameter molybdenum disks are fastened to the thermocouple probe on each side of the pressure vessel. The resulting temperature profiles for the furnace were dramatically improved and considered acceptable for testing based on thermal profiles within the pressure vessel, such as Figure 30. Further details regarding the commissioning can be found in [9].

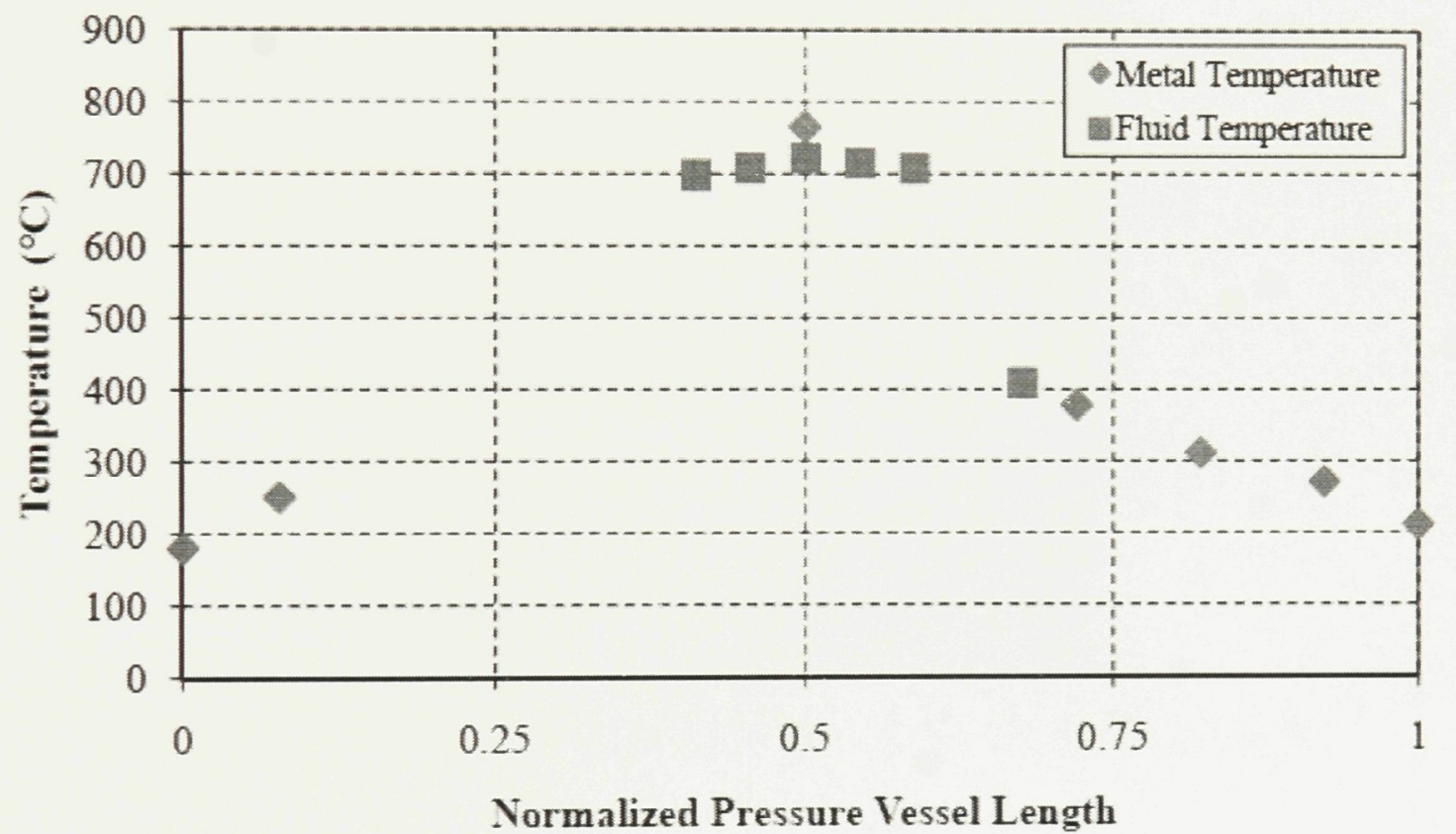

Figure 30: Internal thermal profile of pressure vessel at $700^{\circ} \mathrm{C}[9]$. 


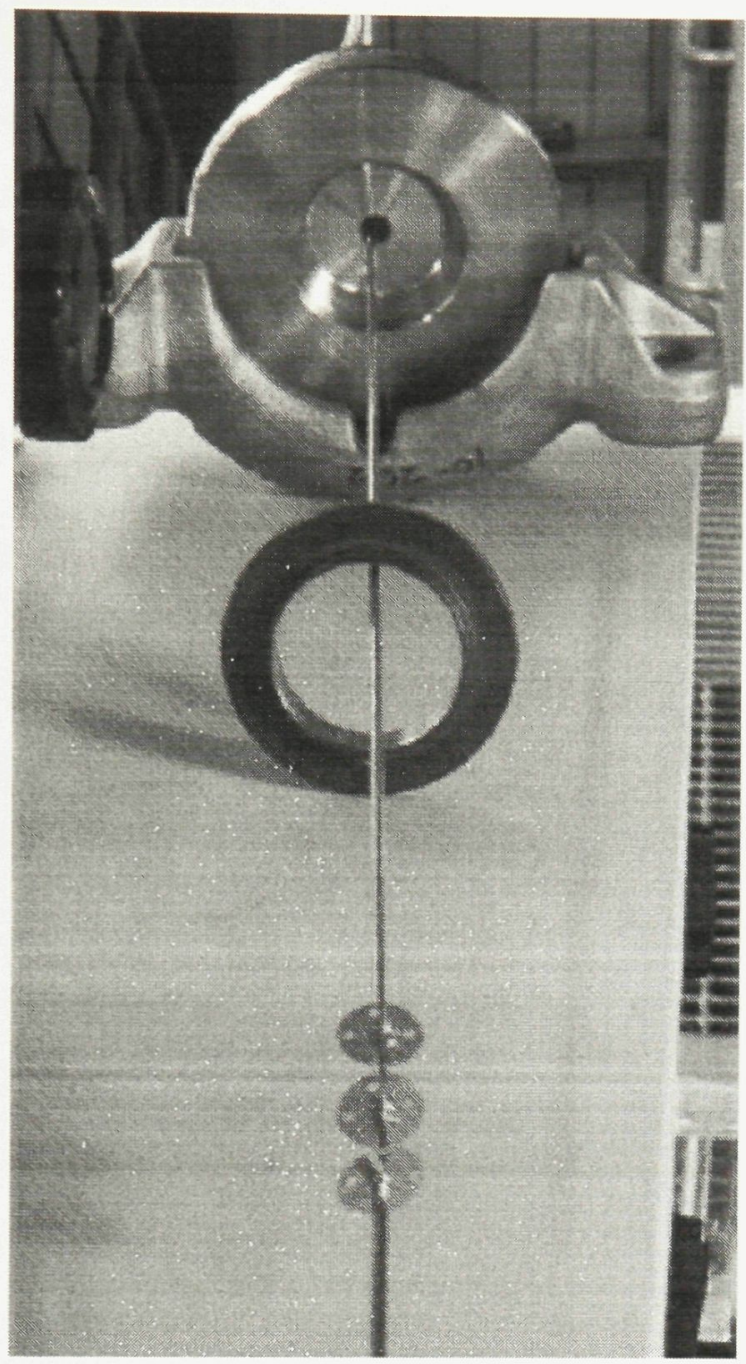

Figure 31: Molybdenum heat reflectors on thermocouple probe [9].

\subsubsection{Rig Operation}

The corrosion test rig is an autoclave design where sample coupons are loaded onto an alumina specimen boat and placed in the centre of the pressure vessel. Both Grayloc(R) end-caps must be loosened and removed to enable positioning of the specimen boat in the pressure vessel, which also requires the removal of the pressure transducer and $\mathrm{CO}_{2}$ process piping at both ends of the pressure vessel. These fittings are all assembled using Swagelok $(\mathrm{R}$, components for rapid removal and assembly while 
providing an effective seal.

The specimen boat is loaded into the pressure vessel using a small metal rod to push it into the middle of the pressure vessel. With the specimen boat in place, the pressure vessel end caps, process piping, and thermocouples can be assembled. The Grayloc(R) fittings should be tightened to a torque of $55 \mathrm{lb}-\mathrm{ft}$, while the Swageloc(R) fittings should be tightened to not allow leakage of $\mathrm{CO}_{2}$ when pressurized.

With the pressure vessel fully assembled, the main $\mathrm{CO}_{2}$ supply valve can be opened to fill the entire rig with $\mathrm{CO}_{2}$. The downstream isolation valve should be momentarily closed to ensure the rig is maintaining a pressure of approximately $1.5 \mathrm{MPa}$. Potential leaks at all fittings can be checked using Snoop liquid and observing for bubbles. After any leaks are rectified, the downstream isolation valve can be opened and the flow control valve can be opened to a rate of $10 \mathrm{~L} / \mathrm{hr}$. The high flow rate, which is maintained for 4 hours, ensures the entire rig is purged of air.

With the rig at a pressure of $1.5 \mathrm{MPa}$ and flow rate of $10 \mathrm{~L} / \mathrm{hr}$, the heating process can begin by turning on the power to the furnace controller. The furnace controller is programmed to increase temperature at a rate of $200^{\circ} \mathrm{C} / \mathrm{hr}$ to set the target temperature. Based on commissioning results discussed in detail in [9], the furnace set points for various target temperature are listed in Table 8.

Due to the increase in thermal conductivity of the $\mathrm{CO}_{2}$ when operating at $25 \mathrm{MPa}$, the set points need to be increased by approximately $30^{\circ} \mathrm{C}$ in each zone to maintain desired operating temperature. This adjustment in target temperature set point brings the temperature readings from the thermocouples at each end of the specimen boat in line with commissioning results.

In preparation for testing, the flow rate should be decreased to a rate of $1-2 \mathrm{~L} / \mathrm{hr}$ for testing from the $10 \mathrm{~L} / \mathrm{hr}$ flow used during heating of the pressure vessel. This rate is approximately equivalent to one bubble per second exiting the flask detailed in Figure 28. 


\begin{tabular}{cccc}
$\mathrm{CO}_{2}$ & \multicolumn{3}{c}{ Set Points $\left({ }^{\circ} \mathrm{C}\right)$} \\
\cline { 2 - 4 } Temperature & Zone 1 & Zone 2 & Zone 3 \\
\hline 400 & 490 & 380 & 490 \\
450 & 540 & 425 & 540 \\
500 & 585 & 470 & 585 \\
550 & 635 & 520 & 635 \\
600 & 680 & 570 & 680 \\
650 & 720 & 620 & 720 \\
700 & 770 & 670 & 770 \\
750 & 820 & 725 & 820 \\
\hline
\end{tabular}

Table 8: Furnace controller set points for $15 \mathrm{MPa}$. [9]

The internal temperature of the pressure vessel can be read on the Graphtec data logger using the thermocouple probes inserted from each end of the pressure vessel. Once the internal temperature has reached the desired target temperature, the process to bring the rig to operating pressure can begin.

The process to increase the rig pressure involves increasing the compressed air supply pressure to the GBT-15/30 gas booster. The regulator upstream from the booster should be completely closed before the compressed air supply is opened. As the compressed air supply valve is opened, the air supply line and regulator are pressurized. The pressure gauge on the side of the regulator displays the supply pressure to the gas booster, which is directly correlated to the $\mathrm{CO}_{2}$ output pressure through the following formula from [37]:

$$
P_{o}=30 \cdot P_{a}+2 \cdot P_{s}
$$

$P_{o}$ represents the outlet stall pressure of the gas booster, while $P_{a}$ is the compressed air supply pressure and $P_{s}$ is the supply $\mathrm{CO}_{2}$ supply pressure. 
The air supply pressure can be increased in by adjusting the regulator. The air supply regulator can quickly be increased to approximately 45 psi and then left for twenty minutes to allow the system to stabilize in temperature and pressure. The pressure vessel pressure should be closely monitored for temperature, pressure leaks, and flow rate adjustment as pressure is increased using the booster pump. With the rapid compression of $\mathrm{CO}_{2}$, there is an immediate proportional increase in temperature, which causes an additional increase in pressure. This heating effect is magnified in the buffer tank and can cause the pressure vessel to quickly overpressurize beyond the output pressure of the booster. The buffer tank temperature can be monitored through thermocouples connected to the line-heater controllers. Once this temperature has dissipated and stabilized, the air supply pressure can be increased in small increments while closely monitoring the pressure vessel pressure and buffer tank temperature. The air supply regulator can continue to be increased in increments of 10 psi until the buffer tank pressure exceeds $50^{\circ} \mathrm{C}$. At this time, pressurization should pause for twenty minutes to allow the buffer tank to stabilize. The rate of pressurization should decrease to about 2-3 psi per 5 minutes when the pressure vessel has reached a pressure within $3 \mathrm{MPa}$ of the desired test pressure in order to allow the entire system to stabilize.

\subsection{Experimental Procedure}

Corrosion experiments were conducted in a series of six sample sets of 1500 hours, where samples were weighed and photo documented in intervals of 100, 250, 500, 1000, and 1500 hours. 90 samples were used for the experiment, 30 of each alloy of 316SS, IN-718, and IN-738. Since the pressure vessel was manufactured from IN-625, two additional sample coupons of IN-625 were manufactured and added to the testing to monitor oxidation within the vessel. These samples were placed at each end of the 
specimen boat.

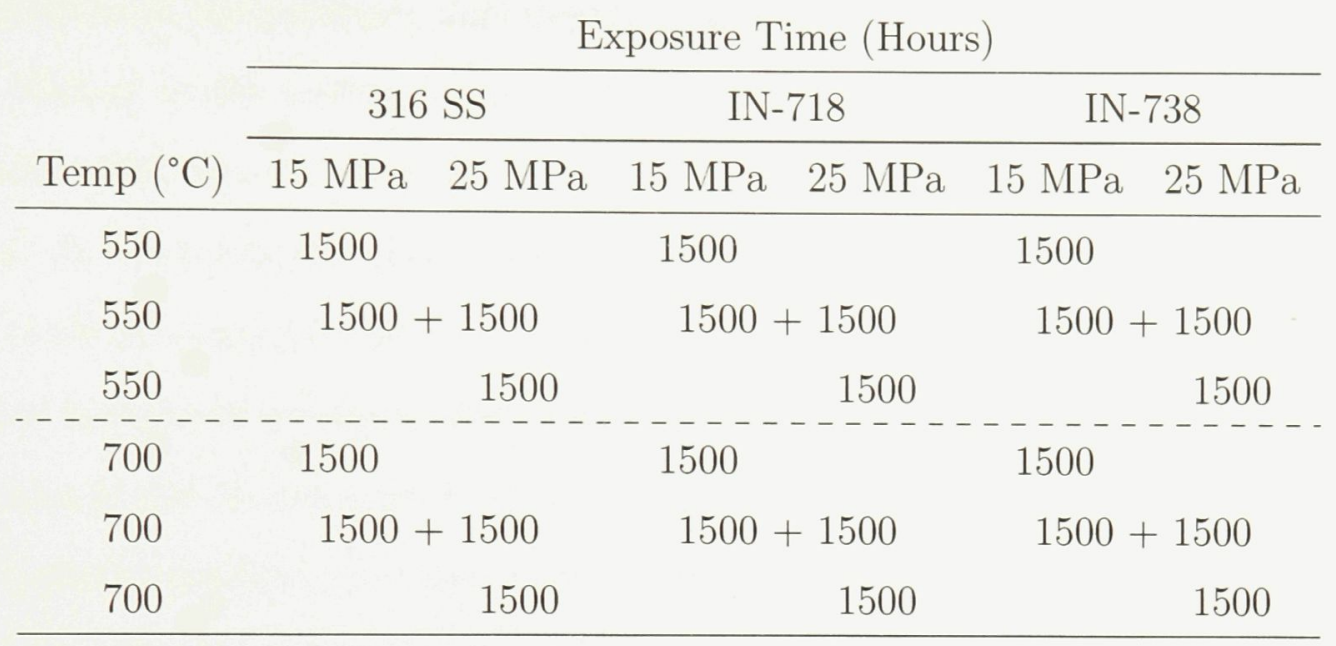

Table 9: Test matrix.

The first ten of each alloy were loaded onto the alumina specimen boat in an alternating pattern, as represented in Figure 32. The alternating pattern allowed for similar positioning of the coupons from alloy to alloy, which helped to negate any difference in weight gain between alloys that could be attributed to location in the specimen boat. The specimen boat was loaded so that the labelled side of the coupons consistently faced towards the flow of $\mathrm{CO}_{2}$.

401-101-201-301-102-202-302-103-203-303-..-110-210-310-402

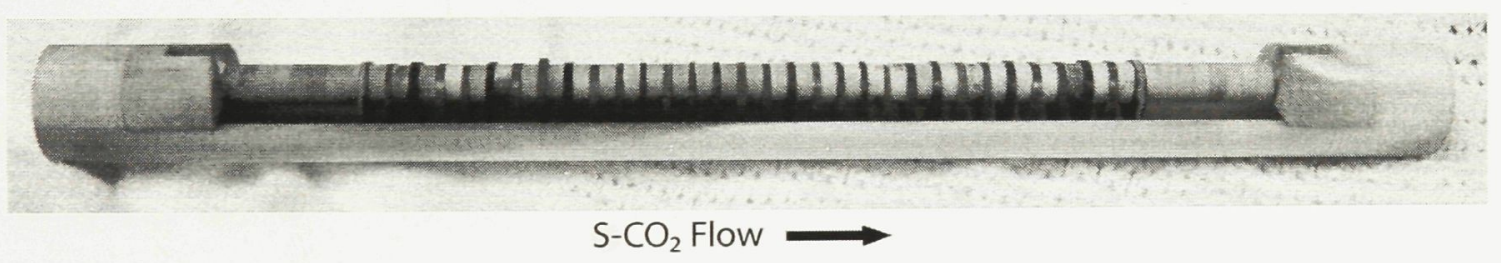

Figure 32: Coupon loading of specimen boat.

With the specimen boat loaded and the rig assembled, experiments began with the heating and pressurization of the pressure vessel, as detailed in Section 3.3.2. Line heaters that were installed around the upstream process piping were not used during any experiments due to the installed controllers causing large fluctuations in 
temperature. When operational, the two line heaters in series would cause unstable fluctuations in temperature, and therefore pressure, throughout the buffer tank and lines leading to the pressure vessel. These fluctuations in pressure would cause the pressure relief valve to open and subsequently remove $50 \%$ of the $\mathrm{CO}_{2}$ in the pressure vessel. At this point, the gas booster would attempt to rapidly pressurize the chamber. The rapid pressurization of $\mathrm{CO}_{2}$ would cause an increase in temperature, causing a further increase in pressure, and would cause the pressure vessel to over pressurize, resulting in the pressure relief valve to open again. It was decided that until proper line heater controllers were installed, the line heaters would not be used in order to avoid the unstable and continuous cycling of the pressure vessel.

Line heater controllers with faster cycle times and PID gain settings are to be installed for future experiments. Alternatively, a conventional space heater was used to heat the gas booster and process piping leading to the pressure vessel. The space heater was effective in maintaining a consistent temperature above $35^{\circ} \mathrm{C}$ in an effort to keep the $\mathrm{CO}_{2}$ supercritical.

The rig was first heated to test temperature by setting the target temperature in the furnace controller. The controller automatically heats the pressure vessel at a rate of $200^{\circ} \mathrm{C} /$ hour and maintains target temperature based on its thermocouple probes positioned on the exterior of the pressure vessel. Without pressurized $\mathrm{CO}_{2}$ in the pressure vessel, the interior temperature will exceed the desired temperature due to a lower thermal conductivity of the fluid. When target temperature was reached within the pressure vessel, the pressure vessel was pressurized using the regulator to increase the air supply pressure to the gas booster. Pressurization would continue until the pressure vessel was stable at approximately $0.2 \mathrm{MPa}$ above target pressure. The rig would be left for 8-10 hours to allow for the entire system to stabilize, causing the pressure to drop by 0.2-0.3 MPa. After the system was stable, the pressure could be adjusted to the target temperature. A representative recording of temperature 
and pressure for a 250 hour experiment is illustrated in Figure 33.

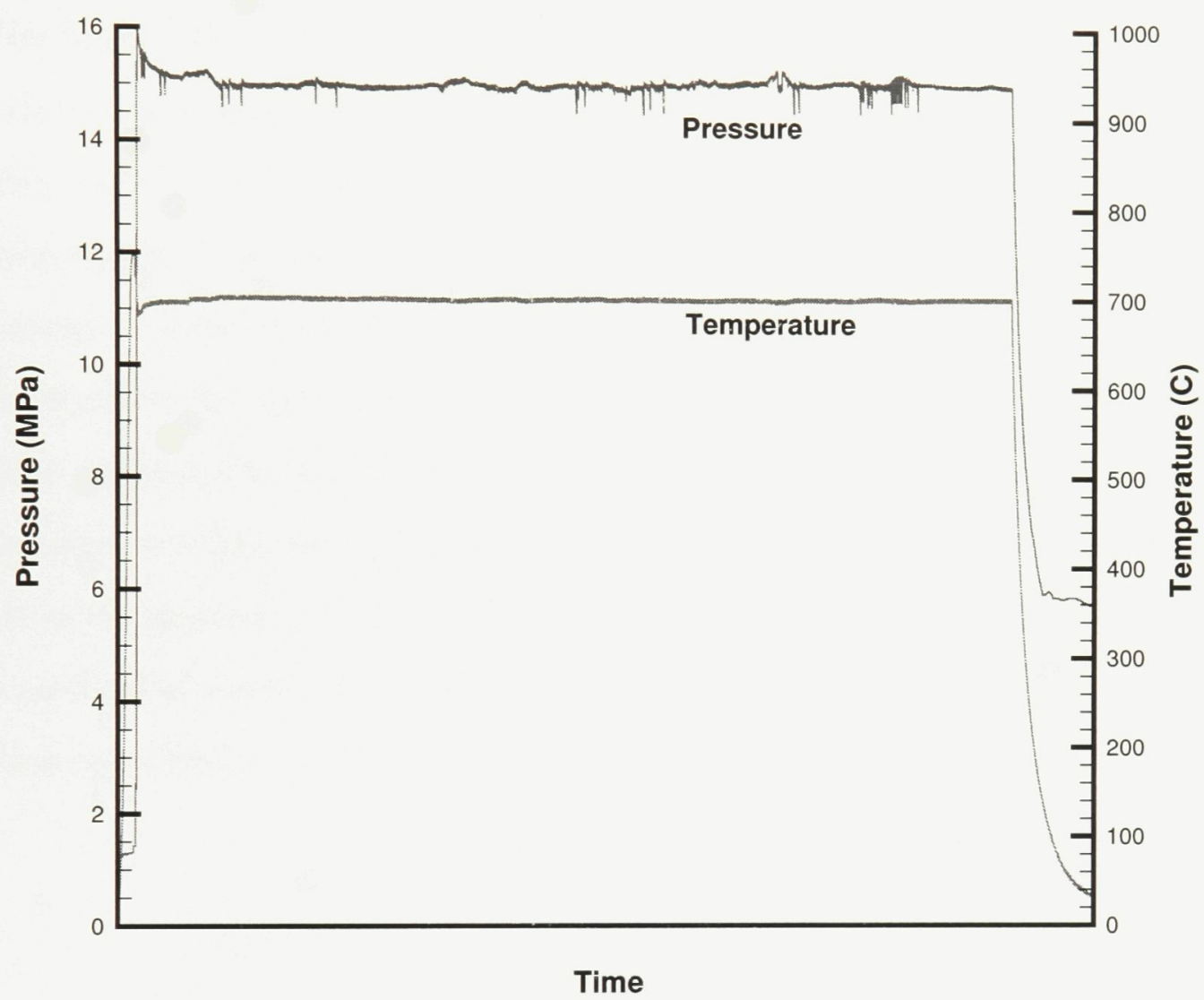

Figure 33: Internal pressure and temperature of corrosion test rig during typical run.

Figure 33 shows small drops in pressure intermittently throughout the test. These points are attributed to the gas booster stalling due to worn internal seals that deteriorated throughout the experiments. At the higher test pressure of $25 \mathrm{MPa}$, the booster was subject to higher loads and the added friction from the worn seals was not large enough to stall the booster cycles.

The corrosion experiment was conducted in two stages: at $550^{\circ} \mathrm{C}$ and $700^{\circ} \mathrm{C}$. A total of 3000 hours of testing was conducted at each temperature, where the first 1500 
hours was at a pressure of $15 \mathrm{MPa}$, and then increased to $25 \mathrm{MPa}$ for the remainder of the test. Out of the thirty samples used of each material, twenty were evenly divided between each of the four combinations of pressure and temperature for a maximum of 1500 hours. The remaining ten samples experienced the increase in pressure and remained in the pressure vessel for a total of 3000 hours.

The samples were removed at each test interval for weight change and photo documentation. One sample from each allow was removed in a systematic fashion and stored in a desiccator for future analysis. The first set of samples removed were the front row in the specimen boat (samples 101, 201, and 301), while the next set of samples removed were the rear set (samples 110, 210, and 310). After 1500 hours, the test pressure was increased to $25 \mathrm{MPa}$ and a new set of five samples of each allow were added to the specimen boat and replaced the five that had previously been removed. This method of sample positioning was employed to limit the effects of change in position on oxidation behaviour in the specimen boat.

\begin{tabular}{|c|c|c|c|c|}
\hline \multirow[b]{2}{*}{ Pressure (MPa) } & \multirow[b]{2}{*}{ Time (hrs) } & \multicolumn{3}{|c|}{ Coupon Removed } \\
\hline & & $316 \mathrm{SS}$ & IN-718 & IN-738 \\
\hline \multicolumn{5}{|c|}{ Start of Test } \\
\hline 15 & 100 & 101 & 201 & 301 \\
\hline 15 & 250 & 110 & 210 & 310 \\
\hline 15 & 500 & 102 & 202 & 302 \\
\hline 15 & 1000 & 109 & 209 & 309 \\
\hline 15 & 1500 & 103 & 203 & 303 \\
\hline \multicolumn{5}{|c|}{ Samples 11-15 Added } \\
\hline 25 & 1600 & 104,111 & 201,211 & 301,311 \\
\hline 25 & 1750 & 108,115 & 208,215 & 308,315 \\
\hline 25 & 2000 & 107,114 & 207,214 & 307,314 \\
\hline 25 & 2500 & 105,112 & 205,215 & 305,315 \\
\hline 25 & 3000 & 106,113 & 206,213 & 306,313 \\
\hline & & Test & & \\
\hline
\end{tabular}

Table 10: $550^{\circ} \mathrm{C}$ experiment: removal of coupons. 


\begin{tabular}{|c|c|c|c|c|}
\hline \multirow[b]{2}{*}{ Pressure (MPa) } & \multirow[b]{2}{*}{ Time (hrs) } & \multicolumn{3}{|c|}{ Coupon Removed } \\
\hline & & $316 \mathrm{SS}$ & IN-718 & IN-738 \\
\hline 15 & $--^{\text {Start }}$ & $\begin{array}{r}\text { of Test } \\
-\frac{--}{116}\end{array}$ & ---- & 316 \\
\hline 15 & 250 & 125 & 225 & 325 \\
\hline 15 & 500 & 117 & 217 & 317 \\
\hline 15 & 1000 & 124 & 224 & 324 \\
\hline 15 & 1500 & 118 & 218 & 318 \\
\hline \multicolumn{5}{|c|}{ Samples 26-30 Added } \\
\hline 25 & 1600 & 119,126 & 219,226 & 319,326 \\
\hline 25 & 1750 & 123,130 & 223,230 & 323,330 \\
\hline 25 & 2000 & 120,127 & 220,227 & 320,327 \\
\hline 25 & 2500 & 122,129 & 222,229 & 322,329 \\
\hline 25 & 3000 & 121,128 & 221,228 & 321,328 \\
\hline \multicolumn{5}{|c|}{ End of Test } \\
\hline
\end{tabular}

Table 11: $700^{\circ} \mathrm{C}$ experiment: removal of coupons.

\subsection{Coupon Characterization}

A total of 90 coupons were used in the corrosion testing of 3 materials. At each time interval outlined in Tables 10 and 11, all of the coupons in the specimen boat were removed from the pressure vessel. Each coupon was photographed and then weighed using a Sartoris BP211D balance with an accuracy of $0.00001 \mathrm{~g} \pm 0.01 \mathrm{mg}$.

After completion of testing, a select set of coupons were chosen to be sectioned using a Buehler Isomet 1000 precision saw and mounted using Buehler Epomet F compression mounting compound. The coupon cross sections were then prepared in four stages of $\mathrm{SiC}$ abrasive paper: 120, 240, 400, and 600 grit roughness. coupons were cleaned using ethyl alcohol, dried, and stored in a desiccator prior to further analysis.

The coupon cross sections were imaged using the Tescan VegaII XMU scanning 
electron microscope at Carleton University. Visual images were prepared using secondary electron imaging at magnifications from 60-7000x magnification. The main purpose of visual inspection was centred on the condition, structure, and adherence of the oxide layer. Figure 34 shows the placement of coupons within the SEM for visual and EDX analysis.

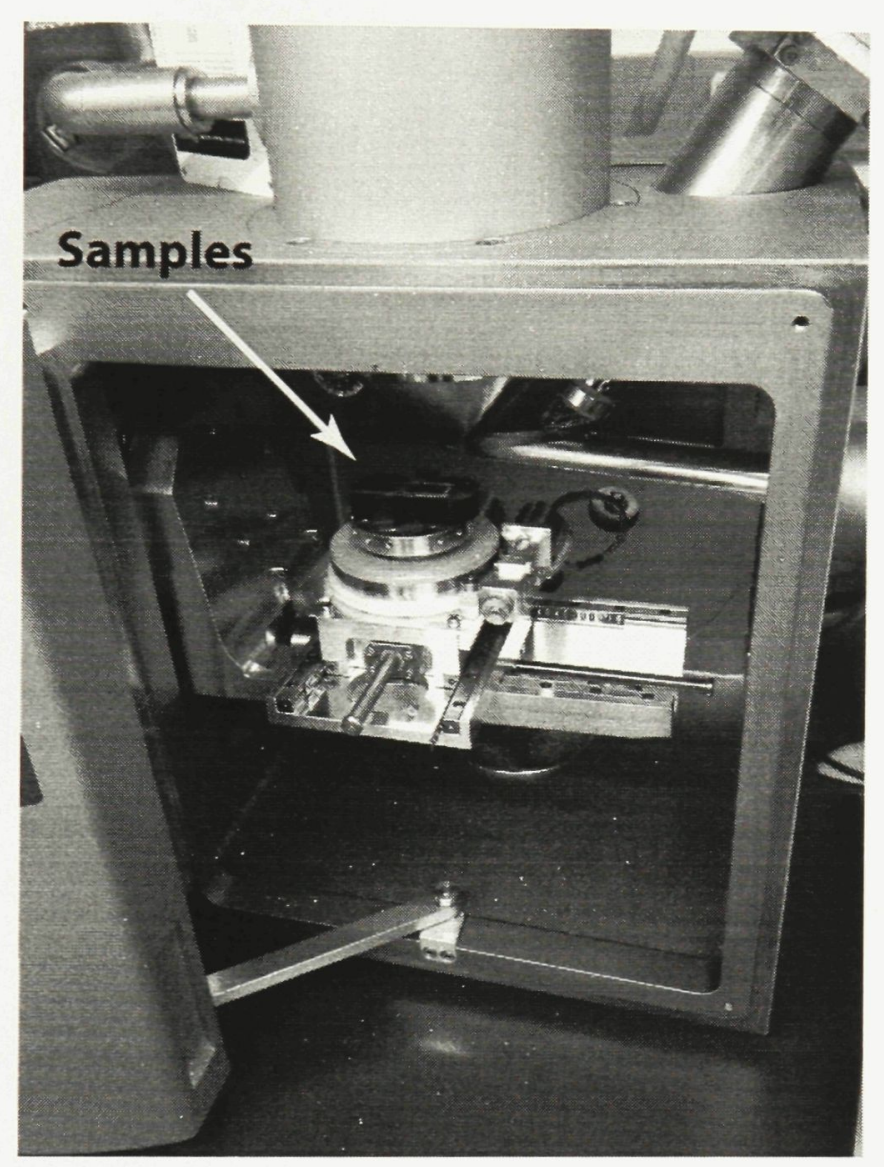

Figure 34: Placement of samples in SEM.

After visual inspection, an elemental analysis was conducted using an Oxford Inca Engery 250X EDS. At a magnification of 2000x, four points were chosen horizontally through the oxide and alloy cross-section, as illustrated in Figure 35. These results provide a means to understand compositional change within the alloy and formation of the oxide layer. 


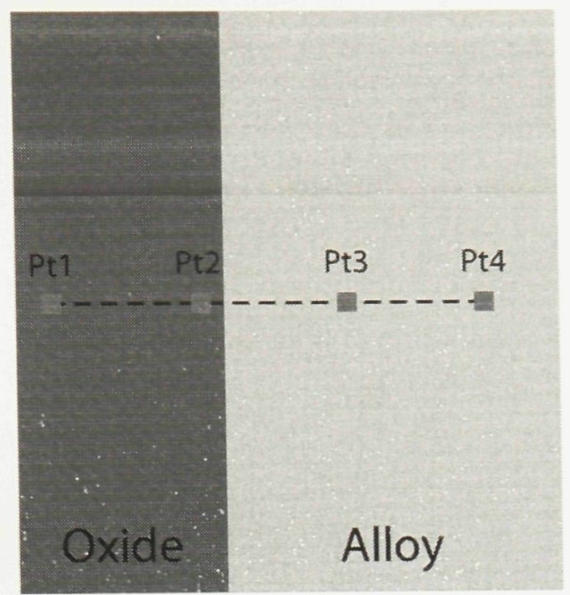

Figure 35: Elemental analysis of sample cross-section using Oxford Inca Engergy 250X EDS. Points 1-4 represent analysis locations at magnification. 


\section{Chapter 4}

\section{Results and Discussion}

The following section outlines the results from corrosion testing of three alloys: IN738, IN-718, and 316SS. A total of 90 samples were used, 30 for each material, and were divided into six sample sets for testing in four different environments. A sample set was applied to each condition of: $550^{\circ} \mathrm{C} / 15 \mathrm{MPa}, 550^{\circ} \mathrm{C} / 25 \mathrm{MPa}, 700^{\circ} \mathrm{C} / 15 \mathrm{MPa}$, and $700^{\circ} \mathrm{C} / 25 \mathrm{MPa}$, each for 1500 hours. The remaining two sample sets were tested for a total of 3000 hours at constant temperature, but experienced an increase in pressure from $15 \mathrm{MPa}$ to $25 \mathrm{MPa}$ after the first 1500 hours. These test conditions are outlined in Tables 9, 10 and 11 on pages 59, 62, and 63, respectively.

The analysis is categorized into three sections: oxide surface characterization, weight gain, and cross-section characterization. The weight gain measurements taken at each time interval identify the magnitude of oxide growth on the sample. The kinetics of oxidation can be interpreted from the weight gain and compared to conventional growth rate laws to determine the oxide's ability to form a protective barrier against corrosion. Further interpretation as to the composition, structure, and integrity of the oxide are done through visual and elemental analysis of the sample cross section, in addition to visual inspection of the oxide surface. 


\subsection{Oxide Surface Characterization}

At each test interval, all of the samples were photo documented to monitor surface oxide growth. From the visual inspection, the oxide formation was observed through change in colour and surface texture of the samples. Two images are included as Figures 36 and 37 for comparative purposes. Figure 36 includes samples after a total of 1500 hours at $15 \mathrm{MPa}$ and $550^{\circ} \mathrm{C}$ in addition to 100 hours at $25 \mathrm{MPa}$ and $550^{\circ} \mathrm{C}$. Figure 37 includes samples from the same time interval except at a temperature of $700^{\circ} \mathrm{C}$.

In Figure 36, samples 11 to 15 have been exposed to 100 hours at $550^{\circ} \mathrm{C}$ and $25 \mathrm{MPa}$. These samples have all changed colour based their initial oxide growth in the first 100 hours. The 316SS samples (111-115) quickly turn a gold colour, which can be attributed to the initial growth of iron oxide. The IN-718 samples (211-215) and IN-738 (311-315) have all turned a varying shade of dark grey, while the IN-738 samples have a slight blue appearance. The blueing of the metal could be due to the growth of nickel and chromia oxide, while IN-718 could be a combination of nickel, chromium, and iron oxide. Besides the initial colour change, no other observations can be made from these samples.

With respect to the samples that have already been exposed to 1500 hours at $550^{\circ} \mathrm{C}$ and $15 \mathrm{MPa}$, the significant exposure to carbon has resulted in a dark-grey appearance. Throughout testing at $550^{\circ} \mathrm{C}$, was any evidence of spallation or breakaway corrosion observed. 

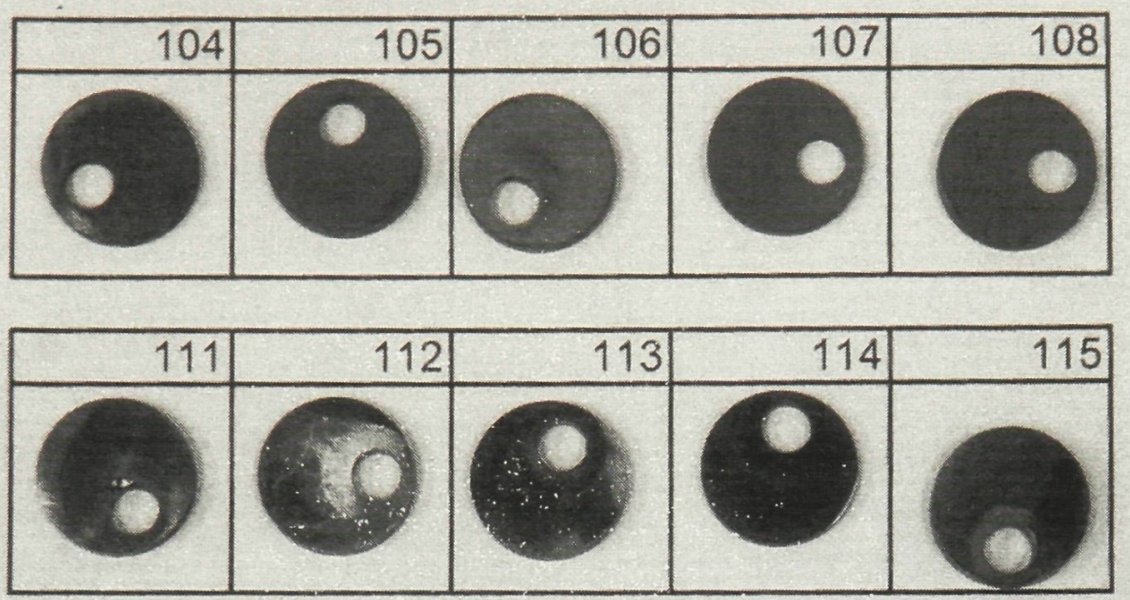

\begin{tabular}{|r|r|r|r|r|}
\hline 204 & 205 & 206 & 207 & 208 \\
\hline 01 & & & 0 & \\
& & 0 & & 0 \\
\hline
\end{tabular}
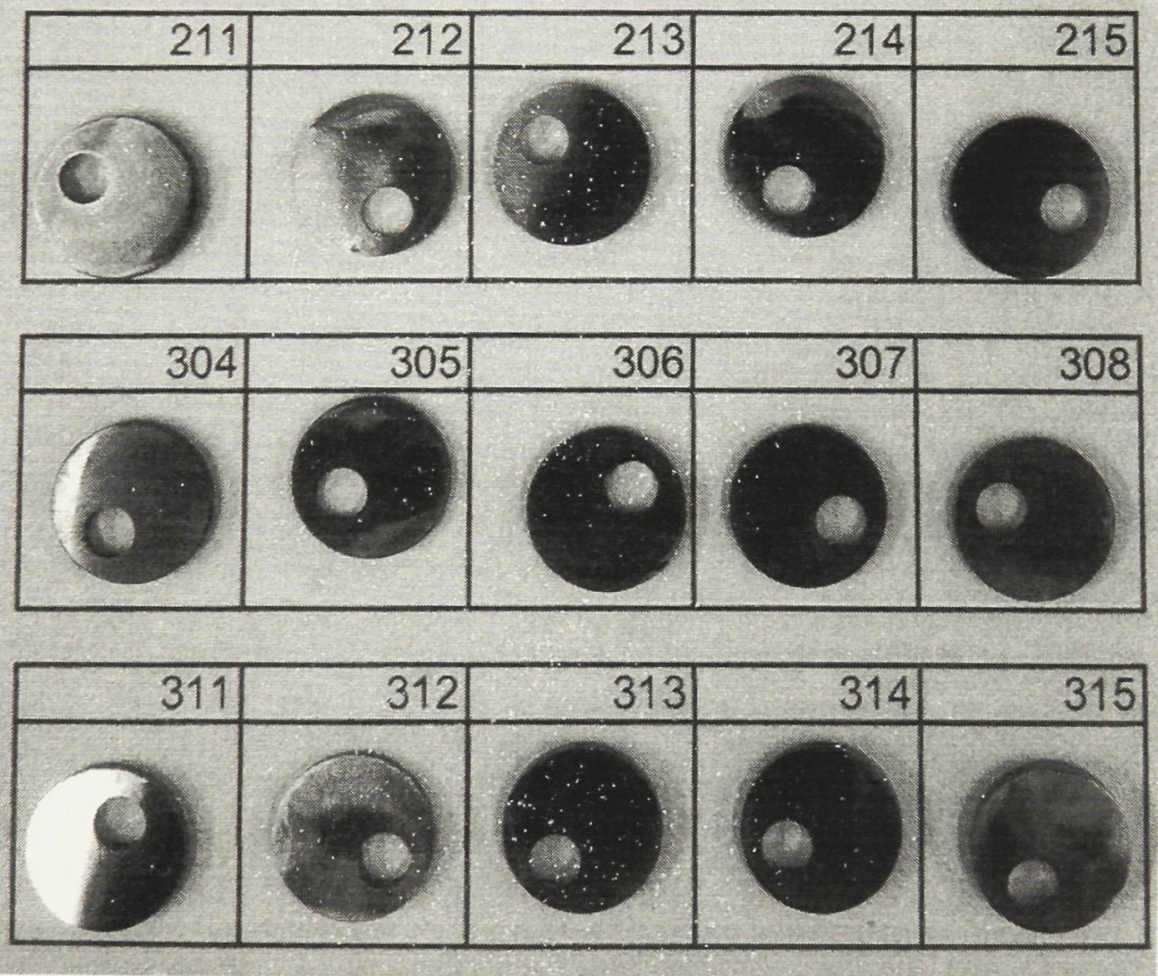

Figure 36: Photos of coupons after 100 hours of exposure to $550^{\circ} \mathrm{C} / 25 \mathrm{MPa} \mathrm{S}-\mathrm{CO}_{2}$. Coupons 4-8 have been already been exposed for 1500 hours at $15 \mathrm{MPa}$. 
In comparison, Figure 37 illustrates samples from the same time interval, except at $700^{\circ} \mathrm{C}$. Samples 26 through 30 have been exposed to only 100 hours and the discolouring of the coupons has been exaggerated. Oxidation can also be noticed in the areas of contact between the coupons and the alumina spacer used to separate coupons in the specimen boat. An attempt was made when loading the specimen boat to allow space between the spacers, but oxidation in these areas was inevitable.

At this temperature, significant oxide growth was observed on 316SS coupons after 1500 hours. The surface of these coupons (19-23) was rough, uneven, and discontinuous. This appearance correlates with SEM images and weight change data, which explains the linear oxide growth rate and inability of 316SS to form a protective oxide at $700^{\circ} \mathrm{C}$.

Coupons 219-230 are IN-718 that have been exposed to 100 hours (26-30) and 1600 hours (19-23). The appearance of oxide growth did not vary beyond the initial darkening of the coupon. The oxide was thin and continuous across the entire surface.

Similar to IN-718, the IN-738 coupons did not vary beyond the initial darkening and blueing of the surface. The oxide was continuous and appeared to be well adhered to the substrate. 

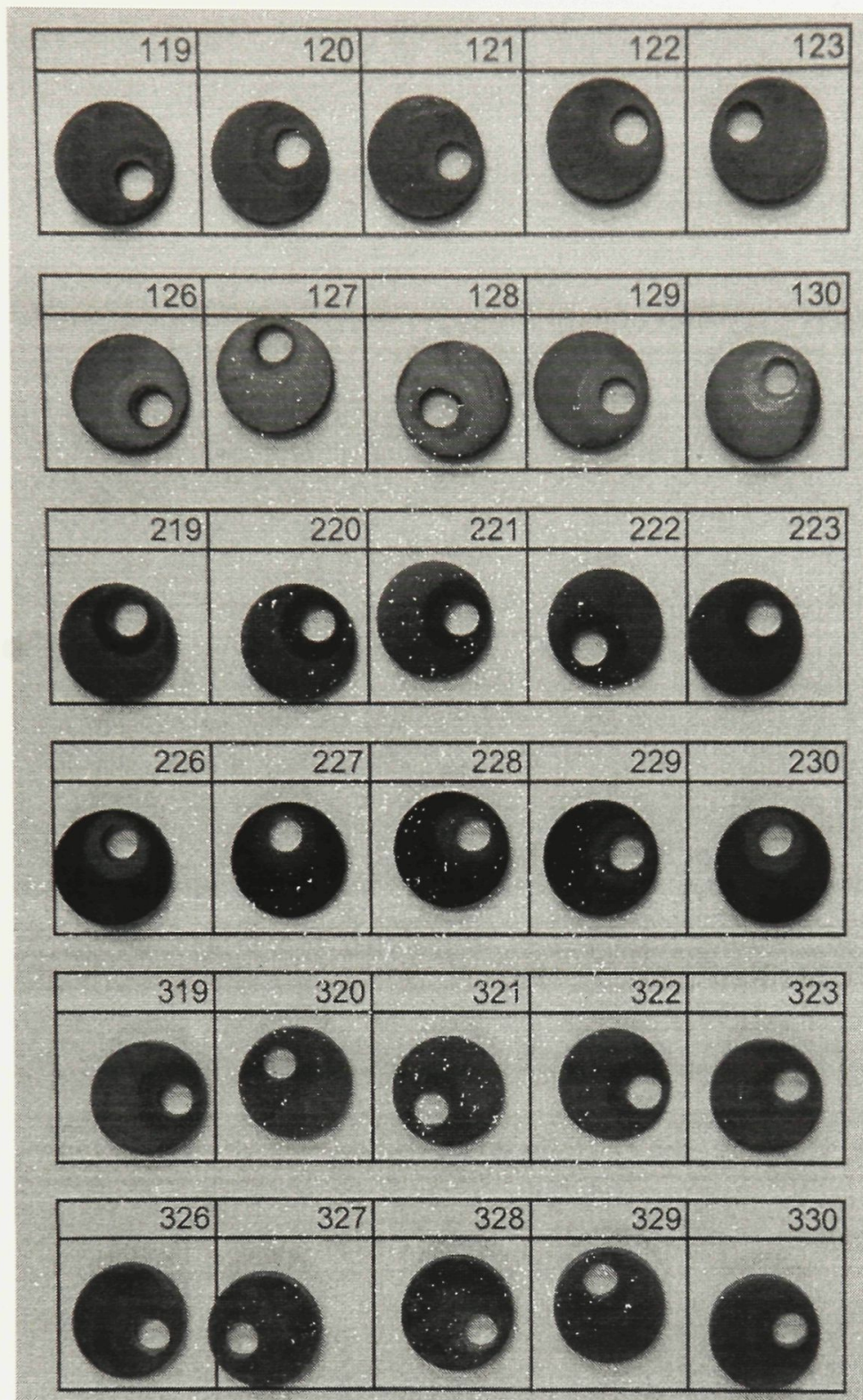

Figure 37: Photos of coupons after 100 hours of exposure to $700^{\circ} \mathrm{C} / 25 \mathrm{MPa} \mathrm{S}-\mathrm{CO}_{2}$. Coupons 19-23 have been already been exposed for 1500 hours at $15 \mathrm{MPa}$. 


\subsection{Weight Gain Analysis}

At each test interval of $100,250,500,1000$, and 1500 hours, each coupon was removed from the pressure vessel and weighed using a Sartoris BP211D balance with an accuracy of $0.00001 \mathrm{~g} \pm 0.01 \mathrm{mg}$. Each coupon was weighed until three measurements were recorded within $0.02 \mathrm{mg}$ of each other. This section offers a comparison between the alloys in terms of these measurements over 1500 hours of testing at four different environments of pressure and temperature. Furthermore, the results are plotted to interpret corrosion dependance on temperature and pressure.

\subsubsection{Comparison of Test Alloys}

The three alloys that were tested included: austenitic stainless steel 316, iron-nickelbase superalloy 718, and nickel-base superalloy 738. Based on the test matrix of Table 9, a total of 20 coupons of each alloy were exposed to conditions at $15 \mathrm{MPa}$, while the remaining 10 were exposed to $25 \mathrm{MPa}$. These pressure conditions were split between two temperatures of $550^{\circ} \mathrm{C}$ and $700^{\circ} \mathrm{C}$. These results for each coupon has been plotted in Figures 38 and 39. The measurements at each time interval represent the change in weight from the coupon's original weight, normalized by its surface area.

Since the pressure vessel was manufactured from IN-625, two additional coupons were added to the front and rear of the specimen boat to monitor corrosion of the test rig itself. Although a lower strength alloy relative to IN-718 and IN-738, IN625 exhibited excellent corrosion resistance in comparison to the other alloys. For comparative purposes, the weight change results for IN-625 has been plotted with the other alloys. The results for each alloy from $550^{\circ} \mathrm{C}$ are shown in plots of Figure 38, while $700^{\circ} \mathrm{C}$ results are found in plots of Figure 39.

At $550^{\circ} \mathrm{C}$, there did not appear to be a clear differentiation between IN-718 and 
316SS, although there was significantly less scatter in the IN-718 results. The corrosion rate of IN-738 was far superior to the other two alloys under these conditions by a factor of approximately two. The IN-738 oxide layer appears to be significantly better protection from the beginning, and should be due to the difference in alloying elements, namely iron, which generally becomes unstable at higher temperatures.

In comparison, the $700^{\circ} \mathrm{C}$ results show a significant difference in oxide growth rate between the 316 stainless steel and the nickel-base superalloys. The 316SS coupons follow a linear growth trend and the produced oxide is considered unproductive due to its inability to slow the rate of oxide growth. After 1500 hours of exposure, there is no evidence that the oxide growth rate will decrease under these operating conditions.

When considering the increase in test pressure after 1500 hours, an immediate increase in weight can be noticed from most of the coupons. This weight gain is even more pronounced in the $700^{\circ} \mathrm{C}$ results. The immediate change in weight after an increase in pressure from $15 \mathrm{MPa}$ to $25 \mathrm{MPa}$ portrays some dependance on pressure for oxide growth and will be discussed in a subsequent section.

Another weight gain comparison is provided in Figure 40 where weight gain results for IN-625 are plotted for the full 6000 hours of exposure. The two IN-625 coupons were used throughout testing at both temperatures and pressures. These results illustrate the variability of corrosion in $\mathrm{S}-\mathrm{CO}_{2}$ under changing conditions of temperature and pressure. As seen in both plots, the increase in temperature from $550^{\circ} \mathrm{C}$ to $700^{\circ} \mathrm{C}$ caused a rapid increase in oxide growth before beginning to stabilize again after another 1000 hours. 
a)

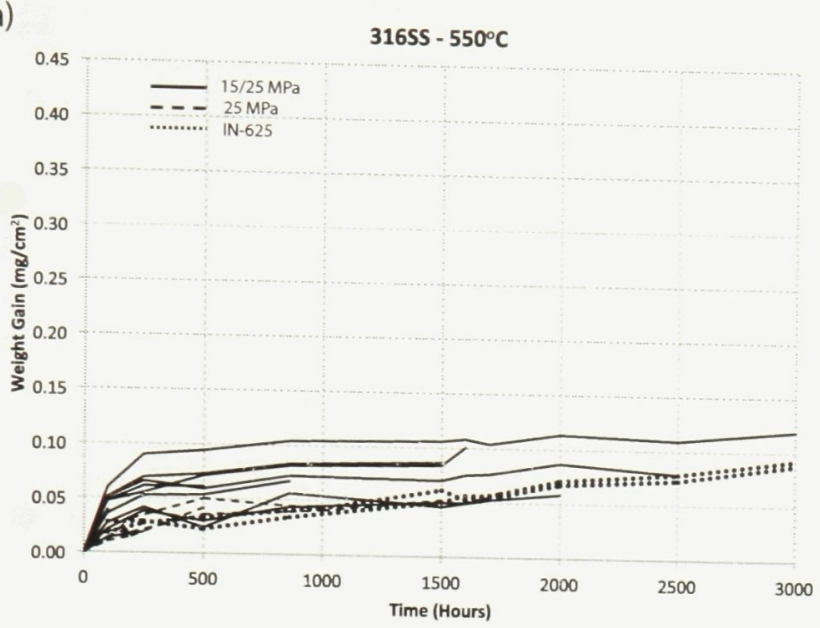

b)

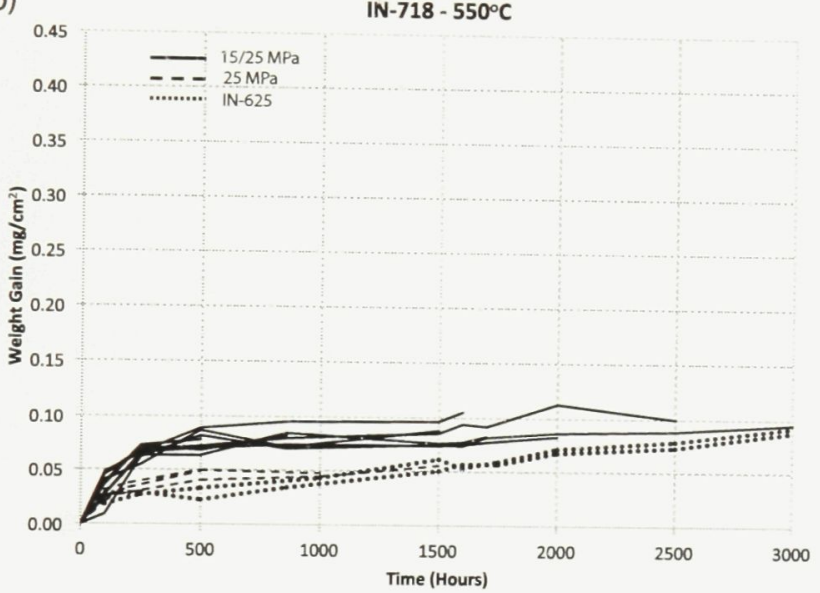

C)

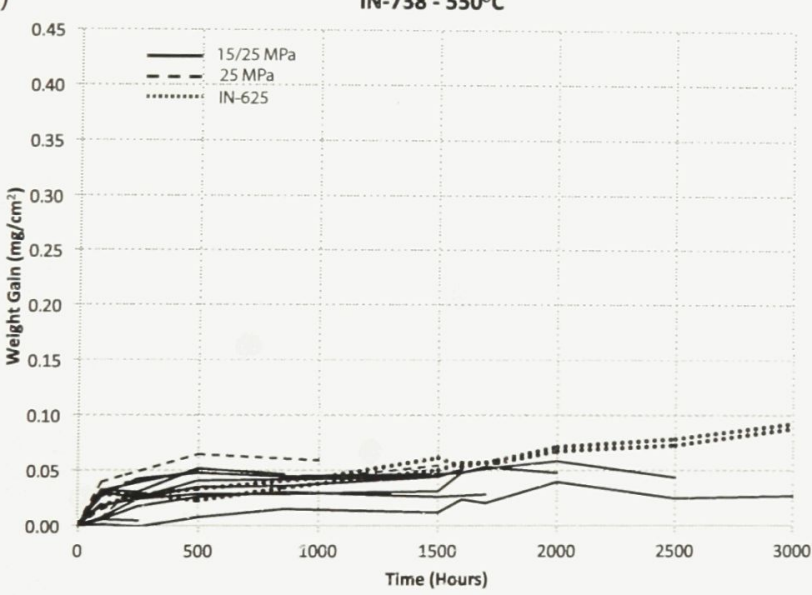

Figure 38: Weight gain plots of individual coupons at $550^{\circ} \mathrm{C}$. A more detailed plot is provided in Appendix A. 
a)

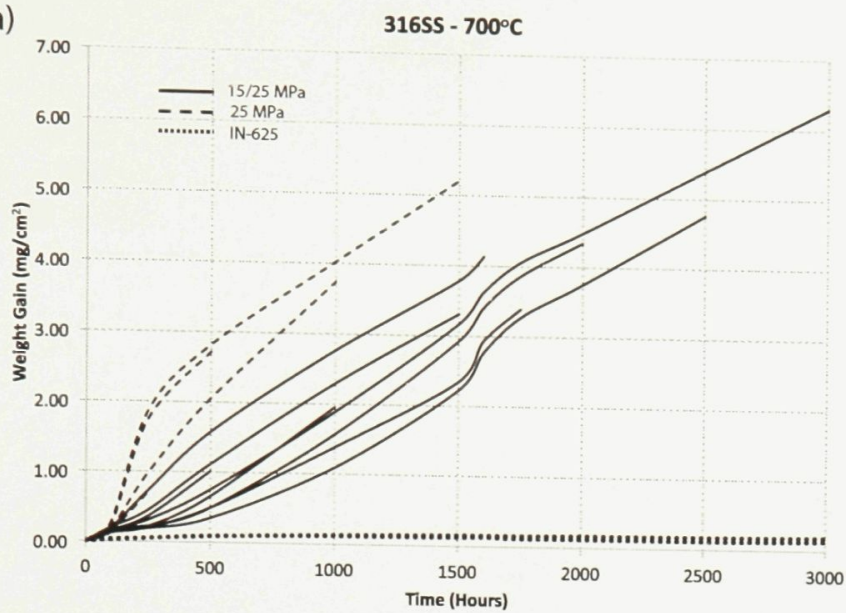

b)

IN-718 $-700^{\circ} \mathrm{C}$

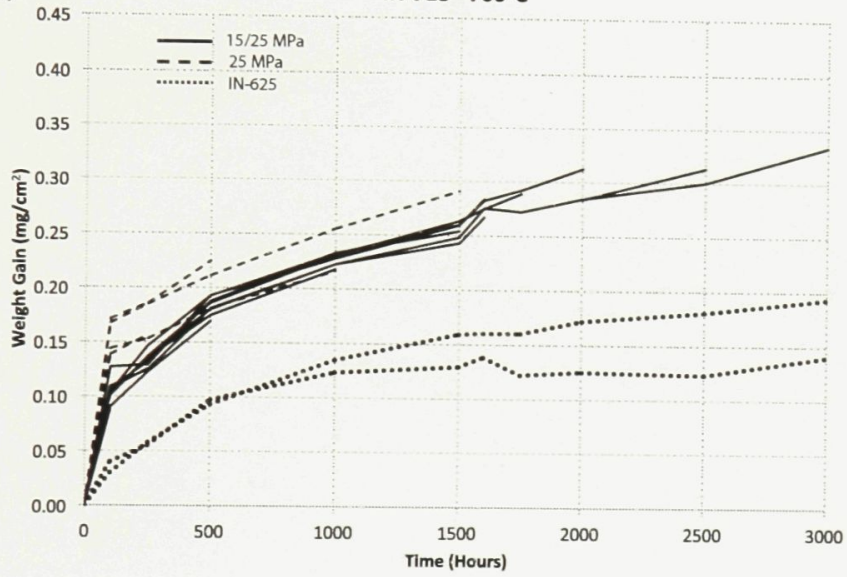

c)

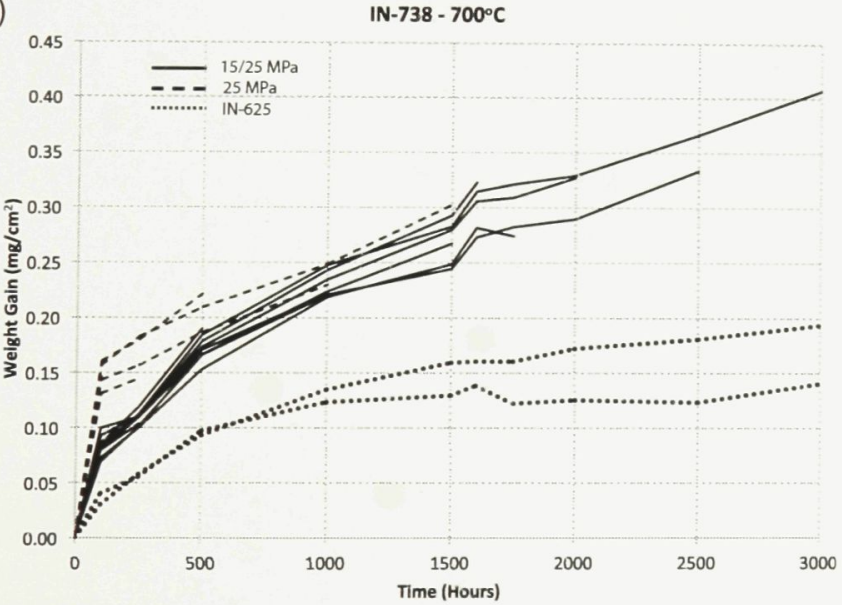

Figure 39: Weight gain plots of individual coupons at $700^{\circ} \mathrm{C}$. Weight gain calculations of IN-625 coupons were based on an artificial zero valued at the total weight gained after 3000 hours of testing at $550^{\circ} \mathrm{C}$. 
a)

IN-718

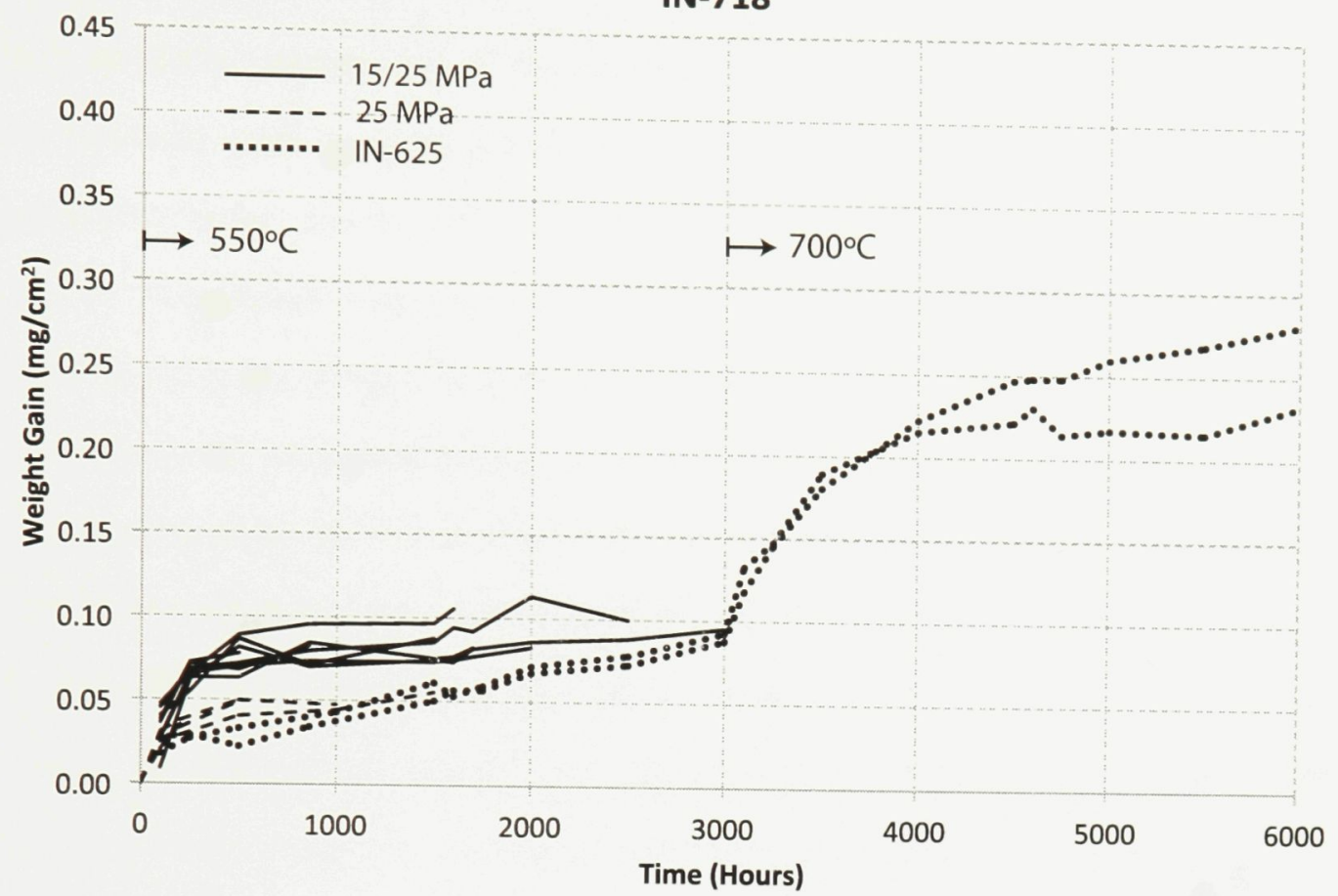

b)

IN-738

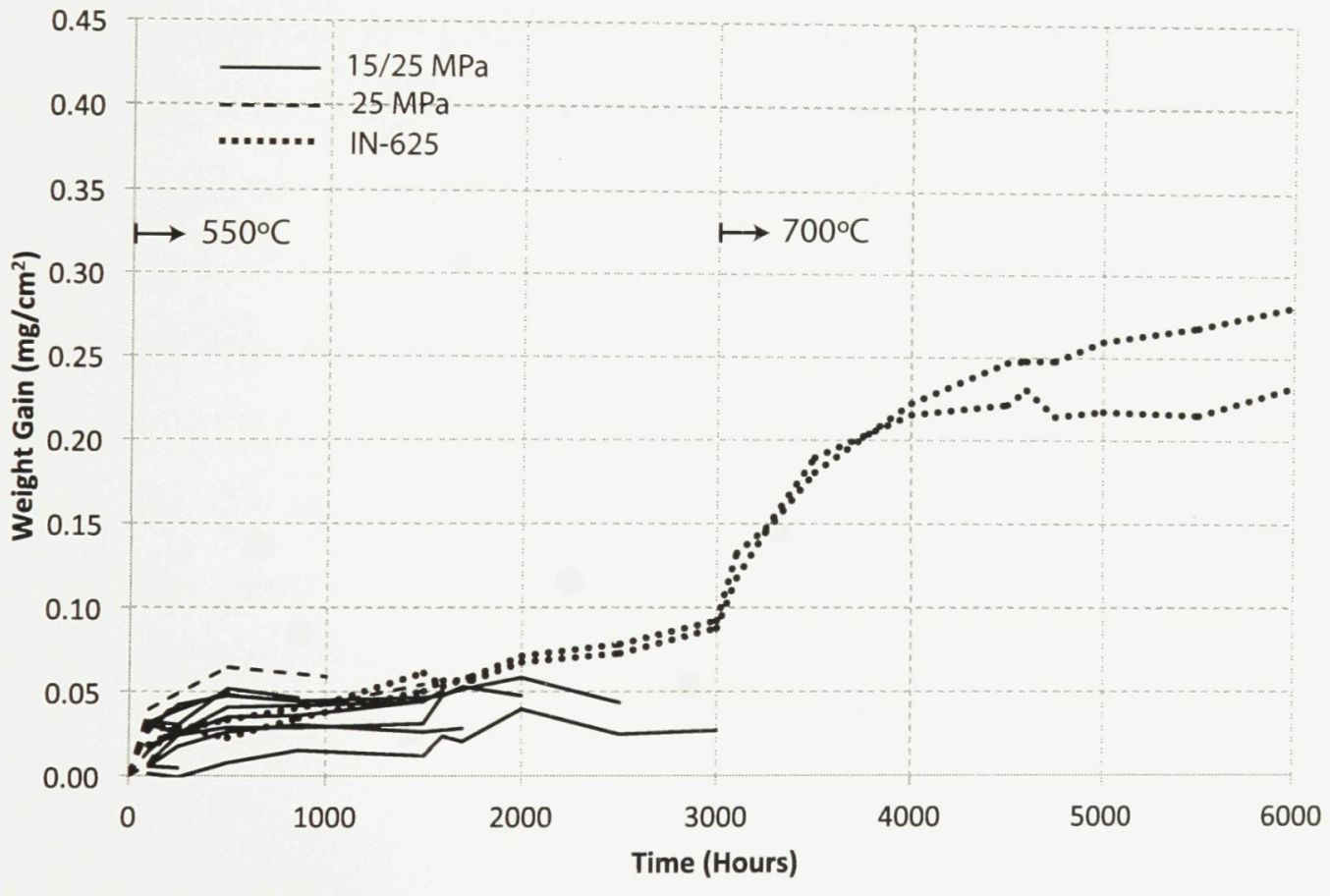

Figure 40: Comparison of IN-718 and IN-738 to IN-625 coupons that were exposed to $15 \mathrm{MPa}$ and $25 \mathrm{MPa}$ at $550^{\circ} \mathrm{C}$ and $700^{\circ} \mathrm{C}$ for at total of 6000 hours. 


\subsubsection{Dependence on Temperature}

From an initial comparison of the corrosion of different alloys, there is a clear distinction between oxide growth trends at different temperatures. From the two temperatures that were tested, $550^{\circ} \mathrm{C}$ and $700^{\circ} \mathrm{C}$, all three alloys resulted in higher weight gains at the higher temperature. These comparisons are illustrated in Figure 41, where the average weight gain from each test interval is plotted for each alloy.

At the lower operating temperature of $550^{\circ} \mathrm{C}$, all three alloys exhibited logarithmic oxide growth rates due to the formation of a stable and thin film oxide that acts as a protective oxide layer preventing further oxidation of the alloy. At this temperature, 316SS and IN-718 followed similar growth rate trends throughout the 1500 hours of testing. In comparison, nearly $50 \%$ less oxide was produced by IN-738 in the same amount of time, which can be attributed to a more protective oxide layer.

When considering the higher operating temperature of $700^{\circ} \mathrm{C}$, IN-718 and IN-738 significantly outperformed 316SS. At this temperature, 316SS resulted in a linear oxide growth rate through the continuous formation of new oxide. The linear growth rate is considered a non-protective oxide and for this reason, undesirable for these operating conditions. In contrast, oxide growth of IN-718 and IN-738 followed a parabolic relationship with significant higher amounts of oxide produced overall when compared to $550^{\circ} \mathrm{C}$. Both alloys exhibit evidence of a protective oxide being formed through the decreasing rate of oxide growth after 1500 hours of testing. Although subsequently stabilized, oxide is initially produced at a rate of 3-5 times faster at $700^{\circ} \mathrm{C}$ in the first 100 hours of testing, than at $550^{\circ} \mathrm{C}$. 
a)

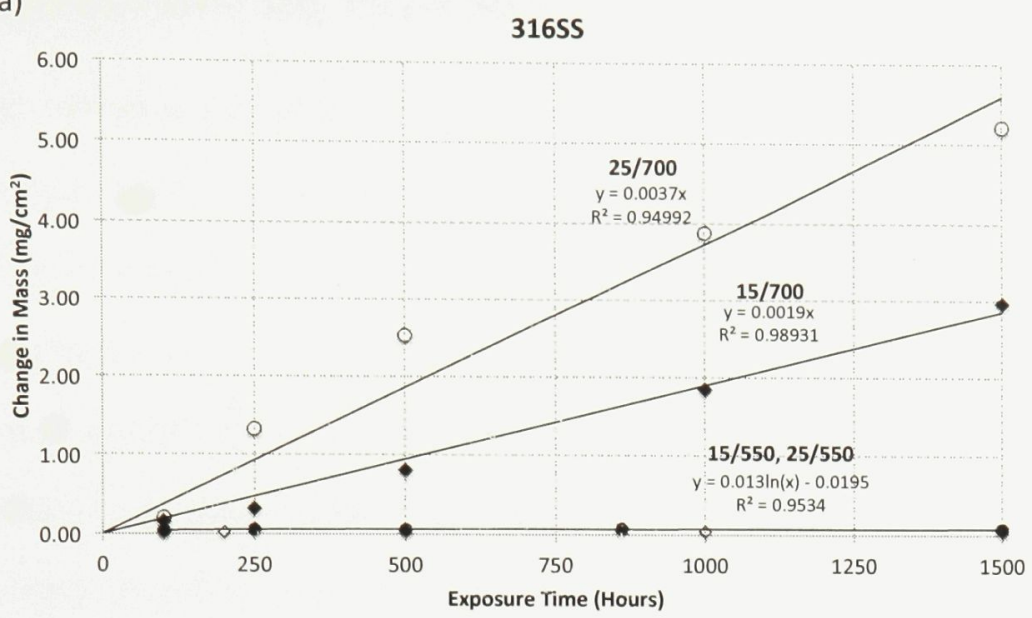

b)

IN-718

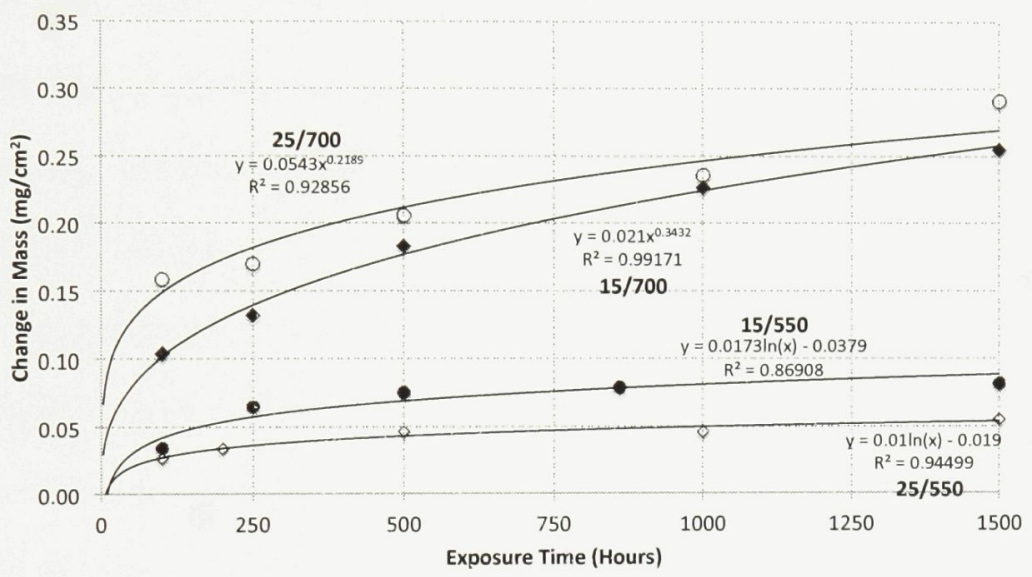

c)

IN-738

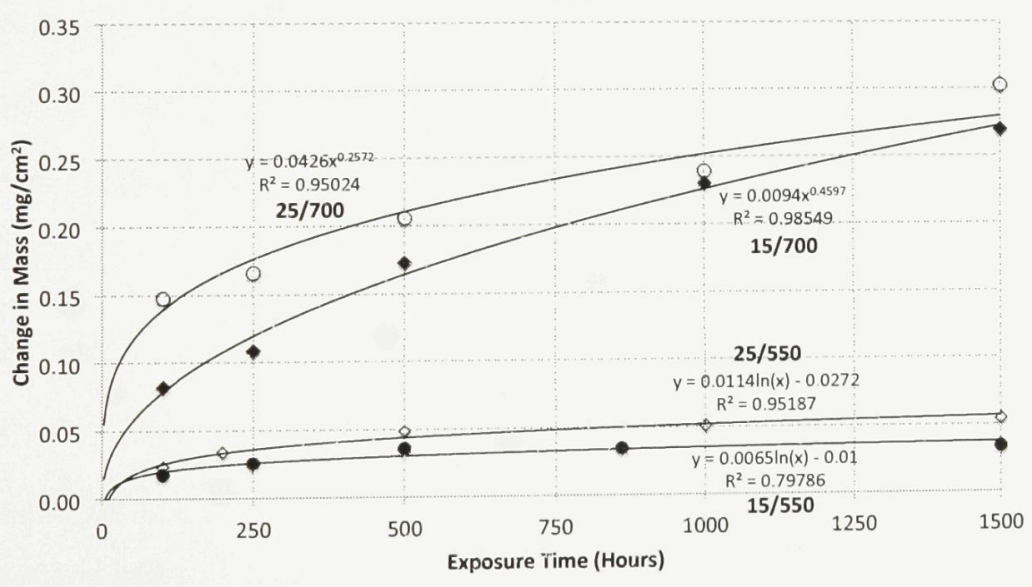

Figure 41: Weight change comparison of 316SS, IN-718, and IN-738 based on temperature and pressure for 1500 hours. The plotted weight gain value at each time interval represents the average weight gain for each alloy at that point in time. Temperature and pressure conditions are indicated as either 15 or 25 in $\mathrm{MPa}$, followed by 550 or 700 in degrees Celsius. Plots of non-averaged results are provided in Appendix A. 


\subsubsection{Dependence on Pressure}

A comparison between the alloys at each combination of pressure and temperature after a maximum of 3000 hours is provided in Figures 42 and 43 . Each plot offers a comparison between each sample set, which was either tested at $15 \mathrm{MPa}, 25 \mathrm{MPa}$, or experienced an increase in pressure from 15 to $25 \mathrm{MPa}$ after 1500 hours of testing.

At the lower operating temperature of $550^{\circ} \mathrm{C}$, the overall effect of pressure is most noticeable within the initial 1500 hours of testing. Both 316SS and IN-718 resulted in less oxide, and therefore more protective when compared to their $15 \mathrm{MPa}$ results. IN-738 followed a nearly identical oxide growth trend as IN-718 at $25 \mathrm{MPa}$, but was more effective at the lower pressure of $15 \mathrm{MPa}$ with as much as $50 \%$ less oxide produced overall. Although varying in the total amounts of oxide produced from $0.04-0.08 \mathrm{mg} / \mathrm{cm}^{2}$, all three alloys exhibit qualities of producing a protective oxide at an operating temperature of $550^{\circ} \mathrm{C}$.

At the higher operating temperature of $700^{\circ} \mathrm{C}$, a pressure of $25 \mathrm{MPa}$ resulted in an increased oxide growth rate for all three alloys. For 316SS, the rate of oxide growth nearly doubled, following an undesirable linear growth rate trend with nearly $6 \mathrm{mg} / \mathrm{cm}^{2}$ produced after 1500 hours. In contrast, IN-718 and IN-738 illustrated an initial increase in oxide growth by approximately 150-200\% within the first 250 hours of testing. This oxide growth trend later merged with $15 \mathrm{MPa}$ results after 1500 hours at a value of $0.25-0.30 \mathrm{mg} / \mathrm{cm}^{2}$. These results indicate a higher operating pressure causes a faster oxide growth rate with negligible additional oxide produced overall.

At 1500 hours, the test pressure was increased to $25 \mathrm{MPa}$ for the remainder of the testing. A dashed trendline is illustrated on each of the plots that considers the overall trend of coupons exposed to the combination of 15 and $25 \mathrm{MPa}$ throughout the 3000 hours of testing. This trendline can be compared to relations drawn for the sample sets before and after 1500 hours of testing for indication of change due to the increase 
in pressure. Although the results illustrated in Figures 38 and 39 for individual coupons exhibit an increase in weight between 1500-1600 hours, a clear relation is not found in the averaged values of Figures 42 or 43 . This scatter can be attributed to the decreasing number of data points as coupons are removed throughout testing, where five coupons are averaged at 1600 hours, but only one coupon remains at 3000 hours. For this reason, in addition to the accuracy of the balance, the effect of an increase in pressure at 1500 hours is indistinguishable in the plotted results of average values. 

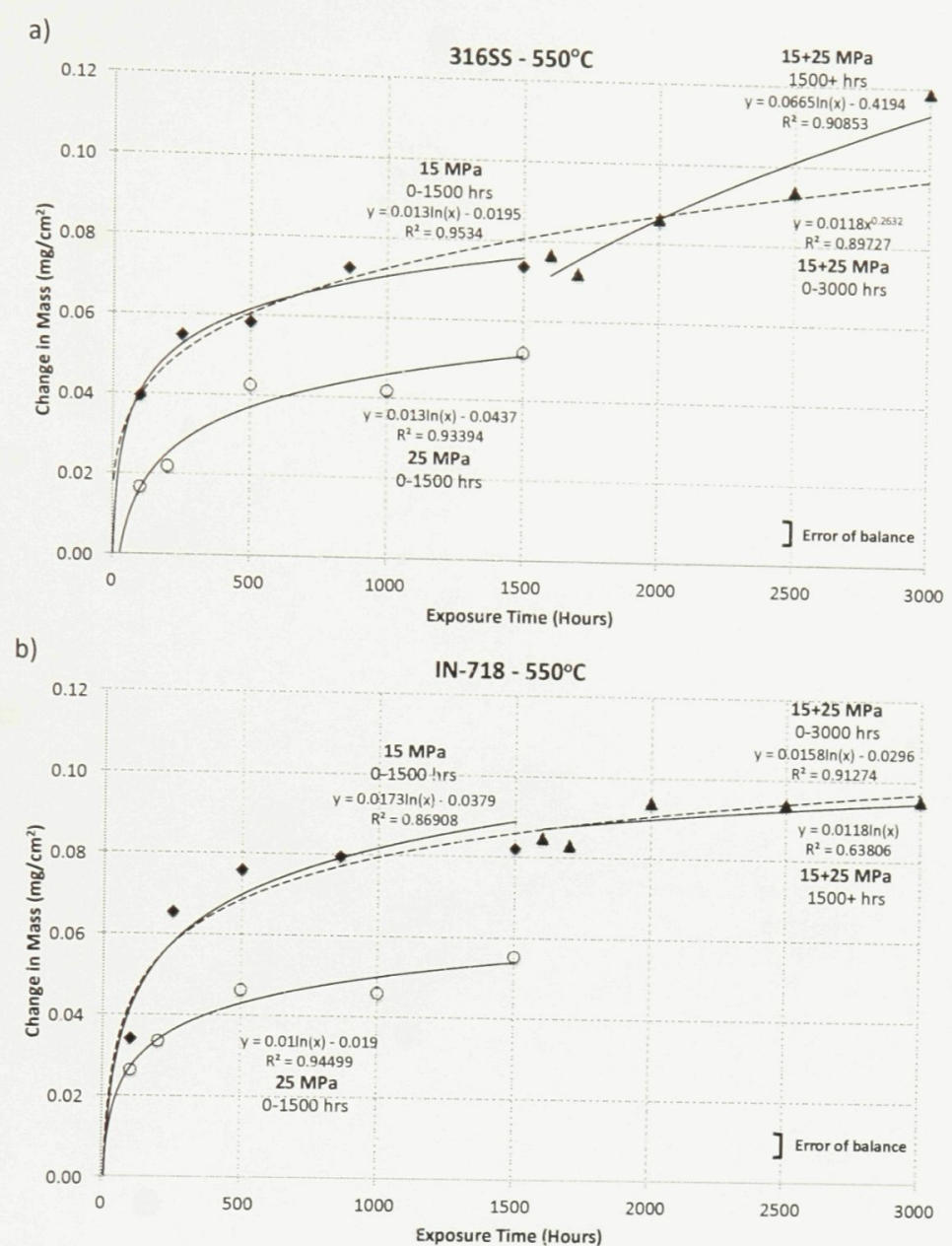

c)

IN-738 $-550^{\circ} \mathrm{C}$

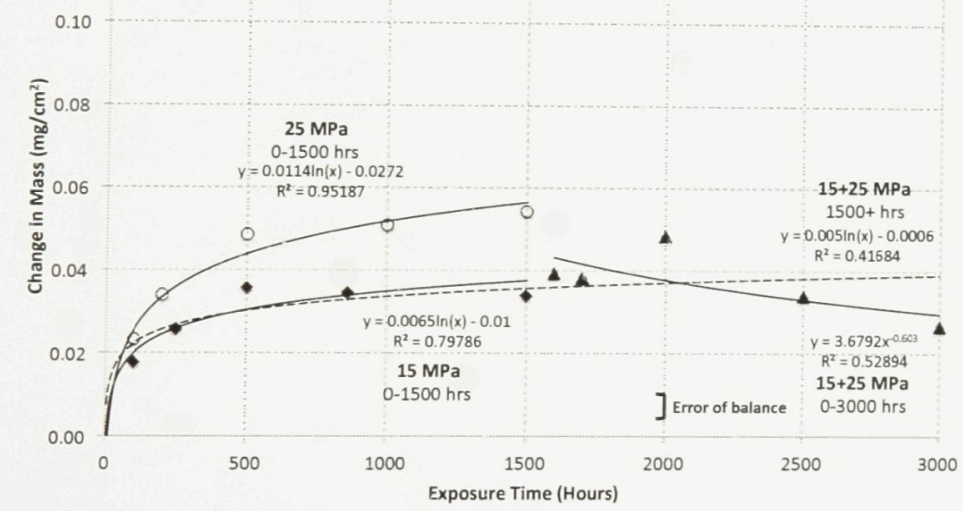

Figure 42: Weight change comparison of 316SS, IN-718, and IN-738 based pressure at $550^{\circ} \mathrm{C}$ for 3000 hours. The plotted weight gain value at each time interval represents the average weight gain for each alloy at that point in time. The dashed line is a trend line that includes the coupons from the first 1500 hours at $15 \mathrm{MPa}$, and also the remaining coupons that saw an increase in pressure to $25 \mathrm{MPa}$ for the remaining 1500 hours. 

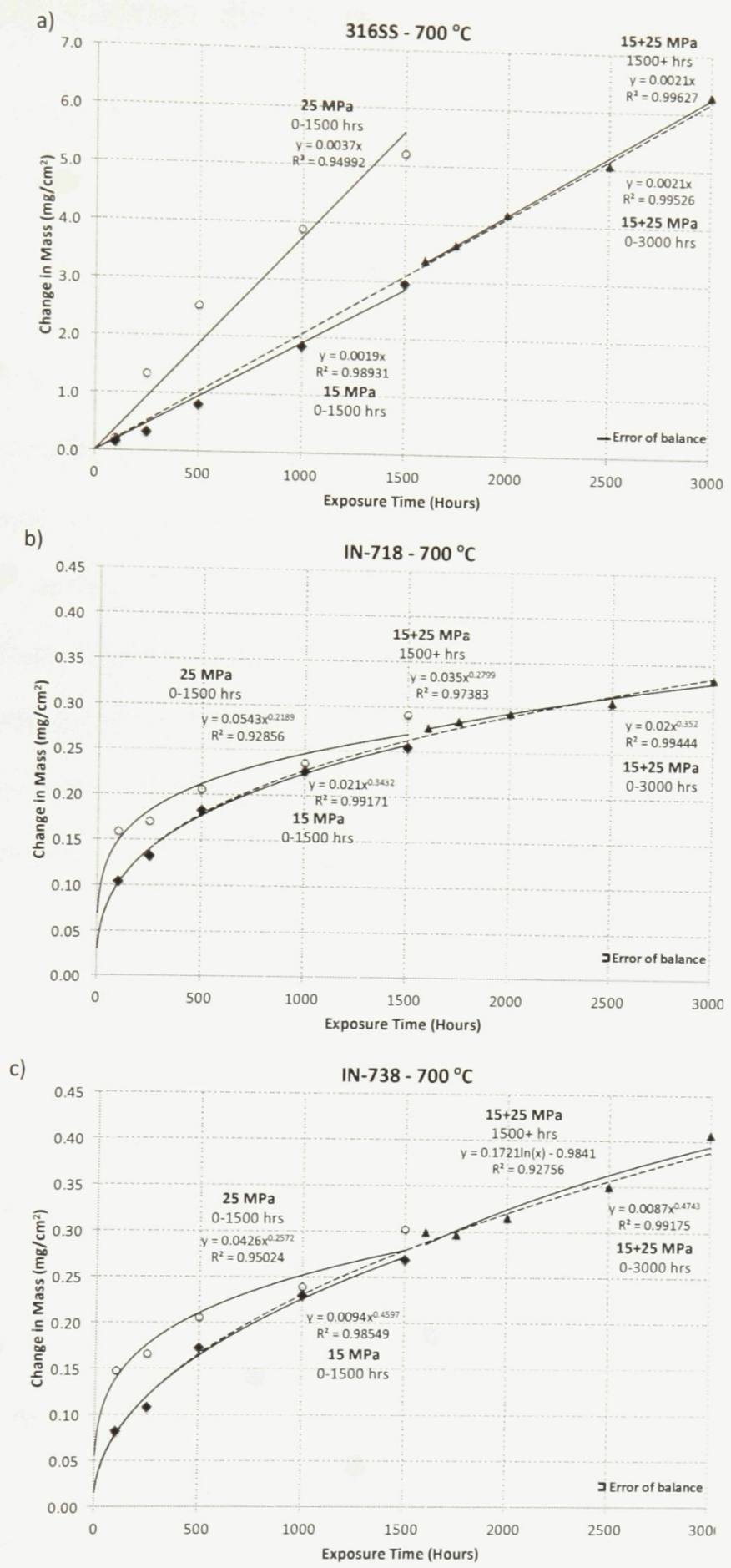

Figure 43: Weight change comparison of 316SS, IN-718, and IN-738 based on pressure at $700^{\circ} \mathrm{C}$ for 3000 hours. The plotted weight gain value at each time interval represents the average weight gain for each alloy at that point in time. The dashed line is a trend line that includes the coupons from the first 1500 hours at $15 \mathrm{MPa}$, and also the remaining coupons that saw an increase in pressure to $25 \mathrm{MPa}$ for the remaining 1500 hours. 


\subsection{Oxide Cross Section Characterization}

A set of coupons that had been exposed for at least 1500 hours were chosen for analysis using the Tescan VegaII XMU scanning electron microscope (SEM) at Carleton University. This section highlights the features found for each of the three alloys based on visual inspection, in addition to an elemental analysis using an Oxford Inca Engery 250X EDS.

The selected coupons were sectioned with a precision diamond saw and prepared to a 600-grit finish using $\mathrm{SiC}$ abrasive paper. Some coupons, including IN-738 and IN-718 presented in this work, were also polished with a TexMet wheel prior to examination Included are images produced at magnifications ranging from 60-7000x using secondary electron imaging for interpretation of oxide growth magnitude and structure. Four points were also chosen throughout the oxide and metal cross section for compositional analysis to determine diffusion mechanisms that occurred throughout testing.

\subsubsection{SS}

316SS experienced the largest amount of oxide growth amongst the three test alloys. Based solely on weight gain data, 316SS produced an unstable and unprotective oxide at high temperatures that was insufficient in acting as a barrier to ion transport. These qualities can be attributed to a porous oxide or one that is susceptible to cracking from thermal cycling. Figure 44 is a SEM image of a 316SS sample after 3000 hours at $700^{\circ} \mathrm{C}$. As expected for austenitic stainless steels, a duplex oxide layer was formed, consisting of a porous and uneven exterior layer. The porous iron oxide layer, in conjunction with a more narrow inner chromia oxide layer were insufficient in providing the protective barrier against oxidation.

The Au-Pd coating that was applied to a portion of the samples was unable to be 
seen, but the alloy surface appears to be severely deformed from the original straight surface.

Images of other samples were very similar to these results and were not included. For this reason, it can be interpreted as the duplex iron-chromia oxide formed at temperatures of $550^{\circ} \mathrm{C}$ is a sufficient barrier to ion transport, but is insufficient at temperatures above $700^{\circ} \mathrm{C}$.
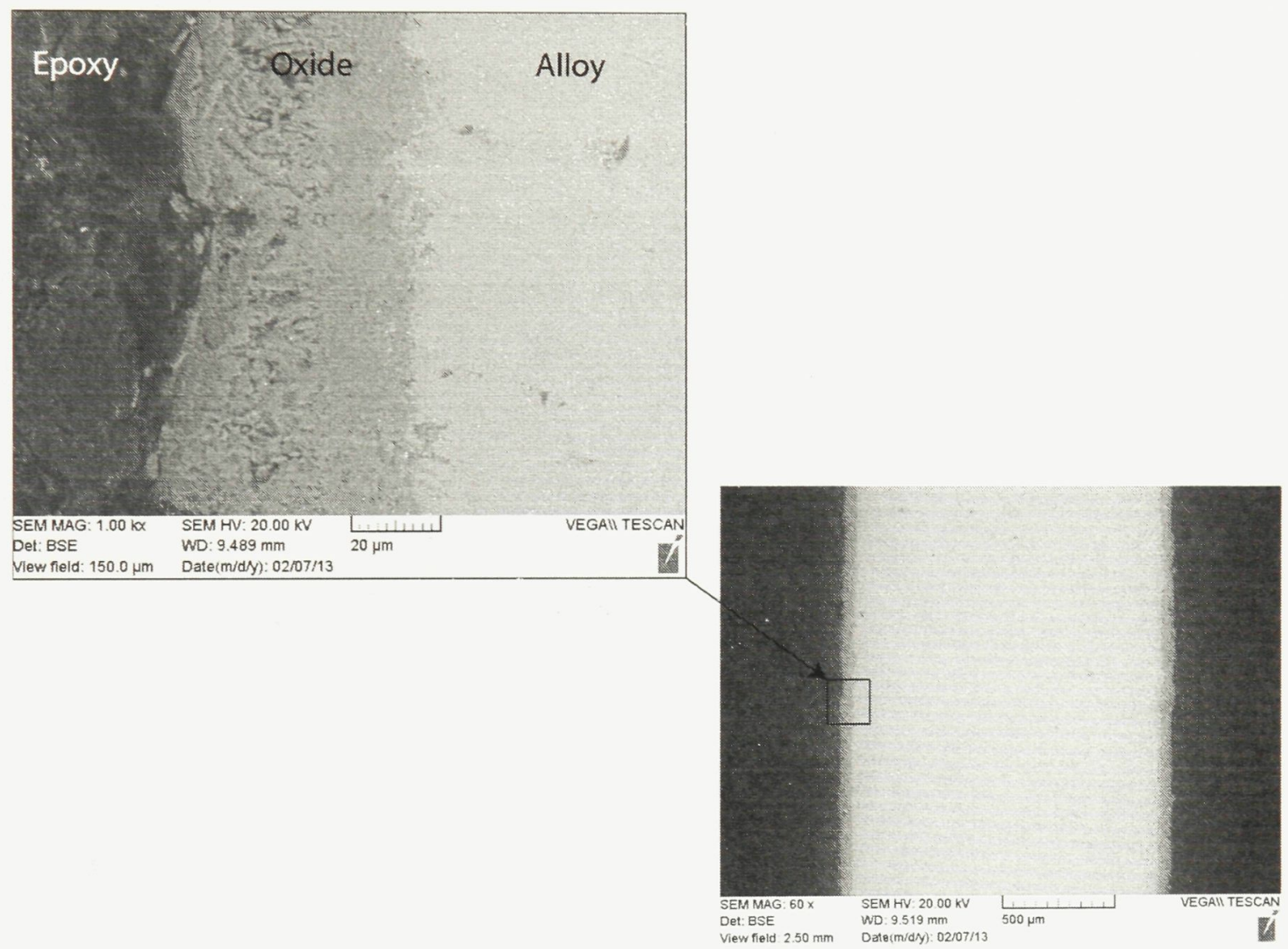

Figure 44: 316SS sample 121 cross section after 3000 hours at $700^{\circ} \mathrm{C}, 15 / 25 \mathrm{MPa}$.

As shown in Figure 45, four horizontal points were chosen across the oxide and metal cross section for compositional analysis. The results of this analysis are illustrated in the energy-dispersive X-ray (EDX) spectrum in the same figure. Furthermore, dominating elements have been plotted as a function of location in Figure 46. These results confirm the expected concentration of iron in forming the iron 
oxide (magnetite) as the exterior oxide, with an inner oxide of predominantly chromia oxide. Within the metal, concentrations of iron and chromium both increase to nominal composition quantities with distance from the oxide. This confirms further expectations of iron and chromium being depleted from the metal through diffusion.

It should be noted that the Oxford Inca Engery 250X EDS is not capable of accurately identifying the quantity of elements of atomic number below, and including oxygen. For this reason, the quantities of carbon and oxygen were only compared relative to each point as tabulated in Table 12. This analysis provided reason to believe carburization had occurred due to significant amount of carbon present at the surface and decreased with distance from the surface. Oxygen was also concentrated within the oxide layers, as expected. 


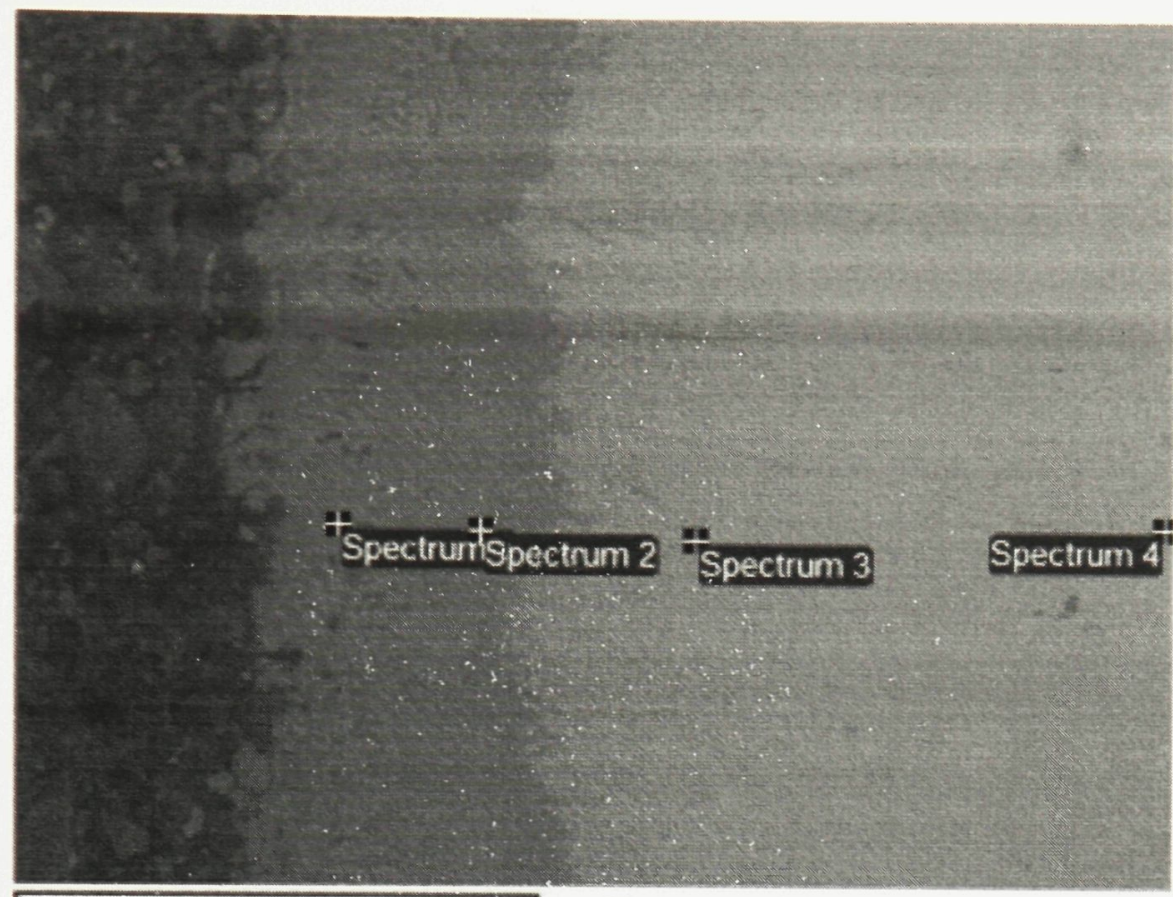

100um

Electron imade 1

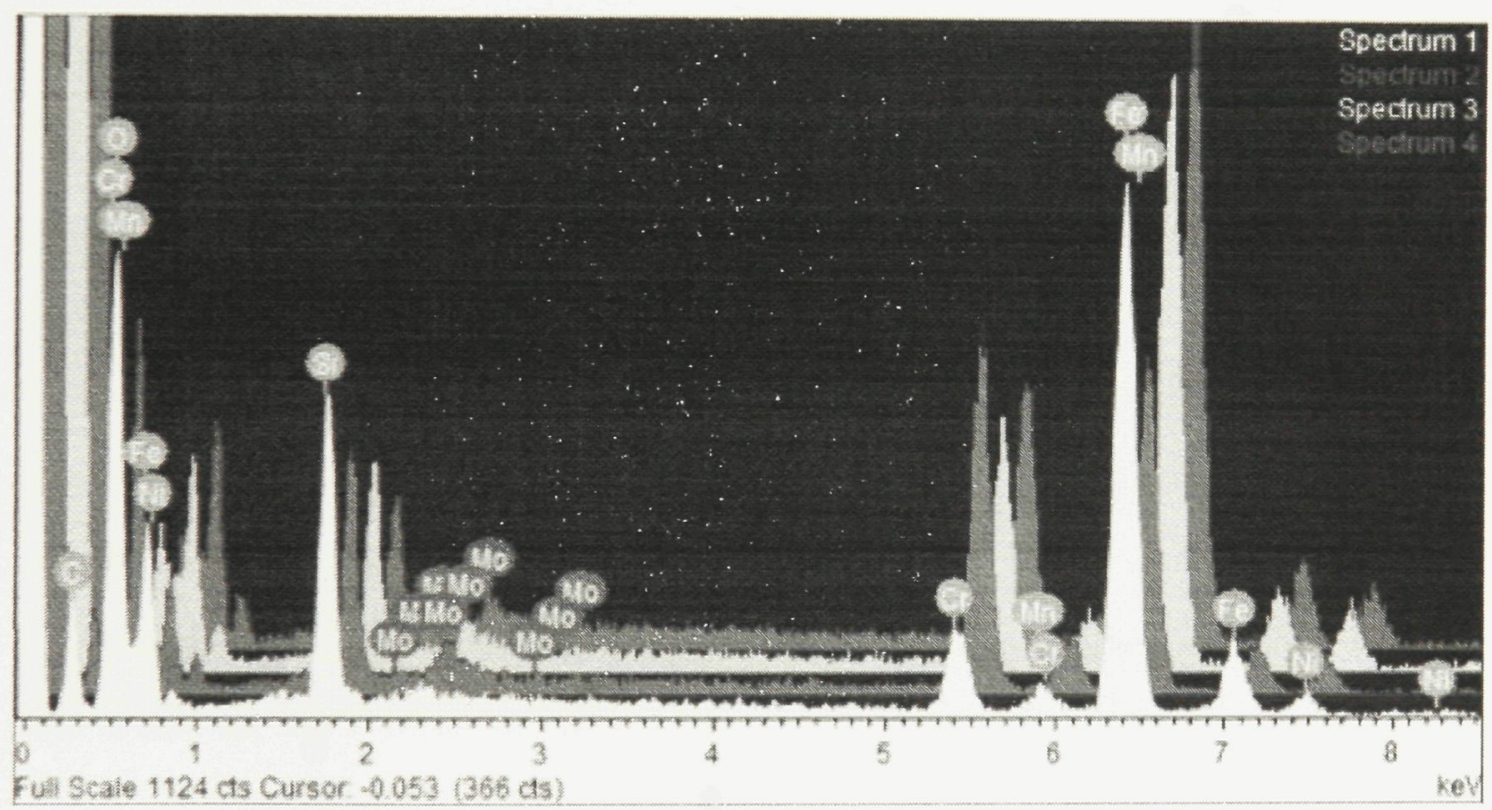

Figure 45: Elemental scan of 316SS sample 121. 


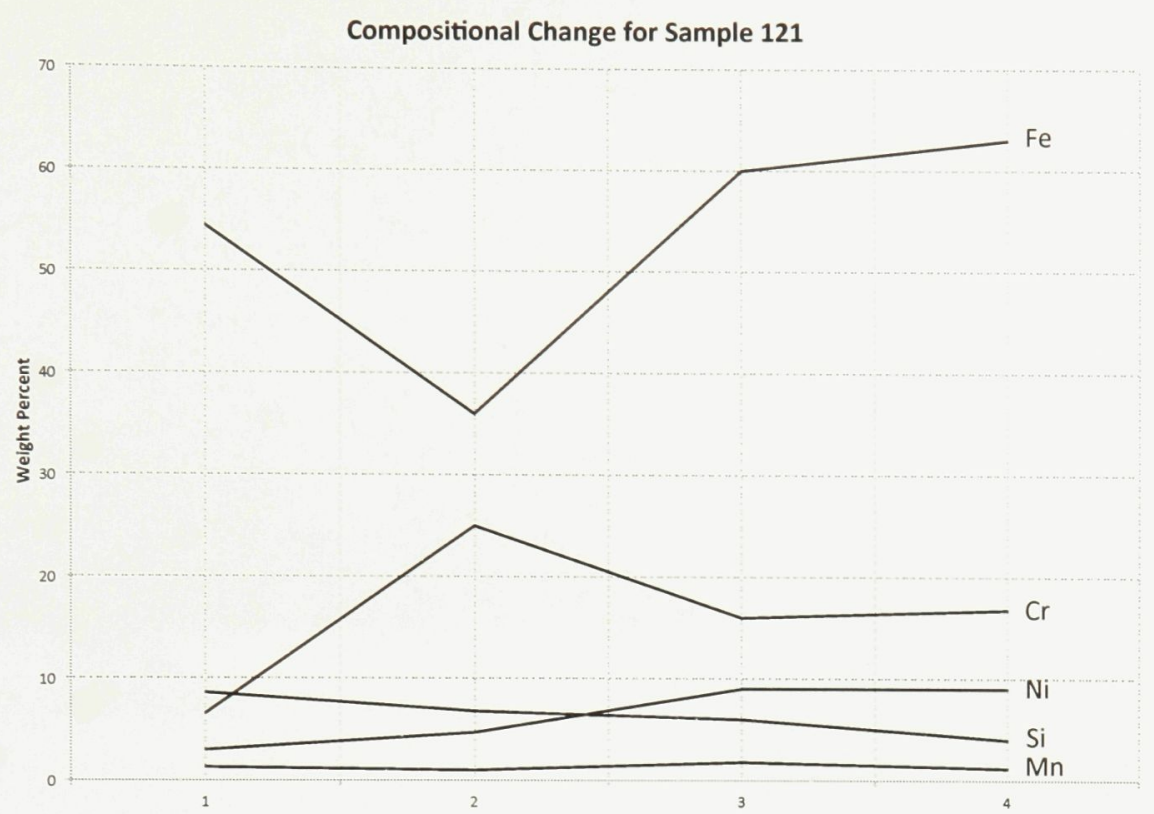

Figure 46: Composition based on varying position of 316SS sample 121.

\subsubsection{IN-718}

Figure 47 is a SEM image of a IN-718 sample after 3000 hours of exposure at $700^{\circ} \mathrm{C}$. The amount of oxide is significantly smaller than that produced with 316SS, which is expected based on weight gain data. Although smaller, the combination of nickel, chromium, and iron created a stable and continuous protective oxide that was a sufficient barrier against ion transport.

An elemental analysis is provided in Figure 48 where higher levels of chromium were found on the exterior of the oxide. 


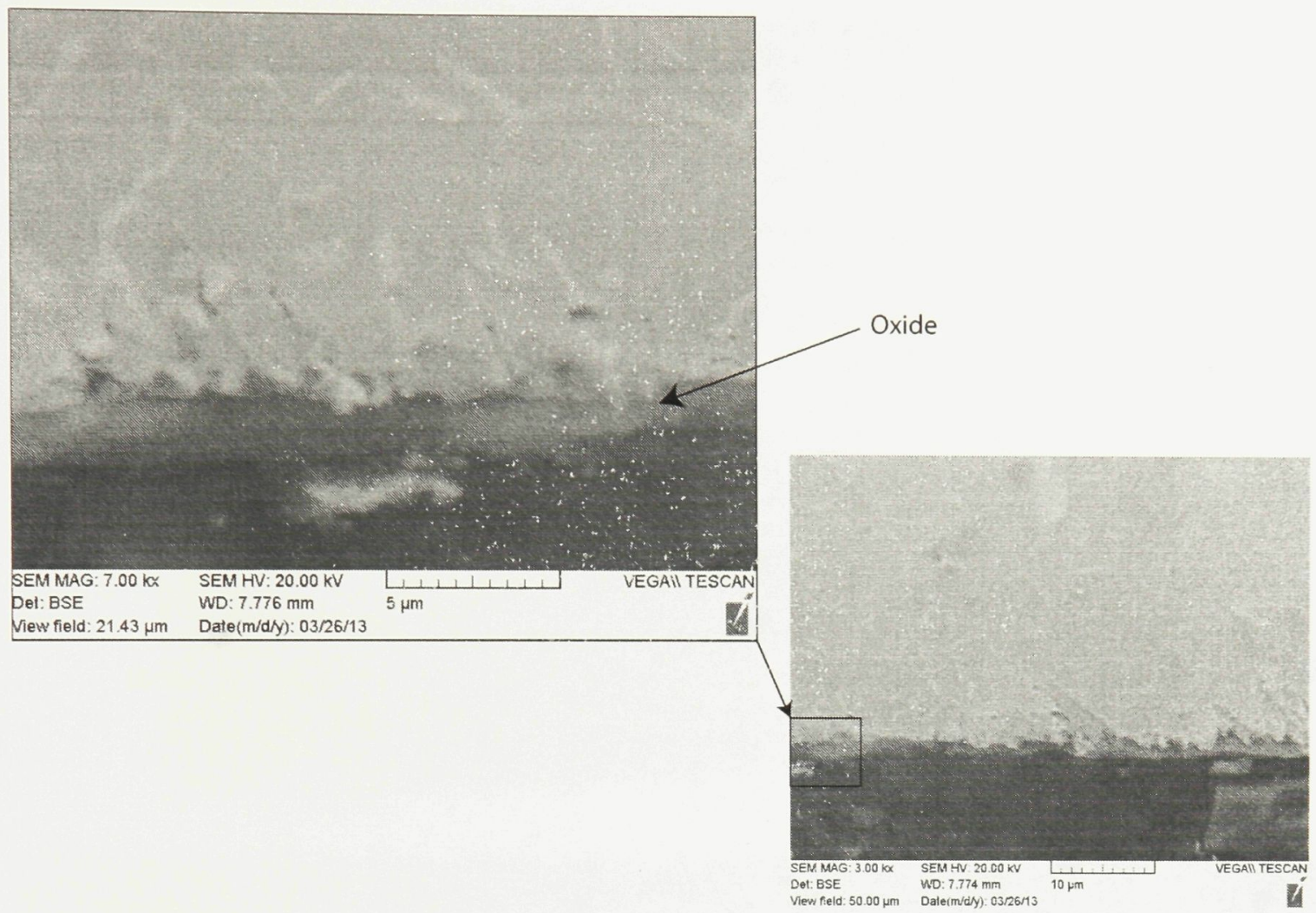

Figure 47: IN-718 sample 221 at $3000 \mathrm{x}$ and $7000 \mathrm{x}$ after 3000 hours at $700^{\circ} \mathrm{C}$ at 15 and $25 \mathrm{MPa}$.

Within the sample, concentrations of nickel, chromium, and iron varied near the surface of the alloy. An increase in chromium was found within the oxide layer, while nickel and iron increased with distance from the oxide layer. Beyond the main oxide/metal interface, the composition of the alloy did not vary significantly, which leads to speculation that the protective oxide was effective in blocking cation diffusion from depleting the substrate of nickel, iron, and chromium. Carburization was also observed based on the $50 \%$ reduction of carbon from locations 1 to 4 of Figure 49 . 


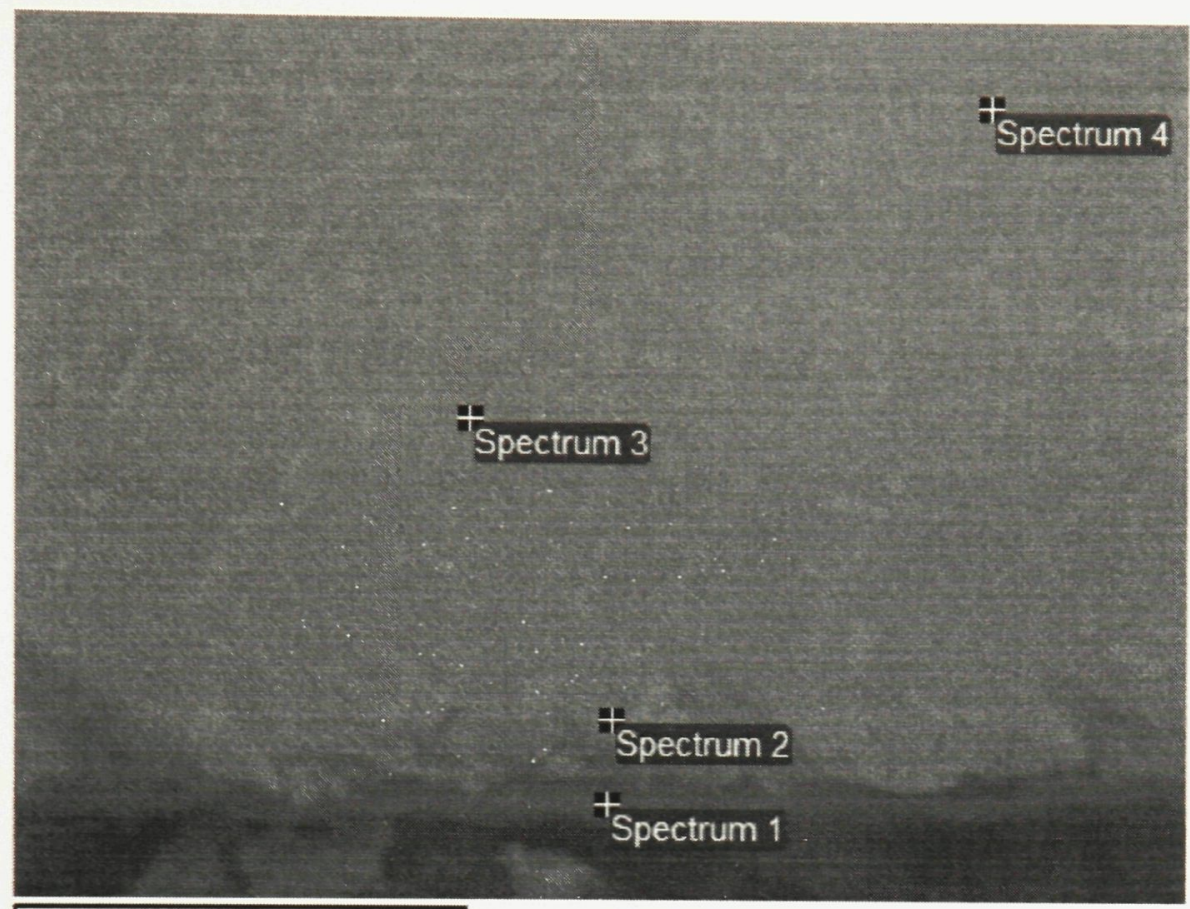

20um

Electron Image 1

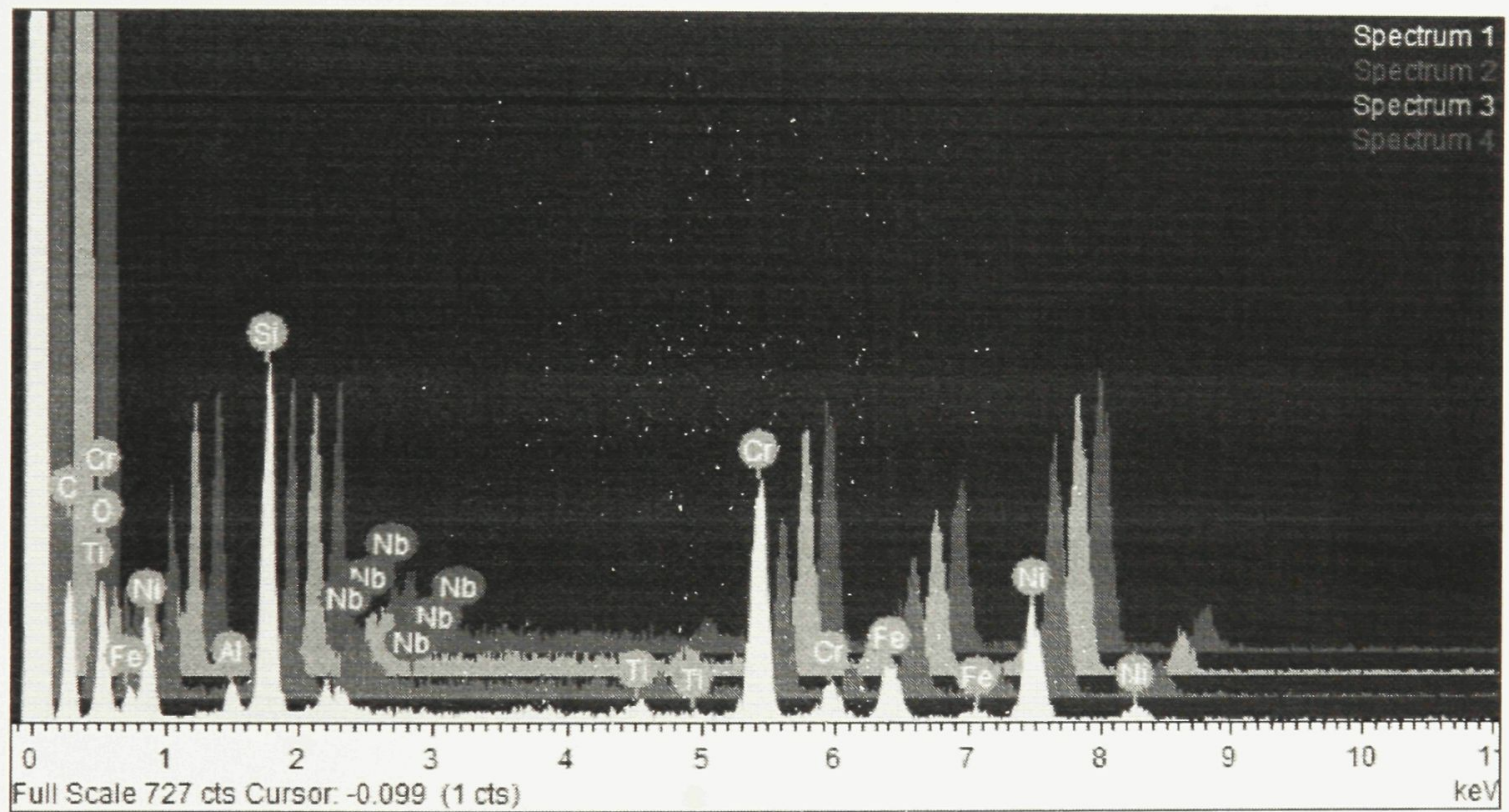

Figure 48: Elemental scan of IN-718 sample 221. 


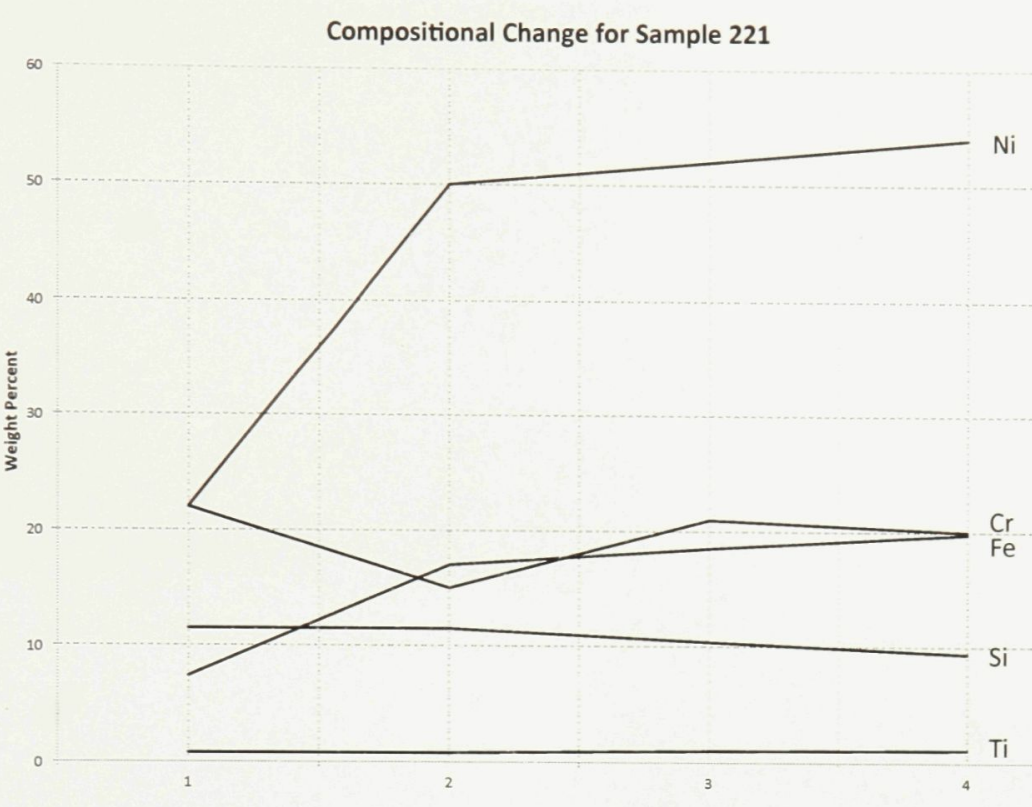

Figure 49: Composition based on varying position of IN-718 sample 221.

\subsubsection{IN-738}

IN-738 exhibited the best qualities in overall corrosion resistance amongst the test conditions due to the efficient formation of a stable and protective barrier against ion transport. Figure 50 is an IN-738 sample that was exposed to $\mathrm{S}-\mathrm{CO}_{2}$ for 3000 hours at $700^{\circ} \mathrm{C}$. At magnifications of $2000 \mathrm{x}$ and $7000 \mathrm{x}$, the oxide layer is sufficiently small but uniform with good adhesion. Beneath the oxide layer is significant evidence of intergranular corrosion. Although the oxide layer was effective for the tested 3000 hours, these results leave reason to believe that the oxide will eventually fail due to a deteriorating substrate. Longer testing would be required to characterize the effect of intergranular corrosion in IN-738. 


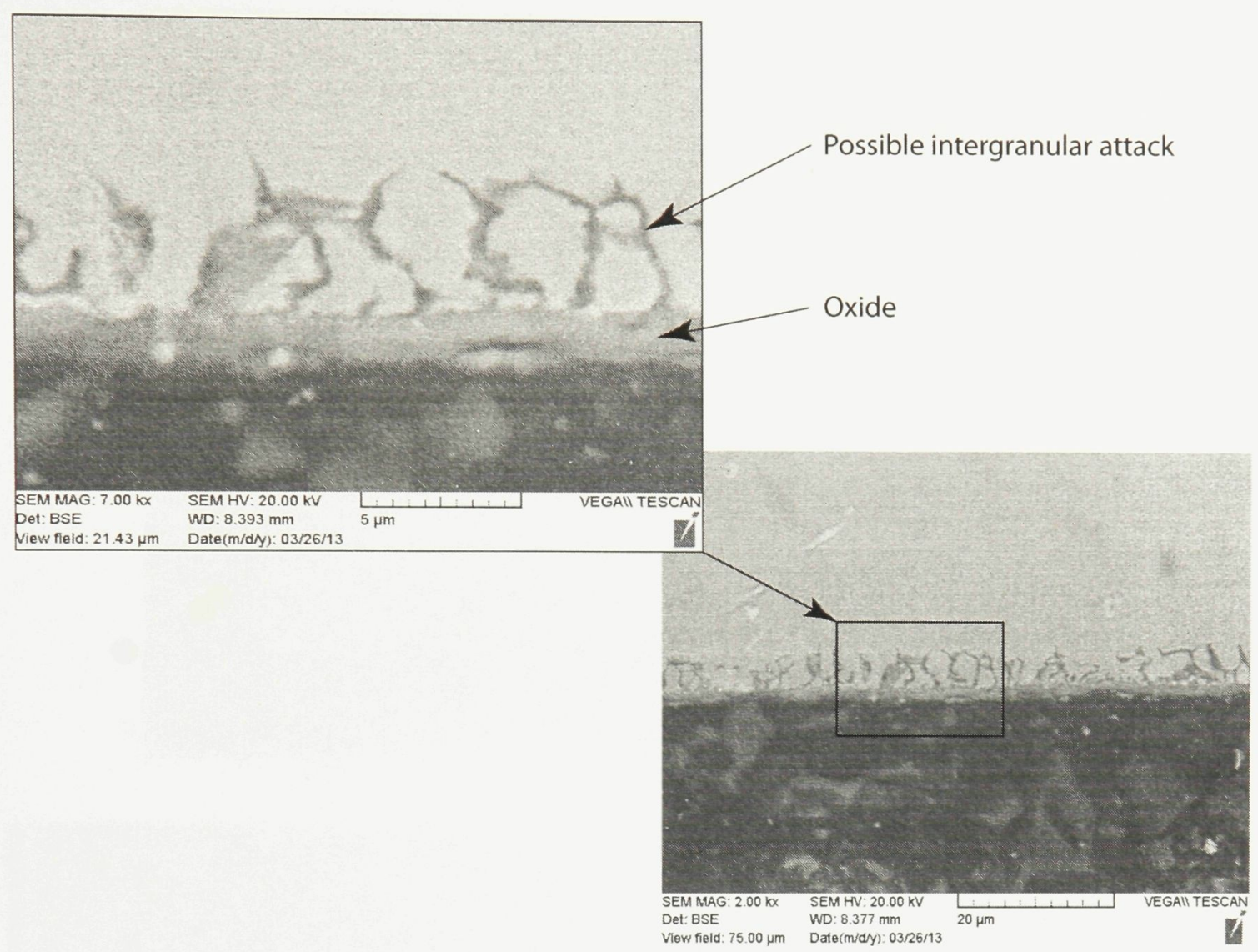

Figure 50: IN-738 sample 321 at 2000x and $7000 \mathrm{x}$ after 3000 hours at $700^{\circ} \mathrm{C}$ at 15 and $25 \mathrm{MPa}$.

A compositional analysis was conducted at select points varying in position from the oxide to inner alloy cross-section. The results of this study are plotted in Figure 51. In comparison to IN-718, IN-738 experienced a similar trend with little depletion of nickel and chromium in the formation of a protective oxide. This can be due to the dominating amount of nickel present in the alloy that, in conjunction with chromium and silicon, that rapidly and efficiency produce an oxide before further attack can take place. 

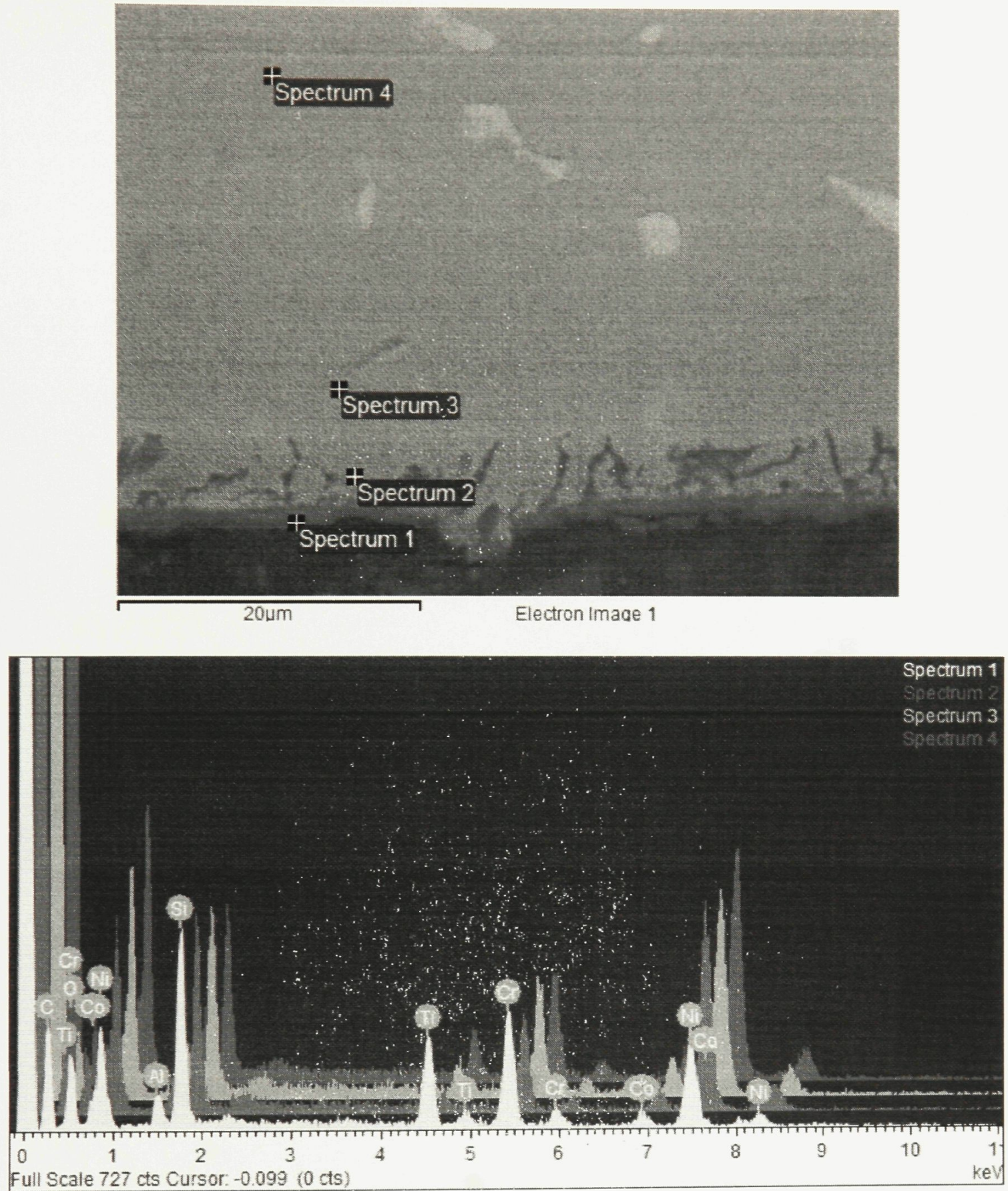

Figure 51: Elemental scan of IN-738 sample 321. 


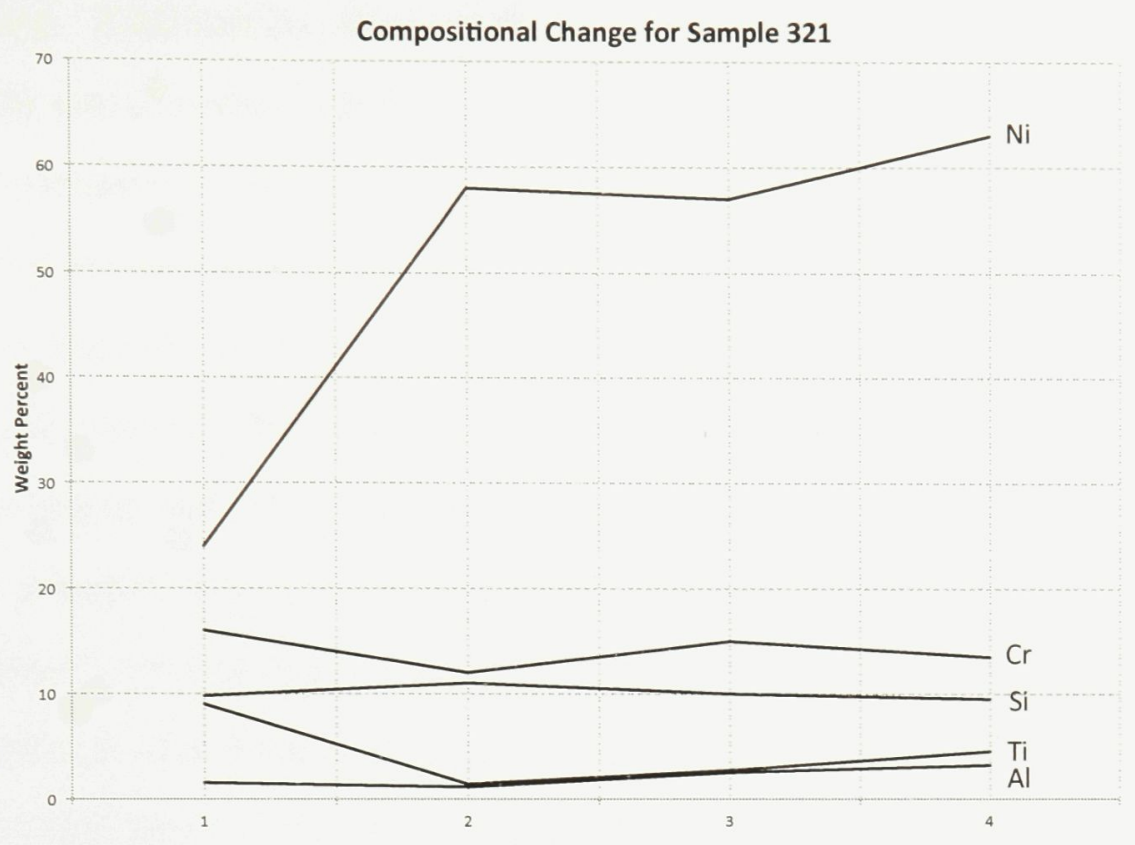

Figure 52: Composition based on varying position of IN-738 sample 321.

\begin{tabular}{lccccc} 
& & \multicolumn{4}{c}{ Sampling Point } \\
\hline Alloy & & 1 & 2 & 3 & 4 \\
\hline 316SS & $\mathrm{C}$ & 1.6 & 1.4 & 1.3 & 1.0 \\
& $\mathrm{O}_{2}$ & 7.1 & 5.4 & 1.7 & 1.0 \\
\hline IN-718 & $\mathrm{C}$ & 1.5 & 1.2 & 1.0 & 1.0 \\
& $\mathrm{O}_{2}$ & 1.9 & 1.3 & 1.0 & 1.0 \\
\hline IN-738 & $\mathrm{C}$ & 1.4 & 1.3 & 1.2 & 1.0 \\
& $\mathrm{O}_{2}$ & 2.6 & 1.6 & 1.3 & 1.0 \\
\hline
\end{tabular}

Table 12: Variation of carbon and oxygen from sample cross-section, normalized to inner sampling point.

\subsubsection{Summary of Results}

The three alloys that were tested, 316SS, IN-718, and IN-738, exhibited varying degrees of corrosion resistance under the four different combinations of pressure and 
temperature. Additionally, in an effort to monitor corrosion of the pressure vessel, two IN-625 samples were added to the specimen boat for the entire testing period and were compared to results obtained from the other alloys.

At the lower temperature of $550^{\circ} \mathrm{C}$, all alloys quickly produced a protective oxide based on a logarithmic weight gain trend. This relation correlates to an immediate formation of oxide that begins to slow further oxidation by preventing further diffusion of oxygen anions and metal cations. Alloys 316SS and IN-718 reacted similarly for each test pressure, where more oxide was formed at the higher pressure of $25 \mathrm{MPa}$. This increase is oxide growth at a higher pressure can be attributed to the increase in partial pressure of oxygen that increases the thermodynamic ability of an oxidizing reaction to take place. This relation is characterized by Gibbs free energy and related to oxide formation through the Ellingham Diagram of Figure 12. In contrast, IN-738 produced less oxide at the higher pressure, outperforming the other alloys by a factor of two. The IN-738 oxide layer appears to be significantly better protection from the beginning, and should be due to the difference in alloying elements, predominantly iron. Iron oxides are known to grow at faster rates than other oxides such as, chromia oxide. Due to significant amounts of compositional iron in IN-718 and 316SS relative to IN-738, the rapid growth of iron oxides could attribute to the increased weight.

At $700^{\circ} \mathrm{C}$, the IN-718 and IN-738 alloys followed a very similar trend in oxide growth at each pressure. Within 500 hours, both alloys quickly produced a protective oxide layer that was effective in slowing the oxidation reaction, illustrated by a parabolic growth rate relation that accumulates to approximately $0.275 \mathrm{mg} / \mathrm{cm}^{2}$ after 1500 hours. It is clear that the additional alloying elements present in the superalloys, notably nickel and silicon, provide the means to produce a stable oxide layer at high temperatures in $\mathrm{S}-\mathrm{CO}_{2}$. The oxidation mechanism present in IN-718 at lower temperatures, most likely due to iron content, does not appear to be a mechanism at $700^{\circ} \mathrm{C}$ due to similarity with IN-738. In contrast, 316SS resulted in unfavourable linear 
growth rate relations at both pressures at $700^{\circ} \mathrm{C}$. This can be attributed to the instability of the duplex iron-chromia-oxide scale exhibited by austenitic stainless steels where porosity and spallation lead to continuous oxide growth. These results correlate with previous testing at lower temperatures and pressures from Gibbs (2010) [7] and Dunlevy (2007) [6], except less distinction between 316SS and nickel-base superalloys was found at a temperature of $610^{\circ} \mathrm{C}$. Some of these results are included as a comparison in Figures 53 and 54 below. Together, these results find evidence that the limiting temperature for corrosion resistance of $316 \mathrm{SS}$ lies within $550-650^{\circ} \mathrm{C}$ and further testing is required to understand the upper limiting temperature of $316 \mathrm{SS}$.

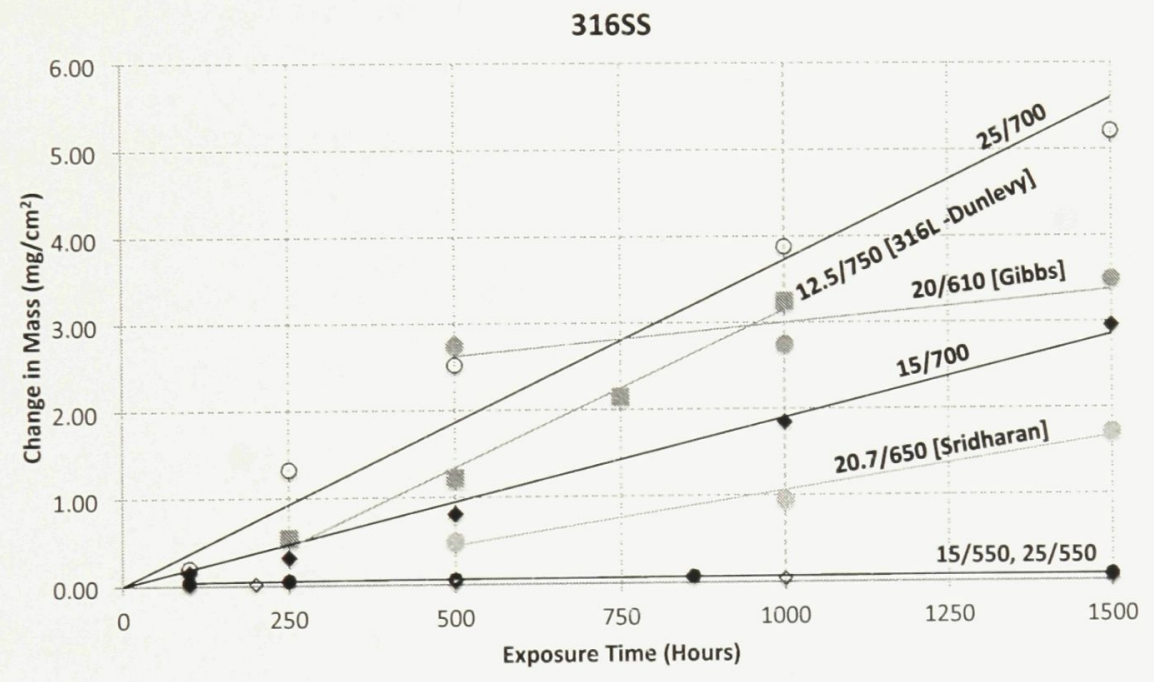

Figure 53: Comparison of corrosion studies for $316 \mathrm{SS}$ in $\mathrm{S}_{-} \mathrm{CO}_{2}$. 


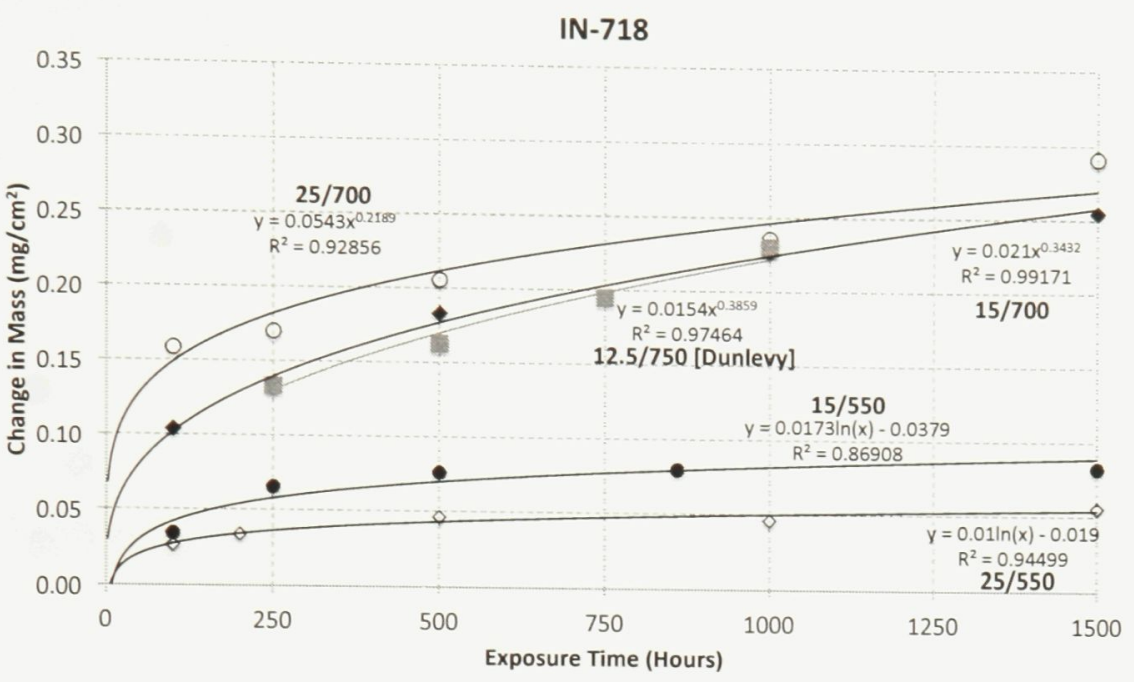

Figure 54: Comparison of corrosion studies for IN-718 in $\mathrm{S}-\mathrm{CO}_{2}$.

Cross-sectional SEM and elemental analysis provided evidence of an expected duplex oxide for the 316SS samples, with depletion of chromium and iron within the substrate. The continual diffusion of chromium and iron to the surface and subsequent oxidation would eventually deplete the substrate of these elements and any means of protection against further oxidation. In comparison, IN-718 and IN-738 produce a thin and continuous oxide layer on the order of $1 \mu \mathrm{m}$, consistent with results obtained by Dunlevy (2007) [6]. The micrographs also illustrated extensive intergranular corrosion present in the IN-738 samples that could lead to eventual failure of the protective oxide scale due to deteriorating substrate. Evidence of intergranular corrosion in nickel-base superalloys has also been found in testing of IN-617 at $1000^{\circ} \mathrm{C}$ and is an attribute that needs to be investigated through use of longer term testing [38]. 


\section{Chapter 5}

\section{Conclusions}

\subsection{Overview}

The Carleton-NRCan corrosion test rig was used to test three alloys under $\mathrm{S}_{-} \mathrm{CO}_{2}$ conditions for up to 3000 hours. Six sets of five samples of each alloy were used to evaluate material compatibility for temperatures of $550^{\circ} \mathrm{C}$ and $700^{\circ} \mathrm{C}$, and pressures of $15 \mathrm{MPa}$ and $25 \mathrm{MPa}$. The purpose of the testing was to understand the kinetics of oxide growth and its dependance on temperature and pressure, while identifying limitations for alloys in $\mathrm{S}_{-} \mathrm{CO}_{2}$. Four sample sets of each alloy were each exposed to one-of-four combinations of temperature and pressure for 1500 hours, while the remaining ten samples experienced an increase in pressure from $15 \mathrm{MPa}$ to $25 \mathrm{MPa}$ midway through a 3000 hour test.

The three alloys that were tested included: austenitic stainless steel 316, ironnickel base superalloy 718 , and nickel base superalloy 738 . Thirty samples of each alloy were prepared into $12.7 \mathrm{~mm}$ diameter coupons and finished with 600-grit $\mathrm{SiC}$ abrasive paper in an effort to replicate as-received surface condition in industry.

Testing was stopped in intervals of 100, 250, 500, 1000, and 1500 hours where each sample was photodocumented and weighed. These results provided information for analysis of kinetics of oxide growth for each alloy. Further characterization consisted 
of the sectioning of select samples for SEM and elemental analysis.

\subsubsection{Weight Gain}

Under conditions of $550^{\circ} \mathrm{C}$, all three alloys produced a protective oxide layer following a logarithmic weigh gain trend. The oxide layer of 316SS consisted of a duplex iron and chromia oxide, that although porous, was effective in acting as a barrier to ion migration. 316SS and IN-718 exhibited similar weight gain trends, while IN-738 instantly grew an oxide layer with roughly half as much weight change.

When considering testing at $700^{\circ} \mathrm{C}, 316 \mathrm{SS}$ experienced a linear weight gain trend, which is indicative of possible cracking or spallation of the oxide. From these results, it can be concluded that $316 \mathrm{SS}$ is not compatible with $\mathrm{S}-\mathrm{CO}_{2}$ environments reaching $700^{\circ} \mathrm{C}$ due to excessive corrosion.

In contrast, both IN-718 and IN-738 efficiently produced protective oxide layers with a total weight gain of roughly $0.25 \mathrm{mg} / \mathrm{cm}^{2}$ after 1500 hours at $700^{\circ} \mathrm{C}$ and $15 \mathrm{MPa}$. Based on all test conditions, both IN-718 and IN-738 were found to be acceptable for tested $\mathrm{S}-\mathrm{CO}_{2}$ conditions.

The dependance on pressure was evident in an increased weight gain rate for the initial 250 hours of testing. The distinction is clear from testing at $700^{\circ} \mathrm{C}$ that $50 \%$ more oxide was formed in the first 100 hours of testing at $25 \mathrm{MPa}$ than at $15 \mathrm{MPa}$, but after 1500 hours, there was negligible difference in total oxide produced between the two pressures. Further analysis included subjecting samples to an increase in pressure midway through a 3000 hour test. All of the alloys exhibited a slight increase in weight during the 1500-1600 time interval based on individual sample plots, but the increase in weight was indistinguishable when averaged results were plotted. 


\subsubsection{Oxide Growth}

Oxide growth was also characterized through the use of a scanning electron microscope. SEM micrographs and EDX elemental analysis were conducted on samples that we exposed to at least 1500 hours.

The porous and discontinuous iron and chomia oxide produced by 316SS was found to be ineffective at high temperatures. Elemental analysis verified the concentration of iron on the exterior of the oxide, while chromium was focused on the inner oxide. Both iron and chromium were found depleted from the outer surface of the alloy, while carbon concentration significantly increased towards the surface. After 1500 hours of testing at $700^{\circ} \mathrm{C}$, a discontinuous and rough surface was observed on the 316SS samples.

Due to significant addition of nickel and chromium in alloys IN-718 and IN-738, the oxide produced was: stable, adherent, and an order of magnitude smaller than 316SS. These results correlate with previous testing of IN-718, where a thin film oxide of approximately $1 \mu \mathrm{m}$ is produced in $\mathrm{S}-\mathrm{CO}_{2}$. Further inspection of IN-738 found evidence of intergranular corrosion beneath the oxide layer, leading to speculation that the oxide layer will eventually fail. Longer term testing is required to determine the effect of the intergranular corrosion on the IN-738 oxide layer.

\subsection{Future Work}

The scope of the work discussed provides an initial look at the compatibility of three alloys and their corrosion resistance in four different environments. Further testing and analysis is required to fully understand the mechanics of the oxide growth in an effort to build an accurate model for corrosion in $\mathrm{S}_{-} \mathrm{CO}_{2}$. Some noteworthy items of future work are included as: 
- Stress-state: the most accurate method to test materials prior to application is under realistic conditions, which should include state of stress. Previous research has shown materials under stress can be subject to more severe corrosion than non-stressed. Stress can consist of tensile, compressive, or fatigue loading that can lead to excessive corrosion and premature failure. With the acceptance on IN-718 and IN-738 under the tested conditions, further testing should take place under replicated stress conditions.

- Temperature: the test conditions resulted in a dramatic differentiation in weight gain between $550^{\circ} \mathrm{C}$ and $700^{\circ} \mathrm{C}$. Further analysis should be done to correlate temperature to oxide growth at temperatures within this region. This can be especially important for 316SS, where the limiting temperature for corrosion resistance exists within the tested temperature range.

- Pressure: the results presented indicate some dependance on pressure for corrosion resistance. Significant variation in pressure can exist in applications such as the Brayton cycle gas turbine. For this reason, further testing should be conducted through the use of more samples at smaller test intervals in the 0-500 hour range.

- Flow: all testing conducted can be considered static due to the negligible flow rate of $1 \mathrm{~L} / \mathrm{hr}$ within a relatively large pressure vessel. At flows that can be experienced within a gas turbine, other corrosion mechanisms such as, erosion, can lead to detrimental consequences.

Beyond these characteristics, there exists a significant need for corrosion data for longer periods of time. Testing of more than 10,000 hours would offer valuable results as to corrosion of materials exposed to $\mathrm{S}-\mathrm{CO}_{2}$ for more than a year. Ideally, many samples are used throughout the testing that can be sectioned at each time interval 
to evaluate oxide thickness and composition in order to correlate oxide thickness to weight gain. This information would provide the data necessary in the development of a corrosion model for materials in $\mathrm{S}-\mathrm{CO}_{2}$ that could be used for predicting corrosion and service life of alloys under operational conditions. 


\section{List of References}

[1] D. Lane. "Brayton Cycle: The Ideal Cycle for Gas-Turbine Engines In Relation to Power Plants." Reno: University of Nevada pages 1-15 (2001).

[2] S. A. Wright, T. M. Conboy, and G. E. Rochau. "Overview of Supercritical CO2 Power Cycle Development at Sandia National Laboratories." Technical report (2011).

[3] V. Dostal. A supercritical carbon dioxide cycle for next generation nuclear reactors. Ph.D. thesis, Massachusetts Institute of Technology (2004).

[4] M. A. Jacobs. Measurement and Modeling of Thermodynamic Properties for the Processing of Polymers in Supercritical Fluids. Ph.D. thesis, Technische Universiteit Eindhoven (2004).

[5] "Mechanical and Aerospace Engineering 4th Year Project - Brayton Cycle Design." Technical report, Carleton University, Ottawa.

[6] M. Dunlevy. An Exploration of the Effect of Temperature on Different Alloys in a Supercritical Carbon Dioxide Environment. Master's thesis, Massachusetts Institute of Technology (2009).

[7] J. P. Gibbs. Corrosion of Various Engineering Alloys in Supercritical Carbon Dioxide. Master's thesis, Massachusetts Institute of Technology (2010).

[8] M. J. Donachie and S. J. Donachie. Superalloys - A Technical Guide. ASM International, 2nd edition (2002).

[9] R. G. Petrusenko. The Development of a High Temperature Supercritical Carbon Dioxide Corrosion Test Rig. Master's thesis, Carleton University (2011).

[10] “316 - 3161 - 317 - 317l." Available at: http://www.stal.com.cn/pdffile/ 31631613173171.pdf. 
[11] "316/316L Stainless Steel - Data Bulletin." Technical report, AK Steel Corporation, West Chester, OH (2007).

[12] E. Mattsson. Basic Corrosion Technology for Scientists and Engineers. IOM Communications Ltd, 2nd edition (1996).

[13] N. Binks, G. H. Heier, and F. Pettit. High Temperature Oxidation of Metals. Cambridge University Press, New York (2006).

[14] G. D. Smith and B. A. Baker. "High-Temperature Gases." ASTM Corrosion Testing and Standards pages 434-447 (2005).

[15] "Ellingham diagrams." Available at: http://web.mit.edu/2.813/01dFiles/ www/readings/Ellingham\_diagrams.pdf (2009).

[16] G. H. Meier, W. C. Coons, and R. A. Perkinst. "Corrosion of Iron-, Nickel-, and Cobalt-Base Alloys in Atmospheres Containing Carbon and Oxygen." Oxidation of Metals 17(3), 235-262 (1982).

[17] A. Kumar and D. L. Douglass. "Modification of the oxidation behavior of highpurity austenitic Fe-14Cr-14Ni by the addition of silicon." Oxidation of Metals 10(1), 1-22. ISSN 0030-770X (1976).

[18] R. Moore and T. Conboy. "Milestone Report - Metal Corrosion in a Supercritical Carbon Dioxide - Liquid Sodium Power Cycle." Technical report, Sandia National Laboratories, Albuquerque, New Mexico (2012).

[19] S. R. Shatynski. "The Thermochemistry of Transition Metal Carbides." Oxidation of Metals 13(2), 105-118. ISSN 0030-770X (1979).

[20] H. J. Grabke and M. Schutze. Corrosion by Carbon and Nitrogen - Metal dusting, carburization and nitridation. 41. Woodhead Publishing Limited, Cambridge, England (2007).

[21] K. Sridharan, M. Anderson, J. Jelinek, G. Cao, and V. Firouzdor. "Corrosion of Candidate Alloys in High Temperature Supercritical Carbon Dioxide." Technical report, University of Wisconsin-Madison (2011).

[22] E. Russick, G. Poulter, C. Adkins, and N. Sorensen. "Corrosive effects of supercritical carbon dioxide and cosolvents on metals." The Journal of Supercritical Fluids 9(1), 43-50. ISSN 08968446 (1996). 
[23] Y.-S. Choi, S. Nesic, and D. Young. "Effect of Impurities on the Corrosion Behavior of CO2 Transmission Pipeline Steel in Supercritical CO2-Water Environments." Environmental science \& technology 44(23), 9233-9238 (2010).

[24] J. E. Antill, K. A. Peakall, and J. B. Warburton. "Oxidation of Mild and Lowalloy steels in CO2 Based Atmospheres." Corrosion Science 8(February), 689 701 (1968).

[25] S. Wu. "EIS study of the surface film on the surface of carbon steel from supercritical carbon dioxide corrosion." Applied Surface Science 228(1-4), 17-25. ISSN 01694332 (2004).

[26] H. Loriers and D. Leclercq. "Corrosion Des Aciers Faiblement Allies dans Le Gaz Carbonique aux Temperatures Moyennes." Journal of Nuclear Materials 25, 144-159 (1968).

[27] G. Tappin, M. D. Division, and A. Energy. "The Oxidation of Dilute Iron-Silicon Alloys in Carbon Dioxide." Corrosion Science 22(2), 69-86 (1982).

[28] H. Li, J. Zhang, and D. J. Young. "Oxidation of FeSi, FeAl and FeSiAl alloys in CO2H2O gas at 800C." Corrosion Science 54, 127-138. ISSN 0010938X (2012).

[29] J. Lim, G. McKrell, E. Ballinger, and R.G. "Corrosion of Materials in Supercritical CO2 Environments." CORROSION 2008 Conference and Expo (2008).

[30] F. Rouillard, F. Charton, and G. Moine. "Corrosion behaviour of different metallic materials in supercritical CO2 at 550C and 250 bars." In "SCCO2 Power Cycle Symposium 2009," SCCO2 Power Cycle Symposium 2009, Troy, NY (2009).

[31] F. Rouillard, F. Charton, and G. Moine. "Presentation: Corrosion behaviour of different candidate steels in SuperCritical-CO 2 at $550 \mathrm{C}$ and 250 bars." In "Symposium on SCO2 Power Cycles," pages 1-27. Troy, NY (2009).

[32] T. Furukawa, Y. Inagaki, and M. Aritomi. "Corrosion Behavior of FBR Structural Materials in High Temperature Supercritical Carbon Dioxide." Journal of Power and Energy Systems 4(1), 252-261. ISSN 1881-3062 (2010).

[33] D. E. Shropshire. "Lessons Learned From GEN 1 Carbon Dioxide Cooled Reactors." In "Twelfth International Conference on Nuclear Engineering," Idaho National Engineering and Environmental Laboratory, Arlington, Virginia (2004). 
[34] T. Totemeier, T. Lillo, and J. Simpson. "Elevated Temperature Strength of FineGrained INCONEL Alloy MA754." Metallurgical and materials transactions 36A, 2552-2555 (2005).

[35] "316/316L Stainless Steel." Technical report, AK Steel, West Chester, OH (2007).

[36] J. R. Davis. Concise Metals Engineering Data Book. ASM International, 5th edition (2010).

[37] SC Hydraulic Engineering Corp. "GB Gas Boosters and Systems - Rev. 10-1506." (2010).

[38] C. Oh, T. Lillo, W. Windes, T. Totemeier, B. Ward, R. Moore, and R. Barner. "Development of a Supercritical Carbon Dioxide Brayton Cycle: Improving VHTR Efficiency and Testing Material Compatibility." Technical report, Idaho National Laboratory (INL) (2006). 


\section{Appendix A}

\section{Weight Gain Plots}

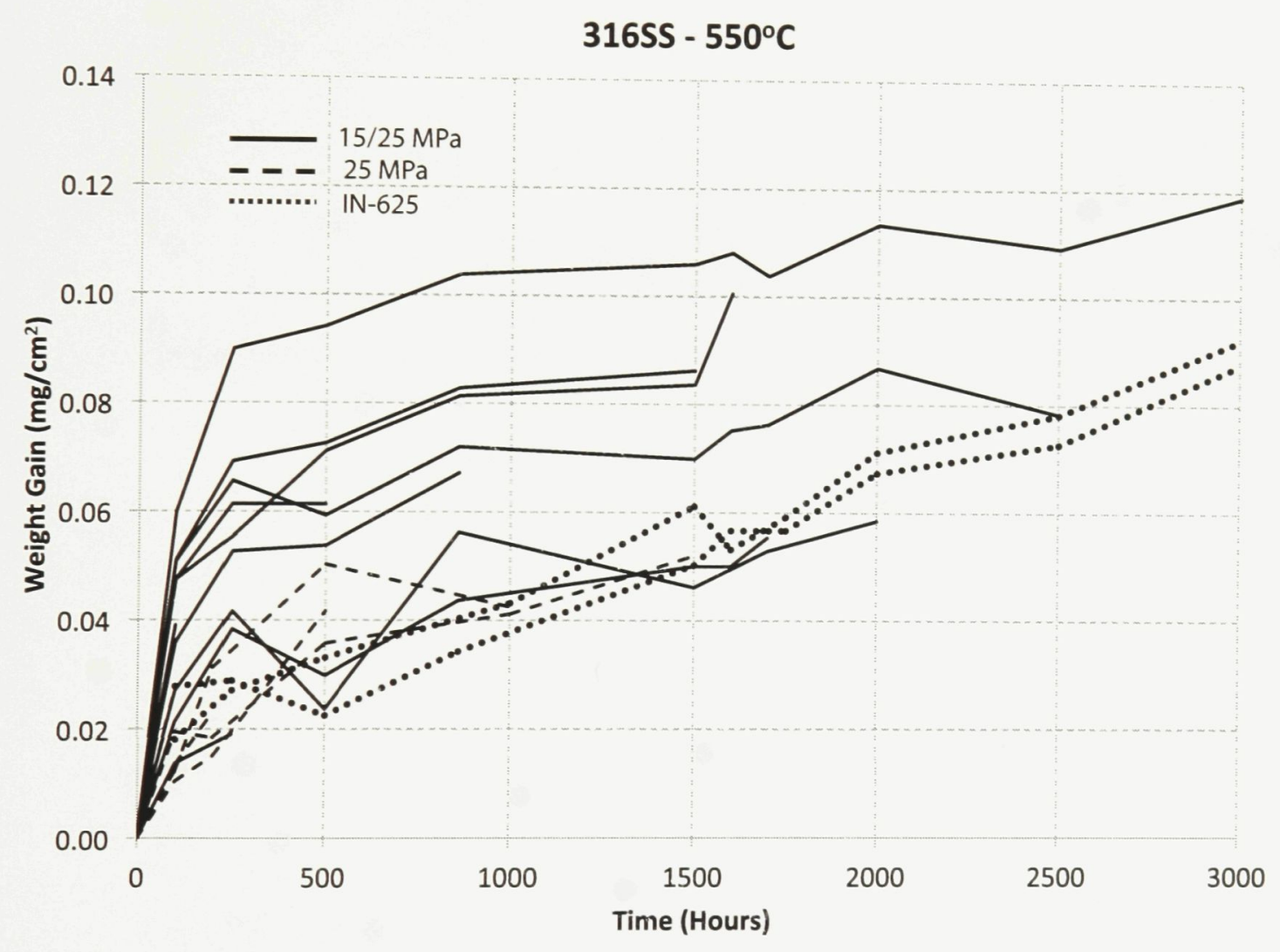

Figure 55: Weight gain for individual $316 \mathrm{SS}$ coupons at $550^{\circ} \mathrm{C}$. 


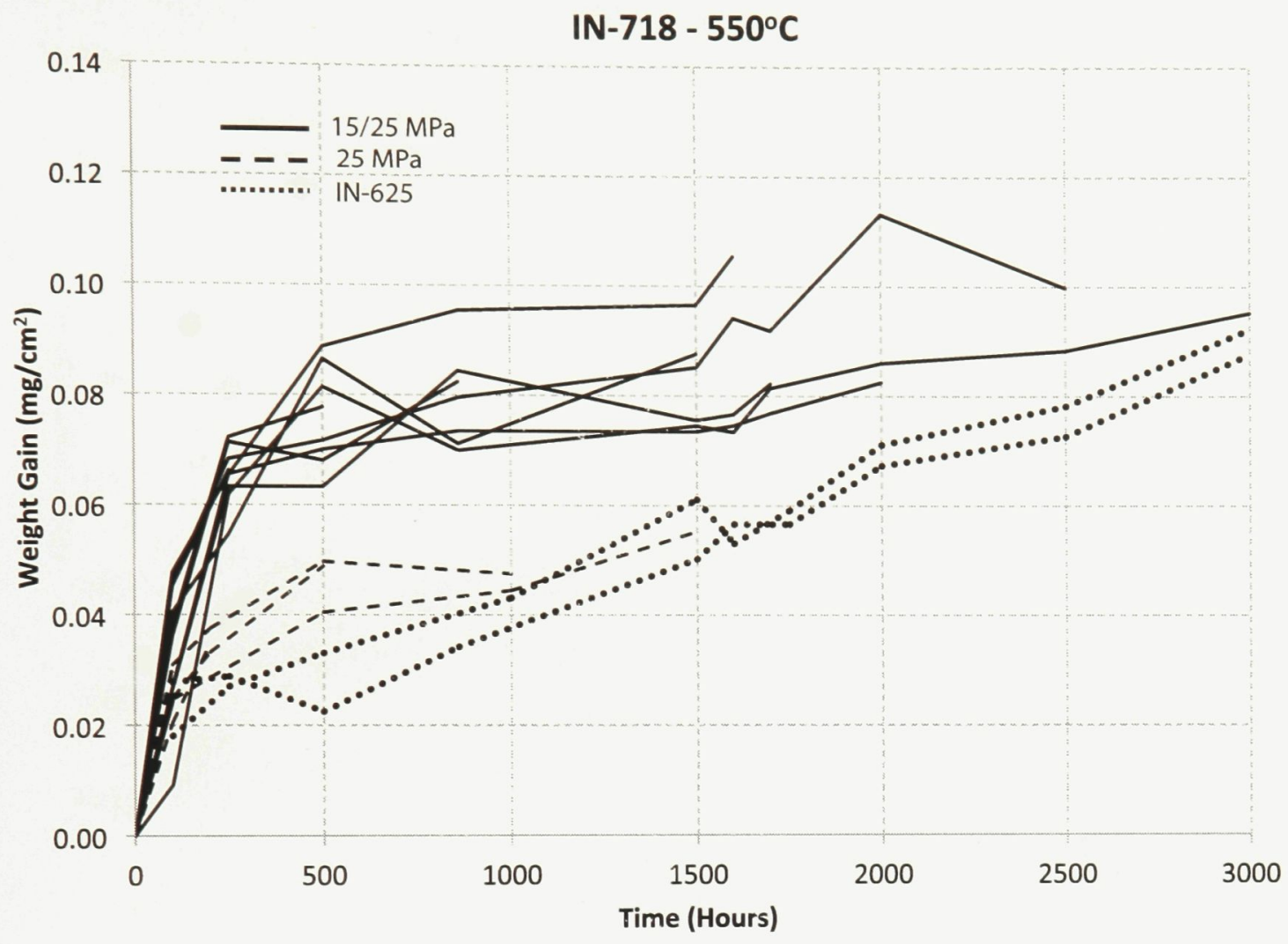

Figure 56: Weight gain for individual IN-718 coupons at $550^{\circ} \mathrm{C}$. 


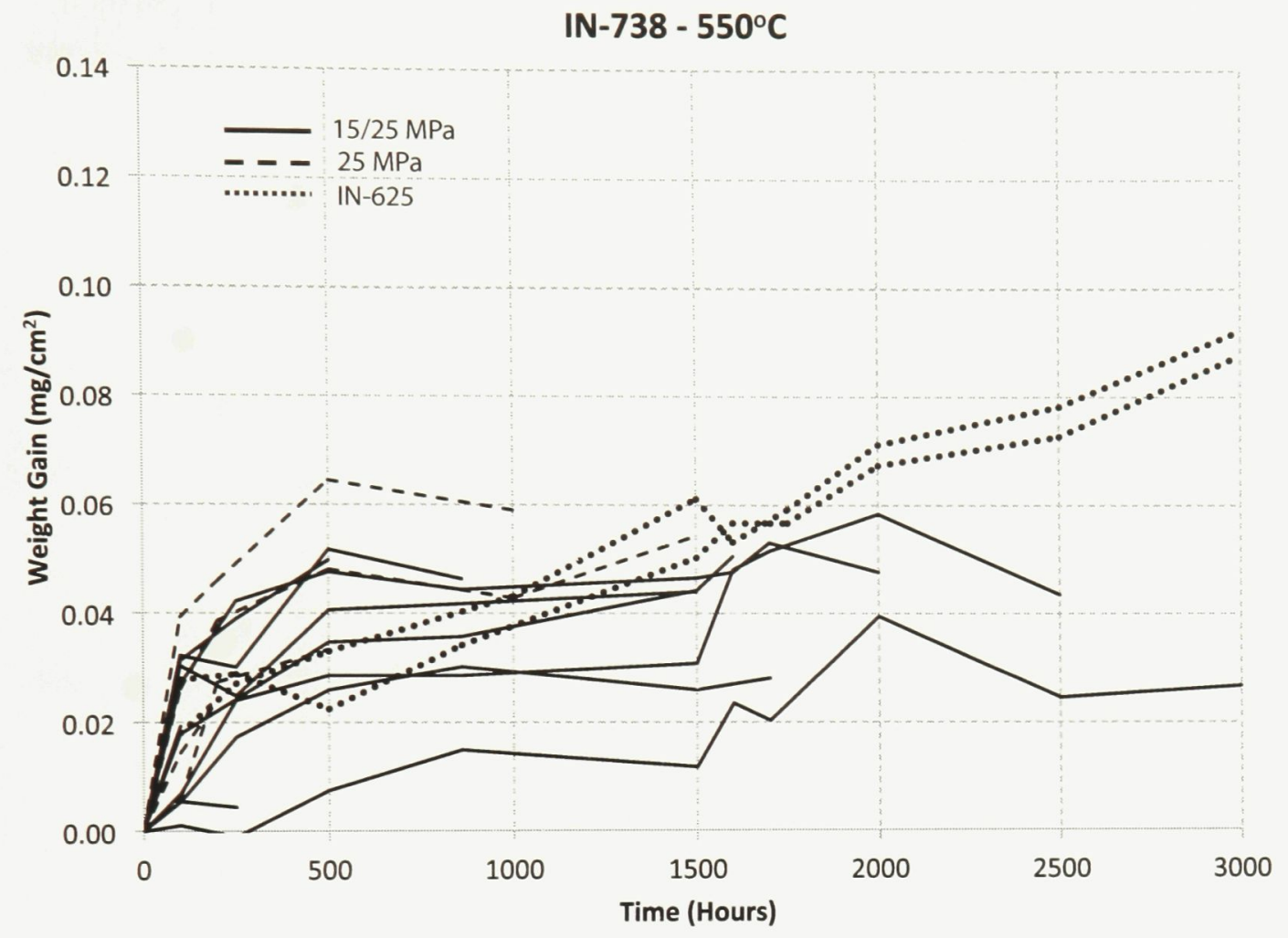

Figure 57: Weight gain for individual IN-738 coupons at $550^{\circ} \mathrm{C}$. 


\section{$316 S S$}

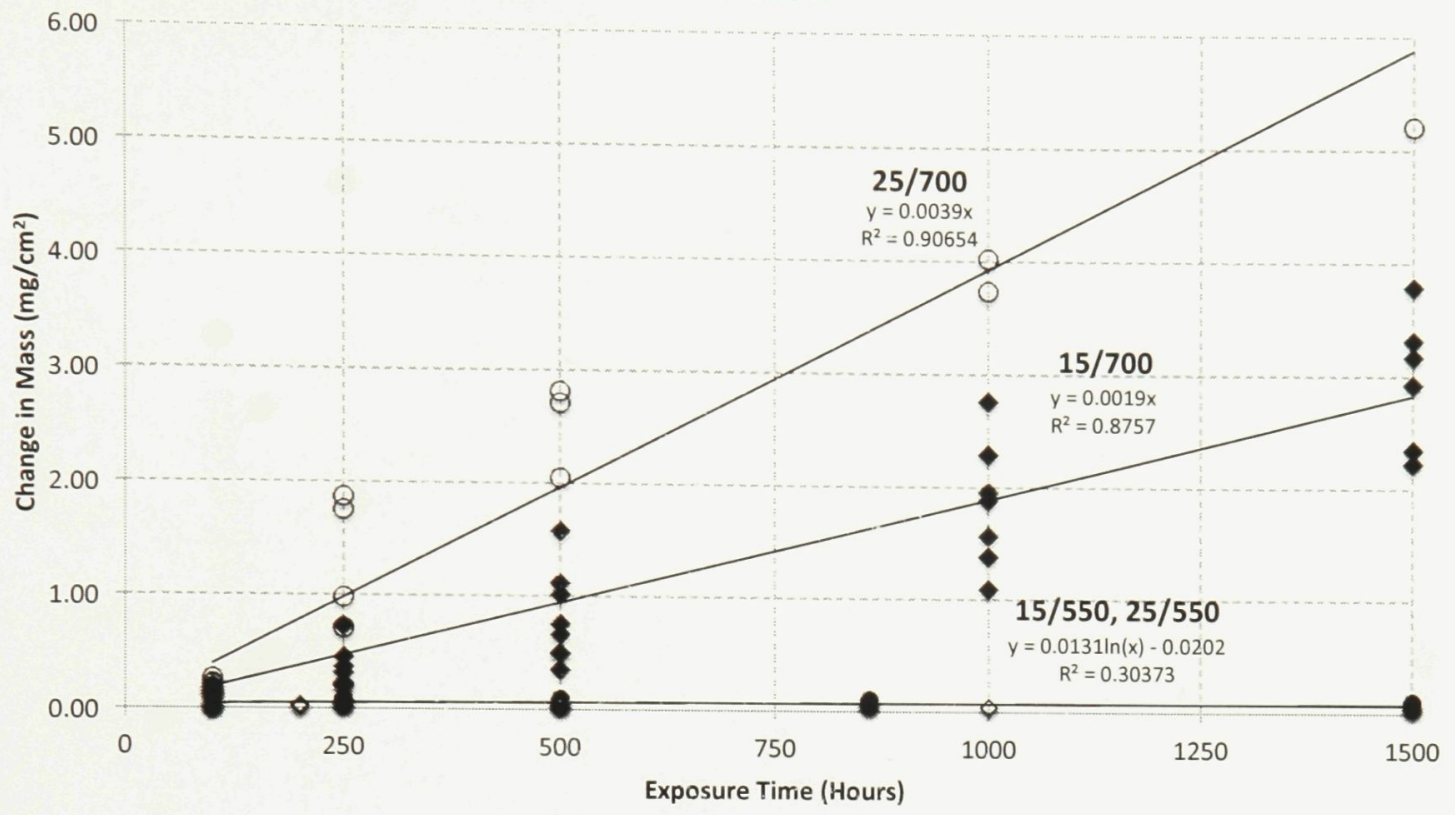

Figure 58: Weight gain for 316SS.

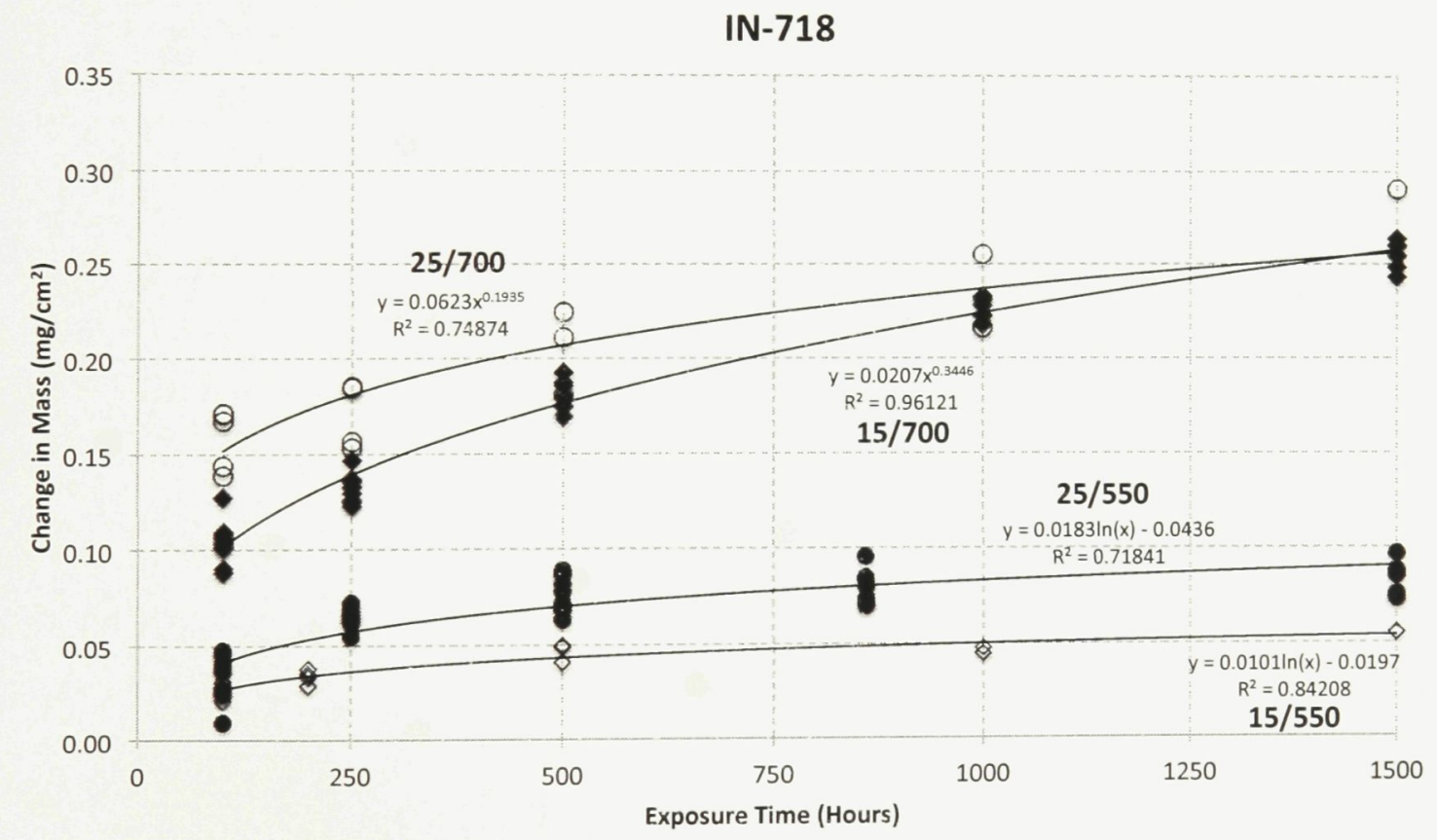

Figure 59: Weight gain for IN-718. 


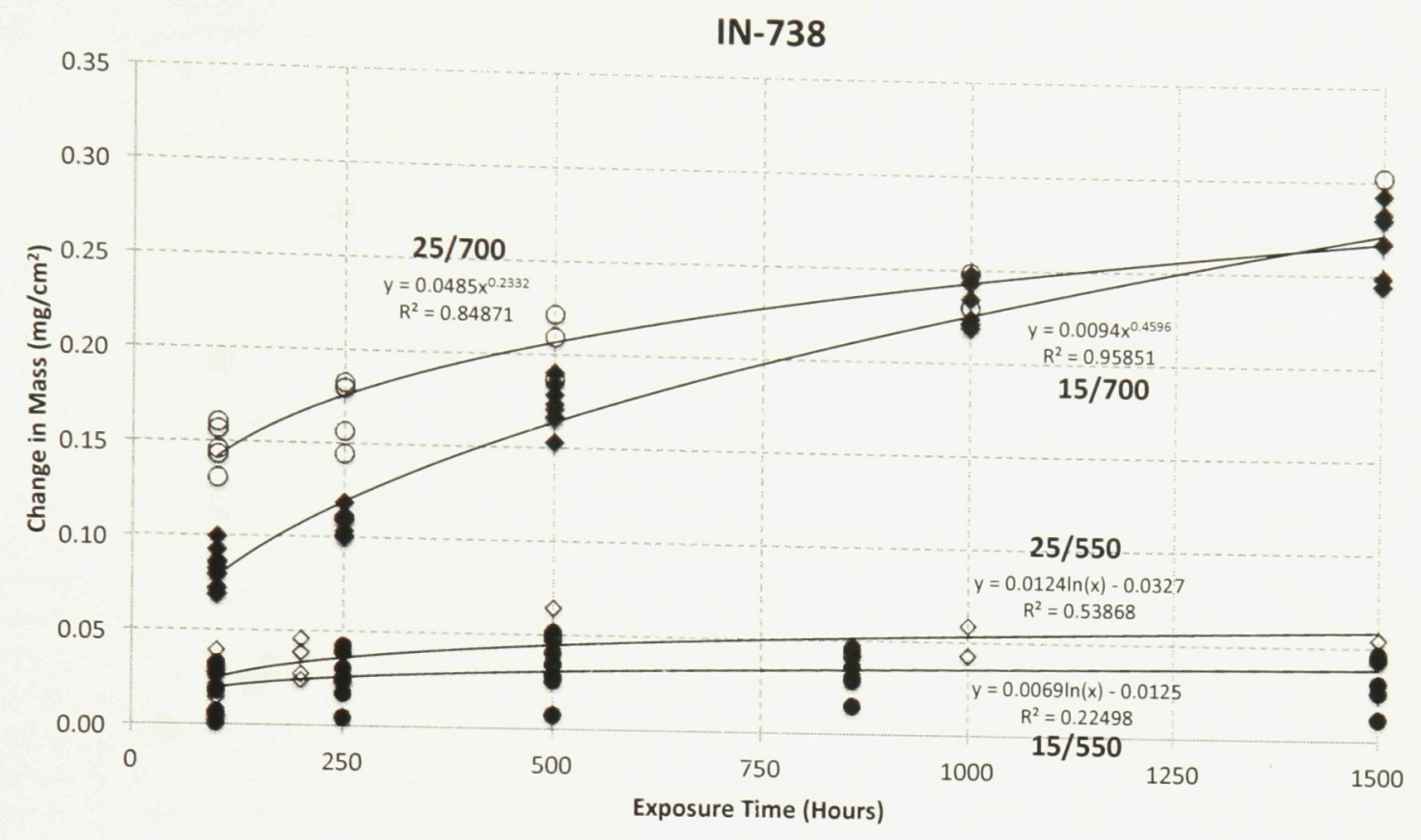

Figure 60: Weight gain for IN-738. 